\title{
CALAGEM E GESSAGEM EM UMA AREIA QUARTZOSA CULTIVADA COM CANA-DE-AÇÚCAR
}

\author{
ELOISA MARQUES MIOTTO ZOTARELLI \\ Engenheira Agrônoma
}

Orientador: Prof. Dr. Antonio Roque Dechen

Dissertação apresentada à Escola Superior de Agricultura "Luiz de Queiroz", da Universidade de São Paulo, para obtenção do título de Mestre em Agronomia, Área de concentração: Solos e Nutrição de Plantas

PIR ACICABA

Estado de São Paulo

Junho - 1992 
Ficha catalográfica preparada pela Seçāo de Livros da Divisāo de Biblioteca e Documentação - PCAP/USP

Zotarelli, Eloisa Marques Miotto

Z89g Calagem e gessagem em uma Areia Quartzosa cultivada com canade-açúcar. Piracicaba, 1992.

73p. ilus.

Diss. (Mestre) - ESALO

Bibliografia.

1. Calcário em cana-de-açúcar 2. Cana-de-açúcar - Nutriçāo 3. Gesso en cana-de-açúcar I. Escola Superior de Agricultura Luiz de Queiroz, Piracicaba 


\section{CALAGEM E GESSAGEM EM UMA AREIA QUARTZOSA CULTIVADA COM CANA-DE-AÇÚCAR}

ELOISA MARQUES MIOTTO ZOTARELLI

Aprovada em 22.09.92

Comissão julgadora:

Prof. Dr. Antonio Roque Dechen

ESALQ/USP

Prof. Dr. Ciro Antonio Rosolem

FCA/UNESP

Prof. Dr. Quirino Augusto de Camargo Carmello ESALQ/USP
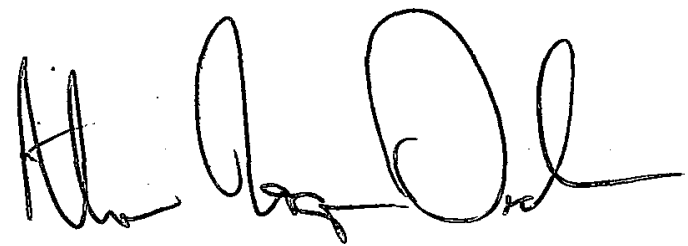

Prof. Dr. ANTONIO ROQUE DECHEN

Orientador 
À meu querido esposo Luiz DEDICO

Aos meus queridos pais Martha e Mário e
avós Maria e Paulo, e Adelina e João, e Nadir
OFEREÇO

À Deus

AGR ADEÇO 


\section{AGRADECIMENTOS}

- Ao Prof. Dr. Antonio Roque Dechen por todo incentivo, apoio, orientação e amizade.

- Ao Prof. Dr. Quirino Augusto de Camargo Carmello e Prof. Dr. Francisco Antonio Monteiro pelo apoio e sugestōes.

- À nossa extinta equipe de Fertilidade e Nutrição da Copersucar, engenheiros e técnicos, em especial ao Prof. Dr. Gaspar Henrique Korndörfer, nosso então chefe, pelos ensinamentos, orientação e amizade.

- À amiga Eng ${ }^{\mathrm{a}} \mathrm{Agr}^{\mathrm{a}}$ Sonia Maria De Stefano Piedade pela dedicação e orientação nas análises estatísticas.

- À Eng ${ }^{\mathbb{a}}$ Agr $^{\mathrm{a}}$ Silvia Regina Stipp e Abdalla pela dedicação e presteza na digitação e editoração do trabalho.

- Ao Dr. T. Yamada pela colaboração e apoio na elaboração da dissertação.

- À Usina São Manuel pela cessão da área do experimento e cooperação prestada.

- À CAPES pela bolsa concedida.

- À todos aqueles que direta ou indiretamente contribuíram para a realização deste trabalho. 


\section{SUMÁRIO}

Página

RESUMO $\ldots \ldots \ldots \ldots \ldots \ldots \ldots \ldots \ldots \ldots \ldots \ldots \ldots \ldots \ldots \ldots \ldots \ldots$

SUMMARY $\ldots \ldots \ldots \ldots \ldots \ldots \ldots \ldots \ldots \ldots \ldots \ldots \ldots \ldots \ldots \ldots$ viii

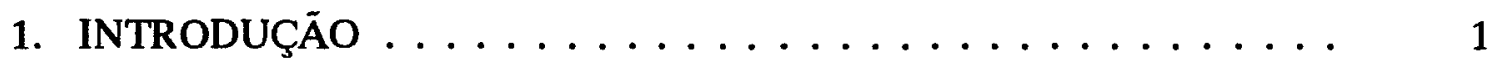

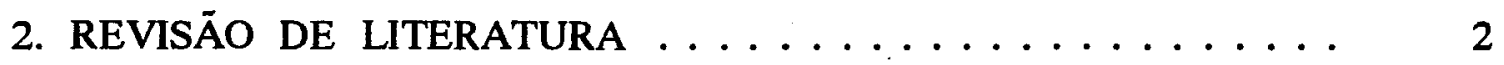

2.1. Desenvolvimento radicular $\mathrm{x}$ condições químicas do solo . . . . . 2

2.2. Composição do gesso e do calcário . . . . . . . . . . . . . 3

2.3. Efeitos do gesso e do calcário no solo . . . . . . . . . . . 4

2.4. Aumentos de produção com o uso de gesso e calcário . . . . . . . 7

2.5. Teores de nutrientes nas folhas de cana-de-açúcar . . . . . . . 8

2.6. Métodos e formas de aplicação de gesso e calcário . . . . . . . . 8

3. MATERIAL E MÉtodos ................. 11

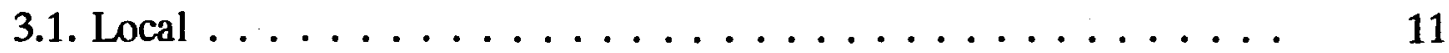

3.2. Variedade $\ldots \ldots \ldots \ldots \ldots \ldots \ldots \ldots \ldots \ldots \ldots$

3.3. Tratamentos e delineamento estatístico . . . . . . . . . 13

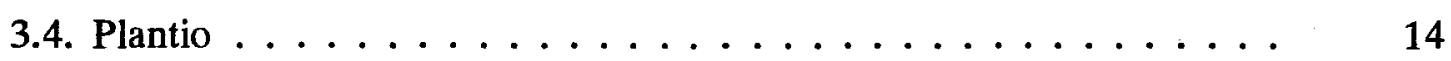

3.5. Avaliações . . . . . . . . . . . . . . . . . . . 15

3.5.1. Número de perfilhos $\ldots \ldots \ldots \ldots \ldots \ldots$

3.5.2. Diagnose foliar . . . . . . . . . . . . . . . 15

3.5.3. Produção de cana-de-açúcar . . . . . . . . . . . . . . 15

3.5.4. Sistema radicular $\ldots \ldots \ldots \ldots \ldots \ldots$

3.5.5. Amostragem de solo . . . . . . . . . . . . . 16

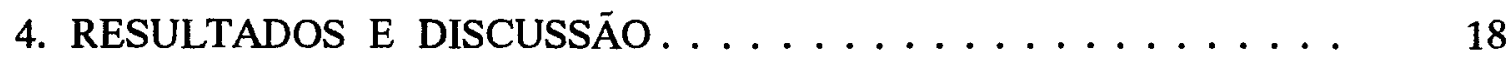

4.1. Número de perfilhos $\ldots \ldots \ldots \ldots \ldots \ldots \ldots$

4.2. Diagnose foliar . . . . . . . . . . . . . . . . . . . 21

4.3. Sistema radicular . . . . . . . . . . . . . . . . . . . . . . . . . 24

4.4. Produção de cana-de-açúcar . . . . . . . . . . . . . 27

4.5. Análise de solo . . . . . . . . . . . . . . . . 29

4.5.1. Antes da aplicação dos insumos . . . . . . . . . . 29 
4.5.2. Após 4 meses da aplicação dos insumos . . . . . . . . 30

4.5.3. Dezoito meses após a aplicação dos insumos . . . . . . . 45

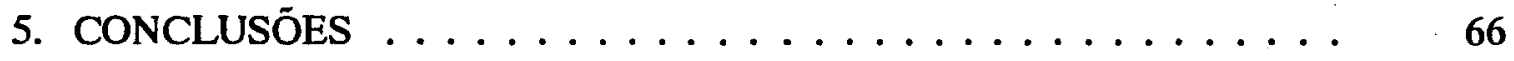

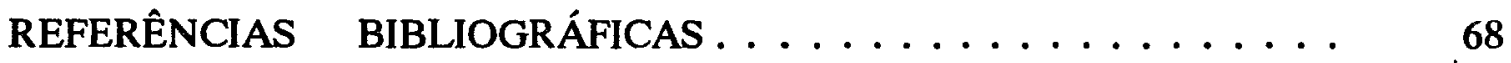




\title{
CALAGEM E GESSAGEM EM UMA AREIA QUARTZOSA CULTIVADA COMCANA-DE-AÇÚCAR
}

\author{
Autora: Eloisa Marques Miotto Zotarelli \\ Orientador: Prof. Dr. Antonio Roque Dechen
}

\section{RESUMO}

Com o objetivo de se estudar os efeitos do uso de calcário e gesso sobre a brotação e o número de perfilhos do canavial; os teores de macronutrientes das folhas +3 , o peso de raízes, a produção de cana e os resultados das análises do solo, 4 e 18 meses após a aplicação, foi instalado o presente trabalho em uma Areia Quartzosa utilizando a variedade SP70-1143.

O delineamento experimental utilizado foi o de blocos casualizados em esquema fatorial $4 \times 4$ com 3 repetições e dois fatores: gesso e calcário. Os tratamentos foram obtidos pelas combinações das doses de gesso $(0,1,2$ e $4 \mathrm{t} / \mathrm{ha})$ com as de calcário $(0 ; 1,6 ; 2,4$ e 3,2 t/ha $)$.

Os resultados obtidos permitiram concluir que:

- O uso de calcário aumentou a brotação do canavial, porém o aumento no número de perfilhos estabilizados foi decorrente da aplicação de gesso;

- As doses de insumos aplicadas foram responsáveis pelo aumento da concentração de cálcio e enxofre das folhas +3 no caso do gesso, e de magnésio, nos tratamentos com calcário;

- O sistema radicular desenvolveu-se mais, principalmente nas profundidades de 0-25 e $25-50 \mathrm{~cm}$, em função do aumento das doses de gesso;

-A produção de cana-de-açúcar aumentou- linearmente em função das doses de gesso;

- Os efeitos da aplicação de gesso no solo nas duas épocas amostradas foram: diminuição dos teores de potássio e magnésio na camada superficial $(0-25 \mathrm{~cm})$, aumento do teor de magnésio no subsolo $(50-75$ e $75-100 \mathrm{~cm})$, aumento dos teores de 
cálcio e sulfato e da soma de bases, da capacidade de troca de cátions e da saturação por bases até $1 \mathrm{~m}$ de profundidade. Os teores de alumínio decresceram até $1 \mathrm{~m}$ de profundidade de maneira linear e consistente, apenas aos 4 meses após a aplicação dos insumos, mas a saturação por alumínio diminuiu em ambas as épocas;

- Com as doses de calcário aplicadas, houve aumento no $\mathrm{pH}$, nos teores de cálcio e de magnésio, $\mathrm{S}$ e $\mathrm{V}$, e diminuição dos teores de hidrogênio + alumínio, alumínio e saturação por alumínio apenas na camada superficial $(0-25 \mathrm{~cm})$ tanto aos 4 meses quanto aos 18 meses após a aplicação;

- Os teores de matéria orgânica não sofreram influência dos tratamentos. 


\title{
LIMING AND GYPSUM A PPLICATION IN A TYPIC QUARTZIPSAMMENT GROWN WITH SUGARCANE
}

\author{
Author: Eloisa Marques Miotto Zotarelli \\ Adviser: Prof. Dr. Antonio Roque Dechen
}

\section{SUMMARY}

The present work was done in a quartzous sand soil with sugarcane variety SP 70-1143 to study gypsum and lime effects in the sprouting, macronutrient concentrations in the +3 leaves, root weight, sugarcane yield and in the soil chemical properties changes at 4 and 18 months after the application.

The statistical design was a randomized complete block, in a $4 \times 4$ factorial for gypsum and lime, with three replications. Gypsum rates were $0 ; 1 ; 2$; and $4 \mathrm{t} / \mathrm{ha}$ and lime rates were $0 ; 1.6 ; 2.4$ and $3.2 \mathrm{t} / \mathrm{ha}$.

The results allowed to conclude that:

- Lime increased the sprouting of sugarcane, whereas the higher number of stabilized sprouts was a consequence of gypsum application;

- Rates of gypsum resulted in increases in calcium and sulfur concentrations in the +3 leaves, and magnesium concentrations were increased by lime rates;

- The root system had better growth, mainly in $0-25$ and $25-50 \mathrm{~cm}$ soil depths, with gypsum rates;

- Sugarcane yield increased linearly with gypsum rates;

- The effects of gypsum rates in the soil properties at the two sampled dates were: decreases in potassium and magnesium concentrations in the surface layer $(0-25 \mathrm{~cm})$, increase in magnesium concentration in the sub-surface layers (50-75 and 75-100 cm), increase of calcium and sulphate concentrations and increases in the sum of exchangeable cations, in the cation exchange capacity and in the basis percentage saturation in the soil profile down to $1 \mathrm{~m}$ depth. Aluminum concentration reduced 
linear and consistently in the profile to $1 \mathrm{~m}$ depth only in soil sampling at 4 months after application, but aluminum saturation was reduced at both sampling dates.

- Lime rates increased soil $\mathrm{pH}$, calcium and magnesium concentrations, sum of exchangeable cations and basis percentage saturation. Also they reduced hidrogen + aluminum concentrations, aluminum concentrations and percentage aluminum saturation only in the surface soil $(0-25 \mathrm{~cm})$, either at 4 or 18 months after the application;

- The organic matter content didn't change with the lime and gypsum treatments. 


\section{INTRODUÇÃO}

Embora o Brasil tenha sido descoberto em 1500, o país só começou a ser colonizado a partir de 1530 , quando aqui chegou a quinta expedição portuguesa, comandada por Martim Afonso de Sousa. O litoral foi percorrido desde o Nordeste até o Sul e, em 1532, foi fundada a vila de São Vicente onde se plantou cana-de-açúcar e construiu-se o primeiro engenho de açúcar brasileiro (engenho São Jorge dos Erasmos).

A cultura da cana-de-açúcar, portanto, faz parte da vida do país desde seu início, há quase meio século, e principalmente nas últimas duas décadas teve sua área de cultivo muito ampliada por causa da crise do petróleo nos anos 70 .

A produção brasileira de açúcar é de 150 milhões de sacos, aproximadamente, e a de álcool de 12 bilhões de litros. Deste total, 11 bilhões de litros são utilizados como combustível, o que torna o Brasil o maior produtor e consumidor mundial de uma fonte renovável de energia em sua frota de veículos. Além disso, é a cultura brasileira que maior número de empregos gera.

O aumento de produção de cana-de-açúcar ocorreu principalmente por expansão da área cultivada. Novas regiões com clima e solos diferentes foram incorporadas, especialmente solos de fertilidade mais baixa, com teores de cálcio e magnésio baixos, e de alumínio elevados. Desta forma, muita pesquisa é ainda necessária para se descobrir como melhorar as condições destes solos e os níveis de produtividade da cultura.

Os objetivos deste trabalho foram analisar os efeitos do uso de calcário e de gesso na brotação e no número de perfilhos do canavial, nos teores de macronutrientes nas folhas +3 , no peso de raízes, na produção de cana e nos resultados das análises de solo após 4 e 18 meses após a aplicação. 


\section{REVISĀODELITERATURA}

\subsection{Desenvolvimento radicular $x$ condições químicas do solo}

O baixo teor de cálcio e a presença de alumínio, freqüentemente em nível tóxico no subsolo, são reconhecidos como importantes impedimentos químicos para o crescimento radicular em profundidade (RITCHEY et al., 1980). Devido à ação do calcário ser limitada ao local da aplicação e ao fato do cálcio não ser translocado da parte aérea das plantas para o sistema radicular em teores suficientes para promover o crescimento das raízes em subsolos deficientes neste nutriente, as plantas cultivadas em solos ácidos geralmente apresentam um sistema radicular superficial, limitando a utilização da água e dos nutrientes presentes nas camadas inferiores do solo (PAVAN \& VOLKWEISS, 1986).

Existe um comportamento diferenciado entre as culturas em relação à acidez do solo. Vários são os fatores responsáveis por estas diferenças, tais como a tolerãncia à toxidez de alumínio e/ou manganês, e a exigência em cálcio e magnésio (QUAGGIO et al., 1983).

MENGEL \& KIRKBY (1987) citam que a lixiviação do magnésio varia entre 2 a $30 \mathrm{~kg} / \mathrm{ha} / \mathrm{ano}$, dependendo do solo. Porém, a maior fraçāo deste elemento está na forma não lixiviável, incluindo todo o magnésio dos minerais primários e a maior parte dos minerais secundários. O magnésio trocável é da ordem de 5\% do total e representa 4 a $20 \%$ da CTC (NEPTUNE, 1986). Esta fração juntamente com a solúvel constitui-se no magnésio disponível às plantas.

O índice de saturação por alumínio e o teor de cálcio do perfil dos solos apresentam comportamentos diferenciados. Enquanto em alguns solos a saturaçāo de $\mathrm{Al}$ cresce significativamente com a profundidade, em outros ela apresenta apenas um ligeiro decréscimo. Mesmo nos solos com baixa saturação por alumínio em profundi- 
dade, as raízes das plantas podem não se desenvolver bem. Estudos desenvolvidos por RITCHEY et al. (1981 e 1983b) indicam que, nesses solos, o problema de enraizamento profundo está associado à deficiência de Ca.

Além da ocorrência natural da acidez do solo, o próprio cultivo tende a acentuar o problema, principalmente pela absorção dos cátions pelas raízes das plantas, deixando em seus lugares quantidades equivalentes de íons $\mathrm{H}^{+}$mas, também, pela atividade biológica, produzindo ácidos, e pelas práticas agrícolas tal como a aplicação de fertilizantes acidificantes (nitrato e sulfato de amônio) (VITTI, 1987).

RITCHEY et al. (1981) observaram que o gesso agrícola aplicado ao solo na camada superficial foi eficiente no deslocamento de $\mathrm{Ca}$ e $\mathrm{Mg}$ até a profundidade de 60 a $75 \mathrm{~cm}$ do solo, após percolação de $1.200 \mathrm{~mm}$ de água. Por essa razão, diversos autores encontraram um sistema radicular melhor distribuído no perfil do solo em função da adição de gesso a solos que apresentavam limitações de natureza química para o desenvolvingento das raízes (RITCHEY et al., 1980 e 1983b).

\subsection{Composição do gesso e do calcário}

O gesso, ou o sulfato de cálcio dihidratado $\left(\mathrm{CaSO}_{4} .2 \mathrm{H}_{2} \mathrm{O}\right)$, é um composto que ocorre naturalmente ou como subproduto de fabricação de ácido fosfórico. É um sal neutro e, portanto, não afeta diretamente a reação do solo $(\mathrm{pH})$. Sua solubilidade em água $(0,204 \mathrm{~g} / \mathrm{l})$ é cerca de 150 vezes maior que a do calcário sendo sua composição de, aproximadamente, 15 a $17 \%$ umidade livre, 26 a $28 \% \mathrm{CaO}$ e 15 a $16 \% \mathrm{~S}$ (VITTI \& MALAVOLTA, 1985), podendo, dessa forma, ser fonte de enxofre e cálcio para as plantas. A alternativa de uso de gesso como adubo sulfurado é bastante promissora, visto que a probabilidade de ocorrência de deficiência de $\mathrm{S}$ na cultura da cana-de-açúcar é grande, especialmente devido ao uso de adubo (uréia e fosfatos de amônio), de fórmulas concentradas isentas de enxofre, e à prática da queimada na colheita que causa a volatilização de S (VITTI \& NOVAES, 1986). Mais de $95 \%$ do $\mathrm{S}$ contido nas folhas é volatilizado nas queimadas, portanto, a cultura da cana-de-açúcar contribui para o esgotamento das reservas de enxofre do solo (VITTl et al., 1992).

O calcário é um material de grande uso porque existe com relativa freqüência e abundância. Seus constituintes neutralizantes são o carbonato de cálcio $-\mathrm{CaCO}_{3}-\mathrm{e}$ o carbonato de magnésio - $\mathrm{MgCO}_{3}$ (ALCARDE, s/d).

$\mathrm{Em}$ função do teor de $\mathrm{MgCO}_{3}$, o calcário pode ser classificado em:

- calcítico, quando o teor de $\mathrm{MgCO}_{3}$ é baixo, de 2 a 5\% (ou 1 a 2,5\% de $\mathrm{MgO}$ ); 
- magnesiano, quando o teor de $\mathrm{MgCO}_{3}$ é de 5 a 12 (ou 2,5 a 6\% de $\mathrm{MgO}$ );

- dolomítico, quando o teor de $\mathrm{MgCO}_{3}$ é maior que 12 (ou maior que 6\% de $\mathrm{MgO})$.

A qualidade do calcário é definida por duas características mais importantes: granulometria e teor de neutralizantes, que juntas originam o Poder Relativo de Neutralização Total (PRNT) do calcário (ANDA, 1988). A granulometria determina a velocidade de reação do calcário no solo, ou sua reatividade, e o teor de neutralizantes é obtido pela determinação do poder de neutralização, expresso em equivalentes de $\mathrm{CaCO}_{3}$.

\subsection{Efeitos do gesso e do calcário no solo}

Existe o interesse em se estudar os meios químicos para reduzir a acidez e facilitar a penetração das raízes no subsolo. O cálcio do calcário é lixiviado muito lentamente, pois o ânion carbonatado $\left(\mathrm{CO}_{3}{ }^{2-}\right)$ reage com os ácidos dos solos que apresentam $\mathrm{pH}$ baixo e é transformado em $\mathrm{CO}_{2}$ que se perde na atmosfera. $\mathrm{O}$ íon sulfato presente no gesso pode servir como meio eficaz para promover o movimento de íons do solo devido às reaçōes de associação com metais, principalmente $\mathrm{Ca}^{2+}$, $\mathrm{Mg}^{2+}, \mathrm{K}^{+} \mathrm{e} \mathrm{Al}^{3+}$, formando complexos solúveis de menor valência $\left(\mathrm{CaSO}_{4}, \mathrm{MgSO}_{4}\right.$, $\mathrm{K}_{2} \mathrm{SO}_{4}, \mathrm{AlSO}_{4}{ }^{+}$) (PAVAN \& VOLKWEISS, 1986).

No solo, a neutralidade elétrica do sistema é mantido em seu equilíbrio dinâmico (RITCHEY et al., 1983a). Portanto, os cátions não são lixiviados isoladamente. Em solos ácidos, os íons carbonato e bicarbonato, resultantes da dissolução do calcário, têm curta existência, antes de sua neutralização pela acidez do solo. Desse modo, a lixiviação do cálcio deverá ser governada pela natureza e pelas características de outros ânions disponíveis. Assim, de uma forma geral, o cálcio poderia apresentar a seguinte ordem de mobilidade, de acordo com o ânion: cloreto > nitrato > sulfato $>$ carbonato $>$ fosfato (GUIMARÃES, 1986). Essa seqüência já foi verificada por outros autores como PAVAN et al. (1984), SOPRANO et al. (1986) e DAL BÓ et al. (1986).

Muitos estudos têm mostrado que as aplicações de cálcio na forma de sulfato (gesso) têm produzido melhores efeitos em profundidade (VITTI \& MALAVOLTA, 1985, RITCHEY et al., 1980). Quando adicionado ao solo, o gesso dissolve-se a uma velocidade que depende de sua dose e da quantidade de água existente e/ou aplicada ao solo. Segundo RITCHEY et al. (1980), para dissolver uma quantidade de gesso $\left(\mathrm{CaSO} 4.2 \mathrm{H}_{2} \mathrm{O}\right)$ que forneça $2.000 \mathrm{~kg} \mathrm{Ca}$ /ha são necessários $226 \mathrm{~mm}$ de precipitação. 
Após a dissolução, é iniciado o processo de movimentação no solo, cuja taxa depende do fluxo de água no solo bem como de suas propriedades químicas.

A dissociação do gesso na solução do solo produz os íons $\mathrm{Ca}^{2+}$ e $\mathrm{SO}_{4}^{2-}$. Aproximadamente $40 \%$ do total de $\mathrm{Ca}$ solúvel está presente como $\mathrm{CaSO}_{4}$ e, portanto, potencialmente móvel no solo, proporcionando a eliminação do alumínio tóxico do solo por reações de complexações $\left(\mathrm{AlSO}_{4}{ }^{+}\right.$) ou polimerizações (PAVAN et al., 1984).

Resultados publicados demonstram que a aplicação superficial de gesso promove aumentos nos teores de cátions básicos no subsolo (REEVE \& SUMNER, 1972; RITCHEY et al., 1980; PAVAN et al., 1984). Contudo, esta lixiviação pode levar magnésio e potássio para horizontes inferiores, distantes das raízes, e afetar negativamente a produtividade das culturas.

PAVAN et al. (1984) verificaram que os tratamentos com gesso reduziram os níveis de $\mathrm{Al}$ e $\mathrm{Mg}$ trocáveis até $100 \mathrm{~cm}$ de profundidade do perfil em um LR distrófico, enquanto aumentaram o $\mathrm{Ca}$ trocável. Além deste, muitos outros trabalhos têm relatado a remoção de magnésio e potássio do solo, proporcionando perdas destes cátions (REEVE \& SUMNER, 1972; RITCHEY et al., 1981 e 1983a; QUAGGIO et al., 1982, PAVAN et al., 1984).

Além da ação de movimentação de cátions básicos no solo, o gesso reduz o nível de $\mathrm{Al}^{3+}$ (alumínio livre) na solução do solo pela associação iônica $\mathrm{AlSO}_{4}{ }^{+}$ (pouco absorvido pelas raízes) e pela formação de polímeros de alumínio (PAVAN et al., 1986).

DAL BÓ et al. (1986), SOPRANO et al. (1986) e CHAVES et al. (1986) observaram a redução do $\mathrm{Al}$ trocável e da saturação por $\mathrm{Al}$ em profundidade com a utilização de gesso. Os dois primeiros trabalhos também encontraram diminuição de $\mathrm{Mg}$ e $\mathrm{K}$ nas camadas superficiais.

A ação do gesso porporcionou decréscimo na saturação por alumínio em profundidade, assim como um razoável aumento na saturação por bases até $75 \mathrm{~cm}$, tanto para a aplicação do gesso em área total e incorporado com grade, quanto sem incorporação e para o aplicado no sulco de plantio de cana-de-açúcar (MORELLI et al., 1987).

Na África do Sul, REEVE \& SUMNER (1972) compararam a eficiência do $\mathrm{Ca}(\mathrm{OH})_{2} \mathrm{e}$ do $\mathrm{CaSO}_{4} .2 \mathrm{H}_{2} \mathrm{O}$ na redução da saturação por $\mathrm{Al}$ do subsolo, verificando que enquanto o $\mathrm{Ca}(\mathrm{OH})_{2}$ reduziu-a de $57 \%$ para $53 \%$, a mesma quantidade de cálcio, 
na forma de sulfato, reduziu-a para $43 \%$, embora tenham sido usadas doses muito altas.

LOPES \& ALVES (1981), comparando cinco materiais (superfosfato simples, calcário calcítico comercial, gesso, óxido de cálcio e calcário calcítico micropulverizado), verificaram que os tratamentos mais eficientes na redução de $\mathrm{Al}$ no subsolo foram o superfosfato simples e o gesso.

O gesso pode, ainda, ser usado em solos com excesso de sódio, com a finalidade de substituir o sódio trocável (de efeito dispersante e desagregador da estrutura do solo) por cálcio (cátion agregador e de efeito favorável na estrutura) (RAIJ \& QUAGGIO, 1984, ROTH et al., 1986).

Uma das conclusōes a que chegou ALCARDE (1984) sobre a calagem e a eficiência dos fertilizantes no Brasil é que "a ausência ou a insuficiência da calagem é um dos principais fatores, senão o primeiro, a limitar a produtividade agrícola brasileira".

A prática mais recomendada para a correçāo da acidez do solo é a calagem, especialmente quando o objetivo é a elevação do pH do solo, uma vez que o gesso nāo é capaz de fazê-lo (CAMARGO et al., 1975; ROSOLEM \& MACHADO, 1984; BORKERT et al., 1987; GALLO, 1987). Porém, a melhoria das características do perfil do solo só com aplicação do calcário requer um tempo mais prolongado e doses superiores às recomendadas (ANJOS \& ROWELL, 1983). Ritchey et al. (1983b) observaram correção do solo até $60 \mathrm{~cm}$ de profundidade com calcário utilizando doses superiores a 7,5 t/ha e depois de 8 anos da aplicação enquanto a dose recomendada para este solo era de 4,0 t/ha. Para solos de textura média e arenosa, o tempo para correção foi menor, em torno de 4 anos.

Segundo TEDESCO et al. (1984), vários são os fatores que afetam a eficiência da correção da acidez do solo com o uso do calcário, sendo as principais a qualidade do calcário (função do valor de neutralização, tamanho das partículas e tipo de minerais presentes), incorporação ao solo e teor de umidade do solo.

Ao descer pelo perfil, o gesso pode produzir um efeito benéfico colocando

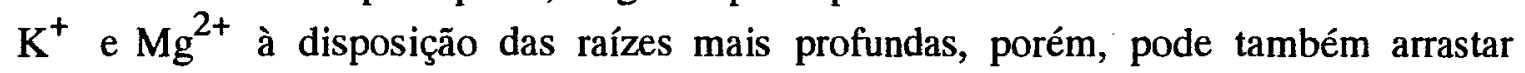
esses elementos para fora do alcance das raízes, causando deficiência (RITCHEY et al., 1983a). Este efeito pode ser atenuado pela associação do gesso com o calcário, onde a calagem aumenta a CTC do solo, com liberação de cargas dependentes de pH, aumentando a retenção de $\mathrm{K}^{+} \mathrm{e} \mathrm{Mg}^{2+} \mathrm{e}$, adicionalmente, favorecendo a menor 
retenção de $\mathrm{S}-\mathrm{SO}_{4}{ }^{2-}$ na camada arável. Se o calcário apresentar teor adequado de $\mathrm{Mg}$, suprirá a cultura com este nutriente (SOUZA \& RITCHEY, 1986).

DEMATTÊ (1986), em ensaios conduzidos em Pirassununga (SP), observou que o emprego da mistura de calcário calcinado com gesso (66:34) foi eficiente para aumentar o teor de $\mathrm{Ca}^{2+}, \mathrm{Mg}^{2+}$ e S-SO4${ }^{2-}$ na superfície e em profundidade, o mesmo acontecendo com a saturação por bases (V\%); houve diminuição do teor de Al trocável e na participação deste na CTC efetiva; houve enriquecimento de $\mathrm{K}^{+}{\mathrm{e} \mathrm{Mg}^{2+}}^{2+}$ nas camadas mais profundas, permanecendo os elementos na zona usualmente ocupada pelas raízes da cana (cultura subseqüente).

A gessagem pode melhorar a fertilidade dos solos principalmente daqueles com altos teores de $\mathrm{Al}^{3+}$, deficientes em $\mathrm{Ca}^{2+}$ e para culturas com sistema radicular profundo. No tratamento em que foi empregada a combinação entre sulfato e carbonato houve menor perda de $\mathrm{Mg}^{2+}$, o que pode diminuir os desequilíbrios nutricionais provocados quando a aplicação for somente de gesso (NOGUEIRA \& MOZETO, 1986).

A aplicação de gesso combinada com calcário promove a redução da saturação por alumínio no perfil do solo, aumenta o pH e a CTC do solo na camada superficial, com liberação de cargas dependentes de $\mathrm{pH}$, diminuindo a retenção de $\mathrm{S}_{-} \mathrm{SO}_{4}{ }^{2-} \mathrm{e}$ aumentando a retenção de $\mathrm{Mg}$ e de $\mathrm{K}$ nesta camada; além do aumento na saturação por cálcio em subsuperfície (DAL BÓ et al., 1986; DEMATTÊ, 1986; MALAVOLTA et al., 1979).

\subsection{Aumentos de produção com uso de gesso e calcário}

MALAVOLTA (1985a) cita trabalhos realizados pela EPAMIG que mostraram os efeitos proveitosos da associação do calcário e do gesso distribuídos antes do plantio e que com o uso combinado de $1,5 \mathrm{t}$ de calcário e 2,5 $\mathrm{t}$ de gesso obteve-se 15 sacas de café a mais em relação à testemunha e 12 sacas a mais do que o uso de calcário apenas.

Produções mais elevadas nos tratamentos que receberam a aplicação conjunta de calcário calcinado e gesso em relação aos tratamentos com calcário ou gesso, foi observada por MALAVOLTA (1985b), e VITTI \& MALAVOLTA (1985) em condiçōes de campo com milho. O gesso foi empregado em doses correspondentes ao teor de $\mathrm{CaO}$ acrescentado pelo calcário, enquanto a mistura foi na proporção de $70 \%$ de calcário e $30 \%$ de gesso. 
A associação de $2 \mathrm{t}$ de calcário com $1 \mathrm{t}$ de gesso aumentou a produtividade de grãos, diminuiu a saturação por $\mathrm{Al}^{3+}$ e aumentou $\mathrm{O} \mathrm{Ca}^{2+}$ trocável até $60 \mathrm{~cm} \mathrm{de}$ profundidade, em relaçāo ao calcário ou gesso aplicados isoladamente (CRAVO et al., 1987).

Resultados apresentados por GUILHERME (1985) mostram consistentemente a interação positiva entre o calcário calcinado e o gesso (proporção 70:30) na cultura do milho e na sucessão soja/trigo.

O emprego de doses crescentes de gesso aumentou a saturação por bases (V\%) em profundidade, o que se refletiu na elevação da produção de cana-de-açúcar em um solo arenoso distrófico de Ribeirão Preto-SP (DEMATTÊ, 1986).

\subsection{Teores de nutrientes nas folhas de cana-de-açúcar}

Vários são os autores que trabalharam com a análise foliar em cana-de-açúcar, conforme PARANHOS (1987); no entanto, MALAVOLTA (1982) e MALAVOLTA et al. (1989) definiram classes mais abrangentes, conforme a Tabela 1.

Tabela 1. Faixas de variação dos teores foliares (\%) dos elementos para a cana-de-açúcar.

\begin{tabular}{ccc}
\hline Elemento & Deficientes $^{1}$ & Adequados $^{2}$ \\
\hline $\mathrm{N}$ & $1,0-1,5$ & $1,9-2,1$ \\
$\mathrm{P}$ & $0,05-0,10$ & $0,20-0,24$ \\
$\mathrm{~K}$ & $<1,00$ & $1,1-1,3$ \\
$\mathrm{Ca}$ & $<0,50$ & $0,8-1,0$ \\
$\mathrm{Mg}$ & $<0,15$ & $0,2-0,3$ \\
$\mathrm{~S}$ & $<0,15$ & $0,25-0,30$ \\
\hline
\end{tabular}

${ }^{1}$ MALAVOLTA (1982).

${ }^{2}$ MALAVOLTA et al. (1989).

\subsection{Métodos e formas de aplicação de gesso e calcário}

VITTI (1987) apresenta métodos propostos para a determinação da dose de gesso que deve ser aplicada: 1) Lopes (1986) recomenda três alternativas para serem 
usadas sempre que nas camadas subsuperficiais $\left(20 \mathrm{~cm} \mathrm{ou} \mathrm{mais)} \mathrm{o} \mathrm{Ca}^{2+}\right.$ for menor que $0,3 \mathrm{meq} / 100 \mathrm{~cm}^{3}$ e/ou nível de $\mathrm{Al}^{3+}$ trocável for igual ou maior que $0,5 \mathrm{meq} / 100 \mathrm{~cm}^{3}$ e/ou a saturação por $\mathrm{Al}^{3+}$ (m) na CTC efetiva for igual ou maior que $40 \%$ substituir $25 \%$ do $\mathrm{CaO}$ do calcário por $\mathrm{CaO}$ do gesso, quando a calagem for calculada pelo método de elevação da saturação por bases (São Paulo); ou adicionar na forma de gesso mais $25 \%$ de $\mathrm{CaO}$ além do $\mathrm{CaO}$ do calcário, quando a calagem for calculada pelo método de $\mathrm{Al}^{3+}$ ou $\mathrm{Ca}^{2+}$ mais $\mathrm{Mg}^{2+}$ trocáveis (Minas Gerais e Goiás); ou para cada $100 \mathrm{~kg}$ de superfosfato triplo ou termofosfato usados adicionar, respectivamente, 115 e $51 \mathrm{~kg}$ de gesso, quando na adubação fosfatada de correção for usado superfosfato triplo ou termofosfato; 2) A EPAMIG (Freire et al., 1984) recomenda substituir 25 a $50 \% \mathrm{CaO}$ recomendado pela calagem pelo gesso; 3) Vitti \& Ferreira (1986), quando da aplicação de produtos comerciais contendo em sua composição calcário e gesso, como por exemplo calcário dolomítico calcinado (70\%) mais gesso (30\%), apresentando a mistura um PRNT de $108 \%$, e quantidade do produto a ser utilizado corresponde à necessidade de calagem, podendo ser determinada pelo critério da elevação da saturação por bases.

SOUSA et al. (1992) citam sugestōes mais recentes para recomendação de gesso: Sousa (1988) indica o uso de gesso sempre que a saturação por alumínio for maior que $30 \%$ e/ou o teor de cálcio for menor que $0,2 \mathrm{meq} / 100 \mathrm{~cm}^{3}$, em amostras de solo das profundidades de 20 a $60 \mathrm{~cm}$ ou, ainda, em função do teor de argila do solo aplicar 0,$5 ; 1,0 ; 1,5$ e 2,0 t/ha de gesso para solos arenosos, médios, argilosos e muito argilosos, respectivamente; Malavolta (1991) sugere que se recomende gesso quando a saturaçāo por alumínio for maior que $20 \%$ e/ou a saturação por cálcio (CTC efetiva) for menor que $40 \%$.

Existe um método biológico (RITCHEY et al., 1983b), baseado na avaliação do crescimento das raízes, que permite avaliar com segurança se o gesso irá ou não favorecer o crescimento das raízes no solo. Utilizando este método, YAMADA (1988) verificou a influência positiva do gesso no crescimento das raízes em solos latossólicos com alumínio e/ou pouco cálcio, mas não em solos podzolizados com teores muito altos de alumínio.

A mistura pode ser aplicada em área total com incorporação superficial no preparo do solo para o plantio. Em cultura perene adulta ou pouco espaçada, o gesso é aplicado a lanço, em cobertura, em toda a área livre da cultura (MALAVOLTA et al., 1979). 
Conforme comentado por QUAGGIO et al. (1982) e MALAVOLTA (1985b), a associação da aplicação de gesso com doses de calcário dolomítico parece ser a prática mais adequada para o tratamento de solos com concentraçāo de Al tóxico e baixa saturação por cálcio em subsuperfície. Assim, essa prática, além de reduzir o $\mathrm{Al}^{3+}$ em profundidade e prevenir possíveis desequilíbrios entre as bases do solo, dispensaria também a necessidade de incorporação profunda da mistura, uma vez que, conforme demonstrado por PAVAN et al. (1984), a precipitação é suficiente para promover a lixiviação do gesso para o subsolo. Por esta razão, em culturas a serem instaladas, após amostragens de solo em profundidade e em que se diagnosticou o problema, a mistura poderá ser aplicada em área total e incorporada com aração e gradagem. No caso de soqueiras, a mistura poderá ser aplicada nas entrelinhas em superfície.

Apesar das evidências dos efeitos positivos do uso do gesso, é ainda reduzido o número de experimentos avaliando doses, métodos de aplicação e efeito residual nos mais diversos tipos de solos (GUIMARĀES, 1986). 


\section{MATERIAL EMÉTODOS}

\subsection{Local}

A escolha do local para ser instalado o trabalho baseou-se em uma amostragem preliminar quando a área foi dividida em 4 partes. Retirou-se de cada parte uma amostra composta por 15 sub-amostras em 2 profundidades $(0-25$ e $25-50 \mathrm{~cm})$ que foram analisadas quimicamente (Tabela 2).

Porções iguais foram retiradas das quatro amostras de $0-25 \mathrm{~cm}$ e misturadas para ser feita a análise granulométrica das partículas do solo, como também da profundidade $25-50 \mathrm{~cm}$ (Tabela 3 ).

Por ser relativamente homogênea quanto às análises química e granulométrica, topografia e ao histórico de uso da terra, foi escolhida a área localizada na Fazenda Pau d'Alho, município de São Manuel, e de propriedade da Usina São Manuel.

A classe de solo da área é Areia Quartzosa, de acordo com a equipe de levantamento de solos da Copersucar.

\subsection{Variedade}

A variedade utilizada foi a SP 70-1143 por ser, na época, a de maior representação nos plantios. 
Tabela 2. Análise química do solo para seleção da área experimental.

\begin{tabular}{|c|c|c|c|c|c|c|c|c|c|c|c|}
\hline Profundidade & $\mathrm{pHCaCl}_{2}$ & M.o. & $\mathbf{P}$ & $\mathbf{K}^{+}$ & $\mathrm{Ca}^{2+}$ & $\mathbf{M g}^{2+}$ & $\mathbf{H}^{+}+\mathbf{A l}^{3+}$ & $\mathbf{A l}^{3+}$ & $\mathbf{S}$ & CTC & $\mathbf{v}$ \\
\hline$(\mathrm{cm})$ & & $(\%)$ & $\left(\mu \mathrm{g} / \mathrm{cm}^{3}\right)$ & $\cdots$ & $\ldots$ & $\ldots$ & $\left(\mathrm{meq} / 100 \mathrm{~cm}^{3}\right)$ & 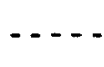 & & $\cdots$ & $(\%)$ \\
\hline $01(0-25)$ & 4,5 & 1,77 & 5 & 0,05 & 0,91 & 0,40 & 2,7 & 0,11 & 1,4 & 4,1 & 33 \\
\hline $02(25-50)$ & 4,4 & 1,43 & 7 & 0,04 & 0,63 & 0,31 & 2,5 & 0,21 & 1,0 & 3,5 & 28 \\
\hline $03(0-25)$ & 4,7 & 1,96 & 7 & 0,05 & 0,98 & 0,48 & 2,6 & 0,08 & 1,5 & 4,1 & 37 \\
\hline $04(25-50)$ & 4,4 & 1,43 & 5 & 0,02 & 0,60 & 0,29 & 2,5 & 0,16 & 0,9 & 3,4 & 27 \\
\hline $05(0-25)$ & 4,5 & 1,77 & 12 & 0,05 & 0,89 & 0,35 & 3,0 & 0,19 & 1,3 & 4,3 & 30 \\
\hline $06(25-50)$ & 4,3 & 1,01 & 5 & 0,02 & 0,36 & 0,21 & 2,4 & 0,31 & 0,6 & 3,0 & 20 \\
\hline $07(0-25)$ & 4,3 & 1,77 & 10 & 0,03 & 0,56 & 0,28 & 3,0 & 0,29 & 0,9 & 3,9 & 22 \\
\hline $08(25-50)$ & 4,3 & 1,43 & 5 & 0,02 & 0,31 & 0,19 & 2,9 & 0,38 & 0,5 & 3,4 & 15 \\
\hline
\end{tabular}


Tabela 3. Análise granulométrica e classe textural das amostras de solo.

\begin{tabular}{ccccccc}
\hline \multirow{2}{*}{$\begin{array}{c}\text { Profundidade } \\
(\mathbf{c m})\end{array}$} & \multicolumn{3}{c}{ Areia } & Limo & Argila & Classe textural \\
\cline { 2 - 4 } & Fina & Grossa & Total & & & \\
\hline & $\ldots \ldots$ & & & & & \\
$0-25$ & 44,60 & 41,73 & 86,33 & 4,12 & 9,55 & Areia barrenta \\
$25-50$ & 51,08 & 34,52 & 85,60 & 4,10 & 10,30 & Areia barrenta \\
\hline
\end{tabular}

\subsection{Tratamentos e delineamento estatístico}

O delineamento experimental escolhido foi o de blocos casualizados em esquema fatorial $4 \times 4$ com 3 repetiçōes e dois fatores: gesso (G) e calcário (C).

As doses de gesso estudadas foram $0,1,2$ e 4 t/ha e as de calcário, $0,1,6,2,4$ e 3,2 t/ha, sendo a dose 1,6 t/ha correspondente à dose recomendada para elevação da saturação por bases a $60 \%$ (ESPIRONELO, 1985), calculada a partir das amostras preliminares retiradas da camada superficial $(0-25 \mathrm{~cm})$.

Os tratamentos a seguir foram obtidos pelas combinações das doses de gesso com as de calcário, sendo $\mathrm{G}_{1}$ e $\mathrm{C}_{1}$, respectivamente, tratamentos sem gesso e sem calcário e $\mathrm{G}_{4}$ e $\mathrm{C}_{4}$, suas maiores doses.

$$
\begin{array}{rlrl}
\mathrm{T} 1 & =\mathrm{G}_{1} \mathrm{C} 1 & \mathrm{~T} 9=\mathrm{G} 3 \mathrm{C} 1 \\
\mathrm{~T} 2=\mathrm{G} 1 \mathrm{C} 2 & \mathrm{~T} 10=\mathrm{G} 3 \mathrm{C} 2 \\
\mathrm{~T} 3=\mathrm{G} 1 \mathrm{C} 3 & \mathrm{~T} 11=\mathrm{G} 3 \mathrm{C} 3 \\
\mathrm{~T} 4=\mathrm{G} 1 \mathrm{C} 4 & \mathrm{~T} 12=\mathrm{G} 3 \mathrm{C} 4 \\
\mathrm{~T} 5=\mathrm{G} 2 \mathrm{C} 1 & \mathrm{~T} 13=\mathrm{G} 4 \mathrm{C} 1 \\
\mathrm{~T} 6=\mathrm{G} 2 \mathrm{C} 2 & \mathrm{~T} 14=\mathrm{G} 4 \mathrm{C} 2 \\
\mathrm{~T} 7=\mathrm{G} 2 \mathrm{C} 3 & \mathrm{~T} 15=\mathrm{G} 4 \mathrm{C} 3 \\
\mathrm{~T} 8=\mathrm{G} 2 \mathrm{C} 4 & \mathrm{~T} 16=\mathrm{G} 4 \mathrm{C} 4
\end{array}
$$


As quantidades de insumos aplicadas foram calculadas com base em suas análises químicas (Tabelas 4 e 5) e em peso seco. Para maior facilidade e precisão na aplicação dos corretivos, cada parcela foi dividida em 8 partes iguais e a operação foi manual no dia 19 de janeiro de 1988. Após a aplicação, houve incorporação com grade leve.

Tabela 4. Resultados de análise de gesso.

\begin{tabular}{lc}
\hline Determinação & $(\%)$ \\
\hline $\mathrm{CaO}$ & 22,94 \\
$\mathrm{SO}_{4}$ & 37,76 \\
Umidade & 36,91 \\
\hline
\end{tabular}

Tabela 5. Resultados de análise de calcário.

\section{Determinação}

$\mathrm{CaO}$

$\mathrm{MgO}$

Umidade

Passou pela peneira 10

Passou pela peneira 50

PRNT
(\%)

33,89

13,08

8,71

99,89

56,41

68,71

\subsection{Plantio}

O plantio foi realizado dia 8 de fevereiro de 1988 com muda de boa qualidade e utilizando-se toletes com 3 gemas viáveis, na densidade de 15 gemas/m de sulco de plantio, com espaçamento de $1,10 \mathrm{~m}$ entre sulcos.

Todos os sulcos receberam $60 \mathrm{~kg} / \mathrm{ha}$ de Furadan 5G FMC (Carbofuran) e 4 I/ha de Heptacloro 40 CE (Heptachlor). 
As parcelas constaram de 8 sulcos de $10 \mathrm{~m}$, espaçamento $1,10 \mathrm{~m}$ e separadas por carreadores, no comprimento de $2 \mathrm{~m}$, ou seja, $88 \mathrm{~m}^{2}$ por parcela.

A adubação básica também feita manualmente com $30-150-150 \mathrm{~kg} / \mathrm{ha}$ de $\mathrm{N}$, $\mathrm{P}_{2} \mathrm{O}_{5}$ e $\mathrm{K}_{2} \mathrm{O}$, respectivamente, utilizando-se $600 \mathrm{~kg} / \mathrm{ha}$ da fórmula 5-25-25 (Tabela 6).

Tabela 6. Resultados de análise da fórmula 5-25-25.

\begin{tabular}{lc}
\hline Determinação & $(\%)$ \\
\hline Nitrogênio & 5,14 \\
$\mathrm{P}_{2} \mathrm{O}_{5}$ solúvel em $\mathrm{H}_{2} \mathrm{O}$ & 22,52 \\
$\mathrm{P}_{2} \mathrm{O}_{5}$ solúvel em citrato neutro de amônio + solúvel em $\mathrm{H}_{2} \mathrm{O}$ & 25,55 \\
$\mathrm{~K}_{2} \mathrm{O}$ & 24,96 \\
\hline
\end{tabular}

Após 3 meses do plantio, foi feita a cobertura com $50 \mathrm{~kg} / \mathrm{ha} \mathrm{de} \mathrm{N} \mathrm{e} 60 \mathrm{~kg} / \mathrm{ha}$ de $\mathrm{S}$ na forma de sulfato de amônio e $30 \mathrm{~kg} / \mathrm{ha}$ de $\mathrm{K}_{2} \mathrm{O}$ como cloreto de potássio.

\subsection{Avaliações}

\subsubsection{Número de perfilhos}

O desenvolvimento do canavial foi avaliado através da contagem da brotação aos 2 meses (média dos 3 sulcos centrais) e do número de perfilhos aos 11,5 meses (média dos 5 sulcos centrais).

\subsubsection{Diagnose foliar}

Aos 6,5 meses, foi realizada a amostragem de 15 folhas +3 por parcela (terço médio com nervura) para a análise de macronutrientes (GALLO et al., 1968). O material vegetal colhido foi lavado, seco em estufa a $65^{\circ} \mathrm{C}$ até peso constante e analisado segundo método descrito por SARRUGE \& HAAG (1974).

\subsubsection{Produção de cana-de-açúcar}

Na colheita, dia 22 de junho de 1989, foram pesadas as plantas inteiras dos 4 sulcos centrais com célula de carga. 


\subsubsection{Sistema radicular}

Entre 3 a 7 de julho de 1989, através de peneiramento, foram separadas as raízes dos volumes de $1,10 \times 1,00 \times 0,25 \mathrm{~m}\left(0-25\right.$ e $\left.25-50 \mathrm{~cm}-0,275 \mathrm{~m}^{3}\right)$, e $1,10 \times 0,70$ x 0,25 m (50-75 e 75-100 cm $\left.-0,1925 \mathrm{~m}^{3}\right)$, de acordo com o método utilizado por SALATA et al. (1986), apenas nos tratamentos que combinavam todas as doses de gesso com as doses de calcário 0 e 3,2 t/ha, ou seja,

$$
\begin{array}{rl}
\mathrm{T} 1=\mathrm{G} 1 \mathrm{C} 1 & \mathrm{~T} 9=\mathrm{G} 3 \mathrm{C} 1 \\
\mathrm{~T} 4=\mathrm{G} 1 \mathrm{C} 4 & \mathrm{~T} 12=\mathrm{G} 3 \mathrm{C} 4 \\
\mathrm{~T} 5=\mathrm{G} 2 \mathrm{C} 1 & \mathrm{~T} 13=\mathrm{G} 4 \mathrm{C} 1 \\
\mathrm{~T} 8=\mathrm{G} 2 \mathrm{C} 4 & \mathrm{~T} 16=\mathrm{G} 4 \mathrm{C} 4
\end{array}
$$

Cada camada foi inteiramente peneirada e as raízes presentes separadas, lavadas, secas em estufa a $65^{\circ} \mathrm{C}$ até peso constante e pesadas.

\subsubsection{Amostragens do solo}

Foram efetuadas amostragens do solo nas seguintes épocas:

- antes da aplicação dos corretivos (19 de janeiro de 1988) em 2 profundidades: 0-25 e $25-50 \mathrm{~cm}$;

- 4 meses após a aplicação (18/05/88) em 4 profundidades: $0-25 \mathrm{~cm}, 25-50 \mathrm{~cm}$, $50-75 \mathrm{~cm}$ e $75-100 \mathrm{~cm}$;

- 18 meses após a aplicação (10/07/89) também nas profundidades acima citadas.

Retirou-se com um trado tipo holandês 15 subamostras por parcela nas entrelinhas da cana.

As amostras de solo foram analisadas no laboratório do Centro de Tecnologia Copersucar segundo os métodos descritos por EMBRAPA (1979) e RAIJ \& QUAGGIO (1983).

Os índices pluviométricos da região durante o experimento estão apresentados na Tabela 7. 
Tabela 7. Valores mensais de precipitaçāo medidos em pluviômetro na Fazenda Pau D' Alho - Posto Serra Negra.

\begin{tabular}{lcc}
\hline Meses & 1988 & 1989 \\
\hline Janeiro & 278,2 & 337,0 \\
Fevereiro & 212,6 & 228,0 \\
Março & 126,5 & 88,0 \\
Abril & 49,0 & 68,0 \\
Maio & 103,5 & 72,0 \\
Junho & 34,5 & 42,5 \\
Julho & - & 85,0 \\
Agosto & - & 23,0 \\
Setembro & 25,0 & 75,0 \\
Outubro & 194,6 & 81,0 \\
Novembro & 85,0 & 144,5 \\
Dezembro & 151,5 & 320,5 \\
\hline Total & $1.206,4$ & $1.564,5$ \\
\hline
\end{tabular}




\section{RESULTADOS E DISCUSSĀO}

\subsection{Número de perfilhos}

O plantio de cana-de-açúcar é feito através de toletes que possuem 3 a 4 gemas. Ao se desenvolver, uma gema originará um colmo primário, de cujas gemas sairão colmos secundários e destes, colmos terciários, formando touceiras. Água, nutrientes, luz, temperatura, pragas e doenças, profundidade e espaçamento são os principais fatores que afetam o perfilhamento (ORLANDO FILHO, 1983).

No início, as plantas emitem um número grande de perfilhos, como se observa neste trabalho e em outros, como o de FERREIRA et al. (1989). Com o desenvolvimento da cultura começa a haver competição entre os perfilhos por água, luz $\mathrm{e}$ nutrientes, e seu número decresce, chegando à estabilização.

Observou-se neste trabalho, ao nível de $10 \%$, um efeito linear sobre o número de perfilhos da lavoura com o uso de gesso, que se mantiveram após a estabilização. Já o calcário teve também efeito linear (a 5\%) mas apenas na brotação inicial (Tabelas 8,9 e 10).

A Figura 1 mostra as retas características do aumento do número de brotos em função das doses de calcário e do aumento do número de perfilhos em função das doses de gesso.

$\mathrm{O}$ aumento do número de perfilhos em $10 \mathrm{~m}$ lineares na lavoura estabilizada pode parecer pequeno, mas por área e na época da colheita significa aumento na produção de cana, como se observa nos dados das Tabelas 8, 9 e 10 . 
Tabela 8. Quadrados médios da análise de variância do número de brotos e perfilhos em $10 \mathrm{~m}$ lineares de sulco.

\begin{tabular}{lccc}
\hline C.V. & G.L. & Brotação (12/4/88) & Perfilho (22/1/89) \\
\hline Blocos & 2 & 2162,15 & 6,52 \\
Gesso & 3 & 339,08 & $53,96^{*}$ \\
Calcário & 3 & 476,52 & 16,13 \\
Gesso x calcário & 9 & 356,54 & 14,08 \\
Resíduo & 30 & 278,23 & 13,70 \\
\hline C.V. (\%) & & 9,97 & 3,02 \\
Média geral & & 167,35 & 122,35 \\
\hline
\end{tabular}

- Significativo a $5 \%$ de probabilidade.

Tabela 9. Quadrados médios da análise de regressão polinomial do número de brotos e de perfilhos, em $10 \mathrm{~m}$ lineares de sulco, em função do uso de gesso e de calcário.

\begin{tabular}{ccccccc}
\hline & & \multicolumn{2}{c}{ Gesso } & & \multicolumn{2}{c}{ Calcário } \\
C.V. & G.L. & Brotação & Perfilho & & Brotação & Perfilho \\
\hline R.L. & 1 & 28,55 & $40,55^{+}$ & & $1380,67^{*}$ & 15,05 \\
R.Q. & 1 & 373,68 & 41,82 & & 37,43 & 1,82 \\
R.C. & 1 & 615,00 & 79,53 & & 11,46 & 31,53 \\
Resíduo & 30 & 278,23 & 13,70 & & 278,23 & 13,70 \\
\hline
\end{tabular}

* Significativo a $5 \%$ de probabilidade.

+ Significativo a $10 \%$ de probabilidade. 
Tabela 10. Médias de brotação de perfilhos obtidas em função das doses de gesso e de calcário.

\begin{tabular}{ccc}
\hline & Brotação & Perfilho \\
\hline Gesso & & \\
G2 & 167,17 & 121,58 \\
G3 & 164,08 & 123,25 \\
G4 & 174,92 & 119,83 \\
Calcário & 163,25 & 124,75 \\
C1 & & \\
C2 & 160,00 & 121,50 \\
C3 & 164,75 & 121,58 \\
C4 & 170,25 & 124,00 \\
\hline
\end{tabular}
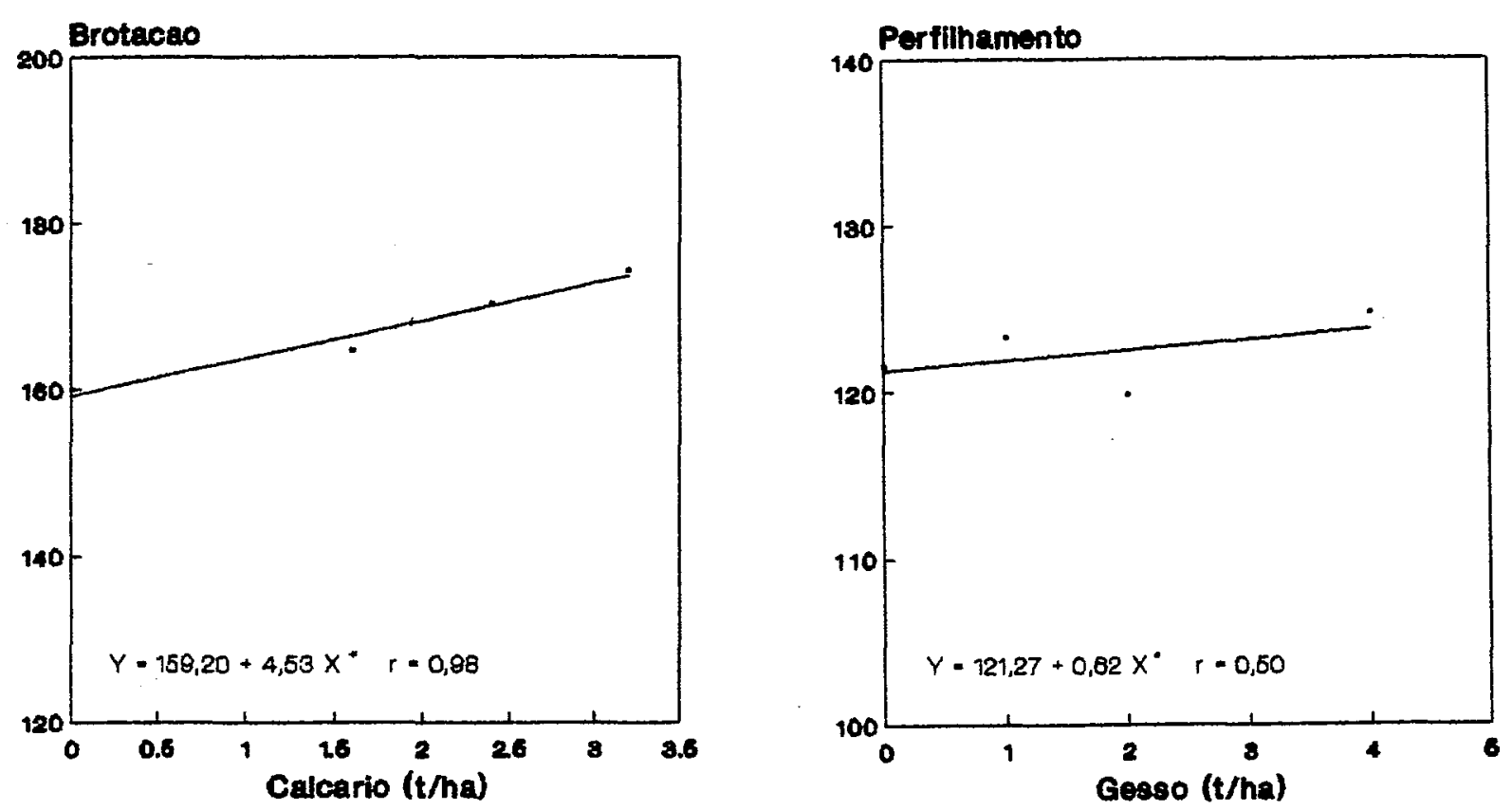

Figura 1. Efeitos das doses de calcário na brotação e de gesso no perfilhamento. 


\subsection{Diagnose foliar}

Os teores de macronutrientes foram analisados quando o canavial estava com 6,5 meses. Nessa ocasião, a cobertura com sulfato de amônio $(50 \mathrm{~kg} / \mathrm{ha} \mathrm{N} \mathrm{e} 60 \mathrm{~kg} / \mathrm{ha}$ S) e cloreto de potássio $\left(30 \mathrm{~kg} / \mathrm{K}_{2} \mathrm{O}\right)$ havia sido aplicada há mais de 3 meses, isto é, no início de maio de 1988.

Observa-se nas Tabelas 11, 12, 13 e 14 que o gesso foi responsável pelo aumento linear dos teores de cálcio e enxofre nas folhas, ambos ao nível de $1 \%$ de probabilidade.

Tabela 11. Quadrados médios da análise de variância dos teores de macronutrientes $(\%)$ nas folhas +3 do canavial com 6,5 meses de idade.

\begin{tabular}{lccccccc}
\hline C.V. & G.L. & $\mathbf{N}$ & $\mathbf{P}$ & $\mathbf{K}$ & $\mathbf{C a}$ & $\mathbf{M g}$ & $\mathbf{S}$ \\
\hline Blocos & 2 & 0,0314 & 0,0002 & 0,0324 & 0,0006 & 0,0049 & 0,0004 \\
Gesso & 3 & 0,0035 & 0,0001 & 0,0053 & $0,0048^{* *}$ & 0,0008 & $0,0072^{* *}$ \\
Calcário & 3 & 0,0070 & 0,0001 & 0,0176 & 0,0001 & 0,0016 & 0,0002 \\
Gesso x calcário & 9 & 0,0046 & 0,0001 & 0,0100 & 0,0008 & 0,0016 & 0,0002 \\
Resíduo & 30 & 0,0069 & 0,0001 & 0,0120 & 0,0009 & 0,0013 & 0,0002 \\
\hline CV (\%) & & 8,01 & 9,32 & 9,70 & 10,56 & 17,83 & 6,64 \\
Média geral & & 1,0354 & 0,1003 & 1,1319 & 0,2850 & 0,1992 & 0,1938 \\
\hline
\end{tabular}

** Significativo a $1 \%$ de probabilidade.

Tabela 12. Quadrados médios da análise de regressão polinomial dos teores de macronutrientes nas folhas +3 em função do uso de gesso aos 6 1/2 meses.

\begin{tabular}{lccccccc}
\hline C.V. & G.L. & $\mathrm{N}$ & $\mathrm{P}$ & $\mathrm{K}$ & $\mathrm{Ca}$ & $\mathrm{Mg}$ & $\mathrm{S}$ \\
\hline R.L. & 1 & 0,0075 & 0,00001 & 0,0041 & $0,0133^{* *}$ & 0,0007 & $0,0213^{* *}$ \\
R.Q. & 1 & 0,0026 & 0,00014 & 0,0090 & 0,0009 & 0,0015 & 0,0002 \\
R.C. & 1 & 0,0003 & 0,00003 & 0,0029 & 0,0002 & 0,0001 & $1 \times 10^{6}$ \\
Residuo & 30 & 0,0069 & 0,00009 & 0,0120 & 0,0009 & 0,0013 & 0,0002 \\
\hline
\end{tabular}

"* Significativo a $1 \%$ de probabilidade. 
Tabela 13. Quadrados médios da análise de regressão polinomial dos teores de macronutrientes nas folhas +3 em função do uso de calcário.

\begin{tabular}{lccccccc}
\hline C.V. & G.L. & $\mathrm{N}$ & $\mathrm{P}$ & $\mathrm{K}$ & $\mathrm{Ca}$ & $\mathrm{Mg}$ & $\mathrm{S}$ \\
\hline R.L. & 1 & 0,0021 & $3 \times 10^{6}$ & 0,0001 & 0,00006 & $0,0041^{+}$ & 0,00002 \\
R.Q. & 1 & 0,0189 & 0,00013 & 0,0241 & 0,00001 & 0,0001 & 0,00063 \\
R.C. & 1 & 0,0001 & 0,00004 & 0,0280 & 0,00008 & 0,0005 & 0,00002 \\
Resíduo & 30 & 0,0069 & 0,00009 & 0,0120 & 0,00091 & 0,0013 & 0,00017 \\
\hline
\end{tabular}

+ Significativo a $10 \%$ de probabilidade.

Tabela 14. Médias dos teores de macronutrientes (\%) obtidos em funçāo das doses de gesso e de calcário.

\begin{tabular}{ccccccc}
\hline & $\mathbf{N}$ & $\mathbf{P}$ & $\mathbf{K}$ & $\mathbf{C a}$ & $\mathbf{M g}$ & $\mathbf{S}$ \\
\hline Gesso & & & & & & \\
G1 & 1,0433 & 0,0984 & 1,1100 & 0,2692 & 0,2017 & 0,1667 \\
G2 & 1,0425 & 0,1000 & 1,1242 & 0,2767 & 0,1917 & 0,1842 \\
G3 & 1,0458 & 0,1035 & 1,1600 & 0,2800 & 0,1942 & 0,2000 \\
G4 & 1,0100 & 0,0993 & 1,1333 & 0,3142 & 0,2092 & 0,2242 \\
Calcário & & & & & & \\
C1 & 1,0092 & 0,0984 & 1,1067 & 0,2833 & 0,1850 & 0,1900 \\
C2 & 1,0617 & 0,1034 & 1,1883 & 0,2858 & 0,1950 & 0,1975 \\
C3 & 1,0492 & 0,1002 & 1,1100 & 0,2833 & 0,2092 & 0,1975 \\
C4 & 1,0217 & 0,0992 & 1,1225 & 0,2875 & 0,2075 & 0.1900 \\
\hline
\end{tabular}

As doses de calcário produziram efeito linear apenas sobre os teores de magnésio das folhas, ao nível de $10 \%$.

Embora tenha havido aumento dos teores de cálcio com o aumento das doses de gesso, esses teores foram baixos se comparados com a Tabela 1 e os citados por RAIJ (1991). Da mesma forma, também os teores de nitrogênio e fósforo seriam 
considerados deficientes. No entanto, considerando-se a adubação básica feita por ocasião do plantio e a adubação de cobertura, deveria se esperar teores mais elevados. É necessário que se lembre que na época da amostragem o solo estava seco (ver Tabela 7 - precipitação mensal) e as plantas estavam com dificuldade para absorver água e nutrientes, o que justifica em parte estes teores.

CHALITA (1991), em estudo de calibração de potássio em cana-de-açúcar, encontrou teores de potássio, cálcio e magnésio em solos de textura semelhante muito próximos aos encontrados neste trabalho.

Outro autor, PENATTI (1991), estudando a mesma variedade (SP70-1143) e na mesma época de amostragem, observou teores de fósforo semelhantes e de cálcio ainda mais baixos nas folhas +3 .

Os trabalhos citados por MALAVOLTA (1989) mostram teores de enxofre nas folhas muito próximos aos aqui obtidos.

A Figura 2 apresenta as retas significativas obtidas pela correlação entre as doses de gesso e os teores de cálcio e enxofre nas folhas +3 , e de das doses de calcário com os teores de magnésio.
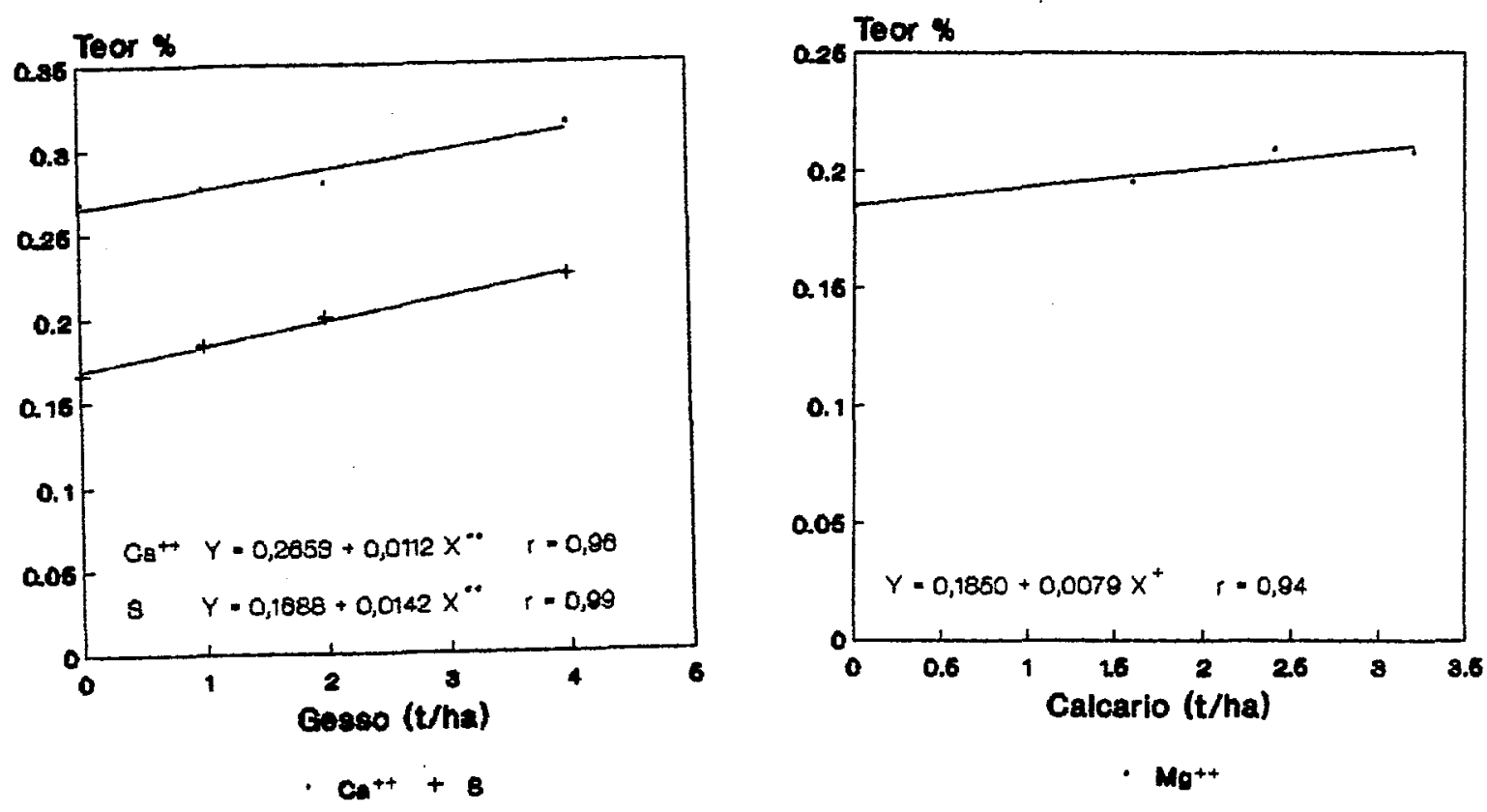

Figura 2. Efeitos das doses de gesso sobre os teores de cálcio e de enxofre das folhas, e de calcário sobre os teores de magnésio. 


\subsection{Sistema radicular}

O sistema radicular da cana-de-açúcar é do tipo fasciculado e pode ser dividido em três partes, segundo DILLEWIJN (1952):

- raízes superficiais absorventes e ramificadas;

- raízes de fixação, mais profundas, $\mathbf{e}$

- raízes-cordão que podem chegar a $6 \mathrm{~m}$ de profundidade. Aproximadamente $60 \%$ do sistema radicular encontra-se a até $40 \mathrm{~cm}$ de profundidade.

KORNDÖRFER et al. (1989) observaram que de 89 a $92 \%$ das raízes de 5 variedades de cana-planta aos 11 meses, cultivadas em um Latossolo Vermelho-Amarelo, situavam-se nos primeiros $30 \mathrm{~cm}$. Os autores explicaram que esta maior concentração radicular superficial era função dos baixos teores de cálcio do solo.

No presente trabalho também foi observada grande concentração de raízes na camada superficial (Tabela 15), na amostragem feita em quatro profundidades.

Tabela 15. Quadrados médios da análise de variância do peso seco de raizes em cada profundidade, 10 dias após a colheita da cana.

\begin{tabular}{lcccccc}
\hline C.V. & G.L. & $\mathbf{0 - 2 5}$ & $\mathbf{2 5 - 5 0}$ & $\mathbf{5 0 - 7 5}$ & $\mathbf{7 5 - 1 0 0}$ & $\mathbf{0 - 1 0 0}$ \\
\hline Blocos & 2 & 1757,055 & 809,205 & 191,318 & 3,215 & 88,165 \\
Gesso & 3 & 4065,729 & 772,192 & 139,188 & 65,858 & $9701,806^{*}$ \\
Calcário & 1 & 932,506 & 39,784 & 254,150 & 16,335 & 152,006 \\
Ges. x Cal. & 3 & 337,226 & 424,124 & 52,505 & 15,615 & 421,325 \\
Resíduo & 14 & 1969,281 & 276,730 & 168,625 & 81,181 & 2964,401 \\
\hline C.V. & & 13,83 & 26,14 & 41,06 & 43,88 & 12,47 \\
Média geral & & 320,933 & 63,638 & 31,629 & 20,533 & 436,733 \\
\hline
\end{tabular}

*Significativo a $5 \%$ de probabilidade.

Na primeira profundidade $(0-25 \mathrm{~cm})$, encontrou-se, em média, $69,9 \%$ das raízes; de 25 a $50 \mathrm{~cm}$ a percentagem baixou para $13,9 \%$; na terceira, $9,8 \%$; e na última $(75-100 \mathrm{~cm})$ foi observado apenas $6,4 \%$ do total de raízes. 
Geralmente, o teor de cálcio dos solos diminui com a profundidade, o que concorre para o menor desenvolvimento radicular em subsuperfície. Outros autores, SALATA et al. (1986) e PENATTI (1991), trabalhando com cana-de-açúcar e em situações de solos semelhantes, encontraram resultados próximos dos encontrados nesse trabalho.

Com o uso de gesso ocorreu um aumento no peso do material seco de raízes, nas duas profundidades superficiais e no conjunto até $1 \mathrm{~m}$ de profundidade, conforme as Tabelas 15, 16 e 17 e Figura 3, apesar de terem sido observados para a camada de $0-25 \mathrm{~cm}$ níveis de probabilidade de $15 \%$ e $12 \%$ para análise de variância e para aregressão linear, respectivamente.

Tabela 16. Quadrados médios da análise de regressão polinomial do peso seco de raízes por profundidade em função do uso de gesso.

\begin{tabular}{lcccccc}
\hline C.V. & G.L. & $\mathbf{0 - 2 5}$ & $\mathbf{2 5 - 5 0}$ & $\mathbf{5 0 - 7 5}$ & $\mathbf{7 5 - 1 0 0}$ & $\mathbf{0 - 1 0 0}$ \\
\hline R.L. & 1 & 5266,007 & $1294,810^{*}$ & 141,286 & 13,477 & 8647,740 \\
R.Q. & 1 & 2551,355 & 811,640 & 150,169 & 108,343 & $10.335,450$ \\
R.C. & 1 & 4379,824 & 210,123 & 126,109 & 75,753 & $10.122,246$ \\
Resíduo & 14 & 1969,281 & 276,730 & 168,625 & 81,181 & 2964,401 \\
\hline
\end{tabular}

* Significativo a $5 \%$ de probabilidade.

Tabela 17. Médias do peso seco de raízes por profundidade (g/camada amostrada) em função das doses de gesso e calcário.

\begin{tabular}{cccccc}
\hline & $\mathbf{0 - 2 5}$ & $\mathbf{2 5 - 5 0}$ & $\mathbf{5 0 - 7 5}$ & $\mathbf{7 5 - 1 0 0}$ & $\mathbf{0 - 1 0 0}$ \\
\hline Gesso & & & & & \\
$\mathrm{G}_{1}$ & 322,767 & 63,200 & 38,633 & 24,833 & 449,433 \\
$\mathrm{G}_{2}$ & 286,167 & 51,650 & 27,750 & 16,833 & 382,400 \\
$\mathrm{G}_{3}$ & 325,600 & 60,767 & 30,617 & 19,700 & 436,683 \\
$\mathrm{G}_{4}$ & 349,200 & 78,933 & 29,517 & 20,767 & 478,417 \\
$\mathrm{Calcá}$ & & & & & \\
$\mathrm{C}_{1}$ & 314,700 & 64,925 & 34,883 & 22,133 & 434,217 \\
$\mathrm{C}_{4}$ & 327,167 & 62,350 & 28,375 & 27,533 & 439,250 \\
\hline
\end{tabular}




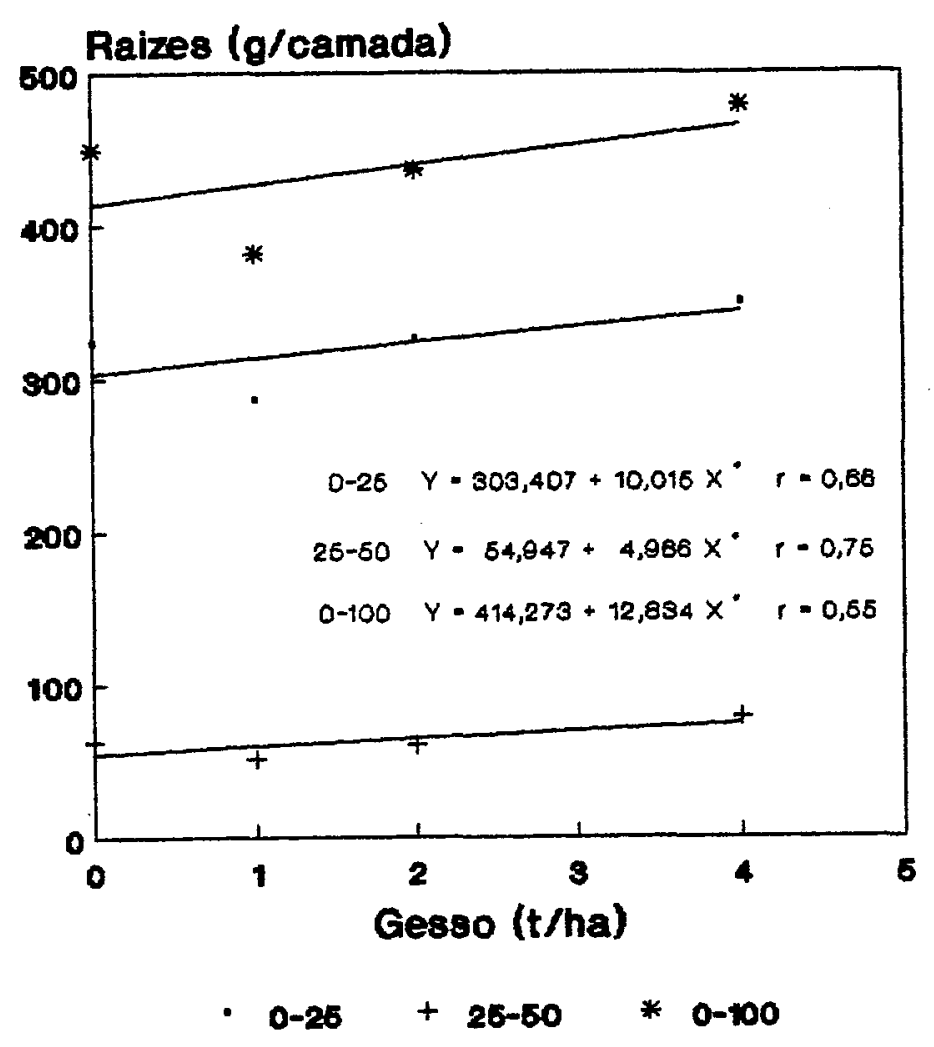

Figura 3. Efeito das doses de gesso sobre o aumento do sistema radicular.

Os teores iniciais de cálcio do solo eram $0,85 \mathrm{meq} / 100 \mathrm{~cm}^{3}$ na camada de 0 a $25 \mathrm{~cm}$, e $0,39 \mathrm{meq} / 100 \mathrm{~cm}^{3}$ na de 25 a $50 \mathrm{~cm}$. (Tabela 21 ).

Após 4 meses da aplicação dos insumos, os teores subiram linearmente ao nível de $1 \%$ de probabilidade com as doses de gesso aplicadas até $1 \mathrm{~m}$ de profundidade (Tabela 24).

Esses teores explicam os aumentos observados no peso seco de raízes, pois na camada de $0-25 \mathrm{~cm}$ foram maiores que $1 \mathrm{meq} \mathrm{de} \mathrm{Ca} / 100 \mathrm{~cm}^{3}$ e na de $25-50 \mathrm{~cm}$ ficaram próximos desse valor. A COPERSUCAR (1988) considera 1 meq de Ca/100 $\mathrm{cm}^{3}$ como teor adequado no solo para a cultura da cana-de-açúcar.

MORELLl et al. (1987), trabalhando com gesso e calcário em cana-de-açúcar, concluiram que o aprofundamento das raízes depende da concentração e da 
disponibilidade de cálcio nas camadas subsuperficiais do solo, concordando com os resultados deste trabalho.

\subsection{Produção de cana-de-açúcar}

Aos 16,5 meses do plantio, foi feita a colheita, cujos dados analisados encontram-se nas Tabelas 18, 19 e 20.

Tabela 18. Análise de variância do peso de cana.

\begin{tabular}{lcc}
\hline C.V. & G.L. & Q.M. \\
\hline Blocos & 2 & 47,25 \\
Gesso & 3 & 91,28 \\
Calcário & 3 & 51,61 \\
Gesso x calcário & 9 & 46,52 \\
Resíduo & 30 & 89,61 \\
\hline C.V (\%) & & 8,89 \\
Média geral (t/ha) & & 106,50 \\
\hline
\end{tabular}

Tabela 19. Quadrados médios da análise de regressão polinomial do peso de cana em função do uso de gesso e calcário.

\begin{tabular}{cccc}
\hline C.V. & G.L. & Gesso & Calcário \\
\hline R.L. & 1 & $259,29^{+}$ & 0,04 \\
R.Q. & 1 & 3,64 & 102,39 \\
R.L. & 1 & 10,91 & 52,40 \\
Resíduo & 30 & 89,61 & 89,61 \\
\hline
\end{tabular}

+ Significativo a $10 \%$ de probabilidade. 
Tabela 20. Médias de produção (t/ha) obtidas em função das doses de gesso e calcário.

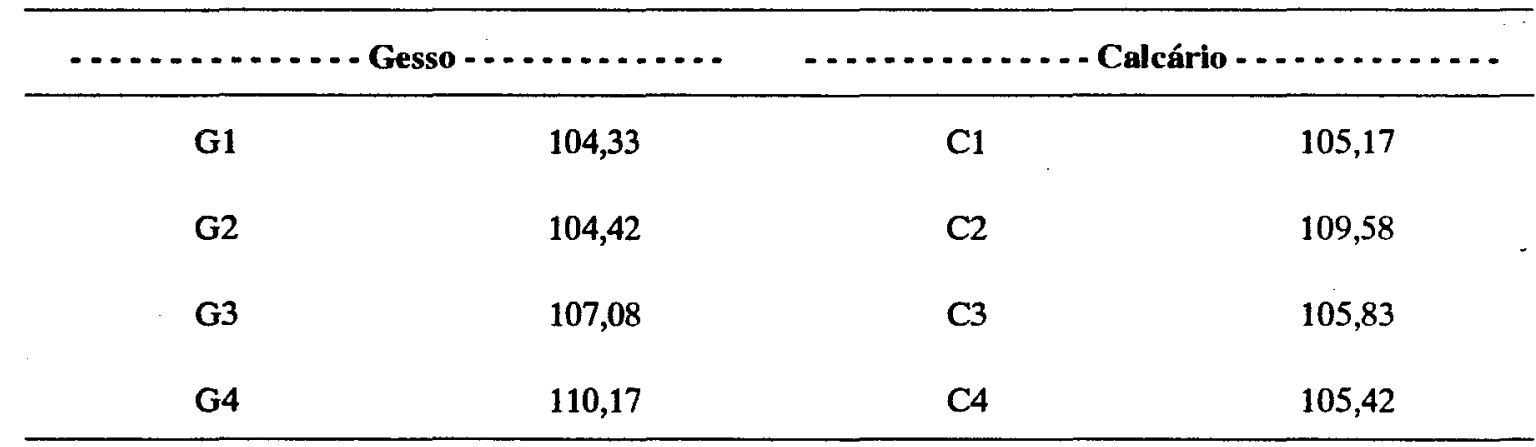

O aumento do número de perfilhos observado aos 11,5 meses de idade, o aumento dos teores de cálcio e enxofre nas folhas aos 6,5 meses e o maior desenvolvimento do sistema radicular em função das doses de gesso refletiram-se em maior produção de cana-de-açúcar por área, apesar do nível de probabilidade ter sido baixo na análise de variância para o efeito das doses de gesso (Tabela 18). A análise de regressão polinomial (Tabela 19) apresentou uma probabilidade ao nível de $10 \%$ para regressão linear.

Em ensaios de campo, MORELLI et al. (1987) observaram efeitos positivos do gesso sobre a produção e o desenvolvimento radicular da cana, em solos arenosos álicos, com baixos teores iniciais de cálcio, tanto na superfície quanto em profundidade $\left(0,2-0,3 \mathrm{meq} / 100 \mathrm{~cm}^{3}\right)$. Concluíram, porém, que a associação do gesso com o calcário produziu sempre mais do que o calcário aplicado isoladamente, o que não foi observado no presente trabalho. Em nenhuma das análises, a interação gesso $\mathrm{x}$ calcário foi significativa, discordando dos resultados obtidos no citado trabalho; apenas o uso de doses de gesso foi suficiente para produzir os efeitos em todas as variáveis estudadas na cana-de-açúcar (Figura 4).

É importante observar que o efeito do gesso como fonte de enxofre foi anulado, uma vez que foram aplicados $60 \mathrm{~kg} / \mathrm{ha}$ de $S$ por ocasião da adubação de cobertura na forma de sulfato de amônio. De acordo com MALAVOLTA (1989), esta dose foi bastante superior à necessária para se obter maior produção de cana devido ao enxofre, que seria de $30 \mathrm{~kg} / \mathrm{ha}$ de $\mathrm{S}$ para cana-planta e de $15 \mathrm{~kg} / \mathrm{ha}$ de $\mathrm{S}$ para soqueiras. 


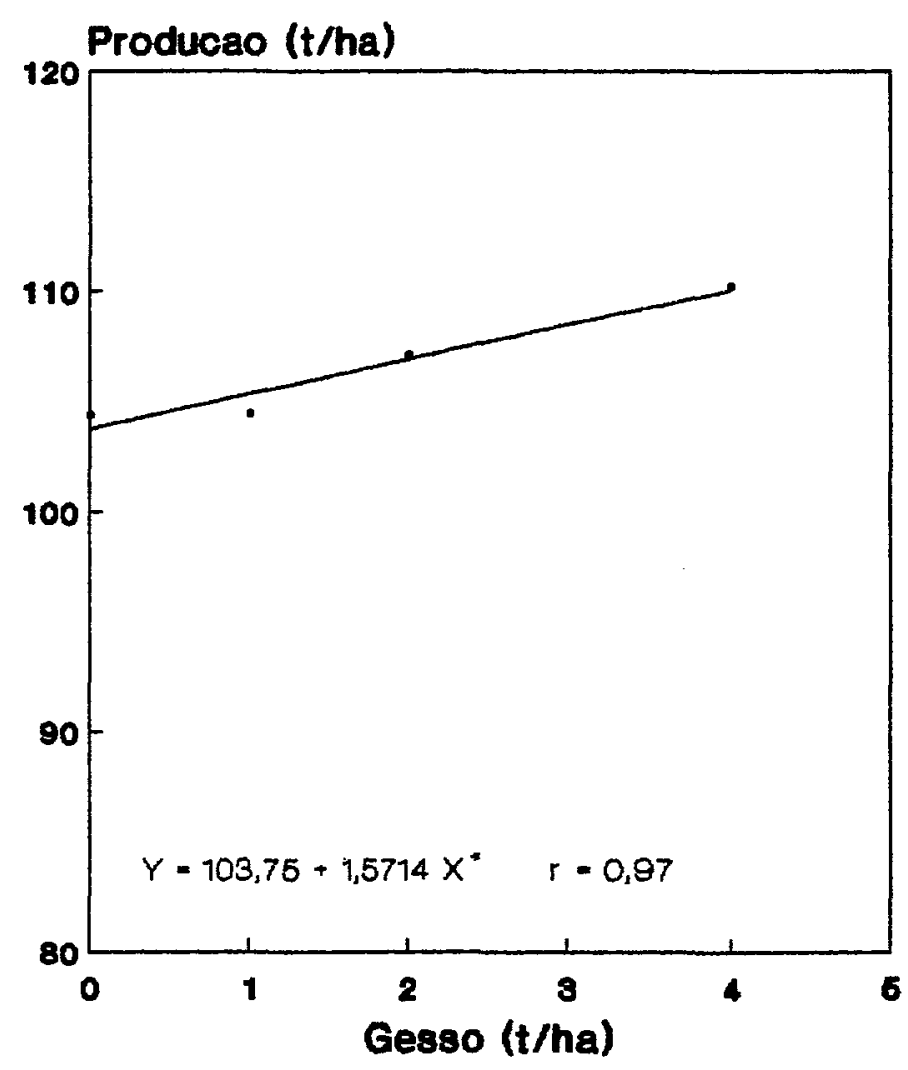

Figura 4. Acréscimos de produção obtidos com o uso de gesso.

\subsection{Análise do solo}

\subsubsection{Antes da aplicação dos insumos}

Esta amostragem foi efetuada com o objetivo de se observar possíveis variações já existentes na área experimental antes da instalação do trabalho. Nas Tabelas 21 e 22 estão os quadrados médios da análise de variância e as médias obtidas.

Era de se esperar que com o aumento da profundidade, a influência dos tratos culturais fosse menos expressiva e, por esta razão, não foram analisadas as profundi- 
dades $50-75 \mathrm{~cm}$ e $75-100 \mathrm{~cm}$. Isto foi confirmado na segunda camada $(25-50 \mathrm{~cm})$, onde todas as análises realizadas não apresentaram diferenças significativas entre as parce las. No entanto, as análises da camada superficial mostraram haver diferença entre as parcelas antes do início do trabalho para $\mathrm{P}, \mathrm{K}, \mathrm{Ca} \mathrm{e} \mathrm{Mg}, \mathrm{e}, \mathrm{em}$ conseqüência, $\mathrm{V} \%$. Contudo, estas diferenças provavelmente não comprometeram os resultados porque os teores médios de fósforo, cálcio, magnésio e potássio poderiam ser diferentes entre si estatisticamente mas, na prática, são todos teores que se encontram na classe de teores baixos, sendo os de potássio considerados muito baixos (RAIJ, 1987).

Tabela 21. Quadrados médios da análise de variância dos resultados da análise do solo antes da aplicação dos insumos.

\begin{tabular}{|c|c|c|c|c|c|c|c|c|c|}
\hline \multirow{2}{*}{ c.v. } & \multirow{2}{*}{ G.L. } & \multicolumn{2}{|c|}{$\mathbf{p H}$} & \multicolumn{2}{|c|}{ M.O. } & \multicolumn{2}{|c|}{$\mathbf{P}$} & \multicolumn{2}{|c|}{$\mathbf{K}^{+}$} \\
\hline & & $0-25$ & $25-50$ & 0.25 & $25-50$ & $0-25$ & $25-50$ & $0-25$ & 25.50 \\
\hline Blocos & 2 & 0,219 & 0,170 & 0,0745 & 0,3753 & 58,59 & 11,66 & 0,0008 & 0,0004 \\
\hline Gesso & 3 & 0,031 & 0,006 & 0,0591 & 0,0068 & 18,52 & 4,30 & 0,0003 & 0,0001 \\
\hline Calcário & 3 & 0,063 & 0,040 & 0,1114 & 0,0947 & 41,45 & 8,75 & 0,0008 & 0,0006 \\
\hline Gesso x calcário & 9 & 0,037 & 0,015 & 0,1318 & 0,0562 & 16,98 & 8,56 & 0,0006 & 0,0003 \\
\hline Resíduo & 30 & 0,034 & 0,038 & 0,0870 & 0,0740 & 10,68 & 9,07 & 0,0002 & 0,0003 \\
\hline \multirow[t]{2}{*}{ C.V. (\%) } & & 4,07 & 4,43 & 14,06 & 18,56 & 31,99 & 40,70 & 21,31 & 40,41 \\
\hline & & & & \multicolumn{2}{|c|}{$\cdots-(\%) \cdots$} & \multicolumn{2}{|c|}{$\cdots\left(\mu \mathrm{g} / \mathrm{cm}^{3}\right) \ldots$} & \multicolumn{2}{|c|}{$--\left(\mathrm{meq} / 100 \mathrm{~cm}^{3}\right)-$} \\
\hline Média geral & & 4,508 & 4,377 & 2,0977 & 1,4657 & 10,21 & 7,40 & 0,0608 & 0,0419 \\
\hline
\end{tabular}

(Continua)

\subsubsection{Após 4 meses da aplicação de insumos}

As Tabelas 23, 24 e 25 apresentam os resultados das análises de variância e de regressão dos resultados das análises de solo após 4 meses e suas médias de acordo com as doses de gesso e calcário. Os resultados da análise de solo mostraram que, após 4 meses da aplicação do gesso e do calcário, não houve efeito dos tratamentos sobre a matéria orgânica e o fósforo do solo. 
Tabela 21. Continuação.

\begin{tabular}{|c|c|c|c|c|c|c|c|c|c|}
\hline \multirow{2}{*}{ c.v. } & \multirow{2}{*}{ G.L. } & \multicolumn{2}{|c|}{$\mathrm{Ca}^{2+}$} & \multicolumn{2}{|c|}{$\mathrm{Mg}^{2+}$} & \multicolumn{2}{|c|}{$\mathbf{H}^{+}+\mathrm{Al}^{3+}$} & \multicolumn{2}{|c|}{$\mathrm{Al}^{3+}$} \\
\hline & & $0-25$ & $25-50$ & $0-25$ & $25-50$ & $0-25$ & $25-50$ & $0-25$ & $25-50$ \\
\hline Blocos & 2 & 0,4105 & 0,1548 & 0,0568 & 0,0372 & 0,102 & 0,058 & 0,0990 & 0,1083 \\
\hline Gesso & 3 & 0,0682 & 0,0086 & 0,0280 & 0,0063 & 0,029 & 0,028 & 0,0042 & 0,0020 \\
\hline Calcário & 3 & 0,3037 & 0,0566 & 0,0425 & 0,0186 & 0,197 & 0,104 & 0,0462 & 0,0308 \\
\hline Gesso x calcário & 9 & 0,0818 & 0,0169 & 0,0207 & 0,0047 & 0,155 & 0,108 & 0,0173 & 0,0116 \\
\hline Resíduo & 30 & 0,0658 & 0,0377 & 0,0119 & 0,0077 & 0,204 & 0,188 & 0,0224 & 0,0312 \\
\hline c.V. (\%) & & 30,25 & 49,52 & 31,51 & 43,31 & 15,60 & 16,30 & 52,80 & 45,81 \\
\hline Média geral & & 0,8479 & 0,3921 & 0,3468 & 0,2029 & 2,894 & 2,663 & 0,2837 & 0,3858 \\
\hline
\end{tabular}

Tabela 21. Continuaçāo.

\begin{tabular}{|c|c|c|c|c|c|c|c|}
\hline \multirow{2}{*}{ C.V. } & \multirow{2}{*}{ G.L. } & \multicolumn{2}{|c|}{$\mathbf{S}$} & \multicolumn{2}{|c|}{ CTC } & \multicolumn{2}{|c|}{$\mathbf{v}$} \\
\hline & & $0-25$ & 25-50 & 0.25 & $25-50$ & 0.25 & $25-50$ \\
\hline Blocos & 2 & 0,678 & 0,112 & 0,272 & 0,027 & 249,25 & 104,31 \\
\hline Gesso & 3 & 0,178 & 0,022 & 0,069 & 0,095 & 67,91 & 7,30 \\
\hline Calcário & 3 & 0,619 & 0,245 & 0,156 & 0,289 & 245,19 & 132,08 \\
\hline Gesso $\times$ calcário & 9 & 0,197 & 0,051 & 0,239 & 0,124 & 81,43 & 36,52 \\
\hline Resíduo & 30 & 0,121 & 0,125 & 0,185 & 0,184 & 62,81 & 82,05 \\
\hline \multirow[t]{2}{*}{ C.V. (\%) } & & 26,98 & 50,82 & 10,31 & 12,80 & 26,36 & 45,43 \\
\hline & & $\ldots$. & $\cdots$ (me & $\left.m^{3}\right) \ldots$ & . . . . & $\ldots$ & $\ldots$ \\
\hline Média geral & & 1,290 & 0,696 & 4,176 & 3,349 & 30,06 & 19,94 \\
\hline
\end{tabular}


Tabela 22. Médias dos resultados da análise do solo antes da aplicação dos insumos.

\begin{tabular}{|c|c|c|c|c|c|c|c|c|c|c|}
\hline \multirow[t]{2}{*}{1} & \multicolumn{2}{|c|}{$\mathbf{p H}$} & \multicolumn{2}{|c|}{ M.O. } & \multicolumn{2}{|c|}{$\mathbf{P}$} & \multicolumn{2}{|c|}{$\mathbf{K}^{+}$} & \multicolumn{2}{|c|}{$\mathrm{Ca}^{2+}$} \\
\hline & 0.25 & $25-50$ & $0-25$ & $25-50$ & $0-25$ & $25-50$ & 0.25 & $25-50$ & $0-25$ & $25-50$ \\
\hline & & & $\cdots \cdots$ & $\ldots$. & $\ldots-(\mu g$ & $\left.\mathrm{cm}^{3}\right) \ldots$ & $\ldots$ & -- (me & $\left.0 \mathrm{~cm}^{3}\right)$ & $\ldots$ \\
\hline \multicolumn{11}{|l|}{ Gesso } \\
\hline$G_{1}$ & 4,475 & 4,367 & 2,0775 & 1,4465 & 8,67 & 7,17 & 0,0586 & 0,0392 & 0,7525 & 0,3683 \\
\hline$G_{2}$ & 4,458 & 4,350 & 2,1677 & 1,4666 & 10,51 & 8,00 & 0,0645 & 0,0433 & 0,8467 & 0,3708 \\
\hline $\mathrm{G}_{3}$ & 4,567 & 4,400 & 2,1368 & 1,4990 & 10,01 & 6,67 & 0,0655 & 0,0425 & 0,9367 & 0,4225 \\
\hline $\mathbf{G}_{4}$ & 4,533 & 4,392 & 2,0087 & 1,4508 & 11,67 & 7,75 & 0,0545 & 0,0426 & 0,8558 & 0,4067 \\
\hline Calcário & & & & . & & & & & & \\
\hline$c_{1}$ & 4,617 & 4,442 & 2,2121 & 1,4825 & 12,84 & 8,09 & 0,0706 & 0,0400 & 1,0717 & 0,4375 \\
\hline $\mathrm{C}_{2}$ & 4,467 & 4,408 & 2,0042 & 1,5433 & 8,51 & 8,17 & 0,0518 & 0,0517 & 0,7258 & 0,4600 \\
\hline$c_{3}$ & 4,475 & 4,317 & 2,0334 & 1,4990 & 9,51 & 6,50 & 0,0638 & 0,0417 & 0,8508 & 0,3583 \\
\hline$c_{4}$ & 4,475 & 4,342 & 2,1410 & 1,3382 & 10,01 & 6,84 & 0,0568 & 0,0342 & 0,7433 & 0,3125 \\
\hline
\end{tabular}

Tabela 22. Continuaçāo.

\begin{tabular}{|c|c|c|c|c|c|c|c|c|c|c|c|c|}
\hline & \multicolumn{2}{|c|}{$\mathrm{Mg}^{2+}$} & \multicolumn{2}{|c|}{$\mathbf{H}^{+}+\mathbf{A l}^{3+}$} & \multicolumn{2}{|c|}{$\mathrm{Al}^{3+}$} & \multicolumn{2}{|c|}{$\mathbf{S}$} & \multicolumn{2}{|c|}{ CTC } & \multicolumn{2}{|c|}{$\mathbf{v}$} \\
\hline & 0.25 & $25-50$ & 0.25 & 25.50 & 0.25 & $25-50$ & $0-25$ & $25-50$ & 0.25 & $25-50$ & 0.25 & $25-50$ \\
\hline & $\ldots \ldots$ & $\ldots$. & $\ldots$ & $\ldots$ & $\cdots(m$ & $\left(100 \mathrm{~cm}^{3}\right)$ & - & & & & $\cdots-c$ & $\cdots$ \\
\hline \multicolumn{13}{|l|}{ Gesso } \\
\hline $\mathrm{G}_{1}$ & 0,3382 & 0,1913 & 2,942 & 2,600 & 0,3066 & 0,3976 & 1,179 & 0,655 & 4,111 & 3,245 & 27,83 & 19,67 \\
\hline $\mathrm{G}_{2}$ & 0,3033 & 0,1797 & 2,900 & 2,692 & 0,2906 & 0,3959 & 1,247 & 0,697 & 4,138 & 3,378 & 29,25 & 19,33 \\
\hline $\mathbf{G}_{3}$ & 0,4157 & 0,2323 & 2,825 & 2,708 & 0,2651 & 0,3712 & 1,463 & 0,755 & 4,283 & 3,454 & 33,42 & 21,08 \\
\hline $\mathrm{G}_{4}$ & 0,3299 & 0,2081 & 2,908 & 2,650 & 0,2724 & 0,3784 & 1,271 & 0,679 & 4,171 & 3,320 & 29,75 & 19,67 \\
\hline \multicolumn{13}{|l|}{ Calcário } \\
\hline$c_{1}$ & 0,4305 & 0,2387 & 2,708 & 2,533 & 0,1986 & 0,3168 & 1,605 & 0,778 & 4,311 & 3,306 & 36,42 & 23,00 \\
\hline$c_{2}$ & 0,3059 & 0,2289 & 2,950 & 2,717 & 0,3147 & 0,3803 & 1,104 & 0,849 & 4,043 & 3,556 & 26,67 & 22,50 \\
\hline$c_{3}$ & 0,3482 & 0,1915 & 2,917 & $.2,742$ & 0,2799 & 0,4309 & 1,305 & 0,623 & 4,213 & 3,351 & 30,17 & 17,92 \\
\hline$C_{4}$ & 0,3027 & 0,1523 & 3,000 & 2,658 & 0,3414 & 0,4151 & 1,146 & 0,536 & 4,135 & 3,183 & 27,00 & 16,33 \\
\hline
\end{tabular}


Tabela 23. Quadrados médios da análise de variância dos resultados da análise de solo, 4 meses após a aplicação dos insumos.

\begin{tabular}{|c|c|c|c|c|c|c|c|c|c|}
\hline \multirow{2}{*}{ C.V. } & \multirow{2}{*}{ G.L. } & \multicolumn{4}{|c|}{$\mathbf{p H}$} & \multicolumn{4}{|c|}{ M.O. } \\
\hline & & - 0.25 & $25 \cdot 50$ & $50-75$ & $75-100$ & $0-25$ & $25-50$ & $50-75$ & $75-100$ \\
\hline Bloco & 2 & 0,280 & 0,343 & 0,101 & 0,013 & 0,0998 & 0,0521 & 0,0494 & 0,0145 \\
\hline Gesso & 3 & 0,033 & 0,076 & 0,035 & 0,066 & 0,0363 & 0,0177 & 0,0019 & 0,0163 \\
\hline Calcário & 3 & $0,484^{* *}$ & 0,012 & 0,017 & 0,035 & 0,0818 & 0,0307 & 0,0023 & 0,0088 \\
\hline $\begin{array}{l}\text { Gesso x } \\
\text { calcário }\end{array}$ & 9 & 0,103 & 0,036 & 0,014 & 0,034 & 0,0367 & 0,0467 & 0,0427 & 0,0174 \\
\hline Resíduo & 30 & 0,030 & 0,029 & 0,021 & 0,024 & 0,0534 & 0,0364 & 0,0154 & 0,0306 \\
\hline \multirow[t]{2}{*}{ C.V. (\%) } & & 3,71 & 3,91 & 3,43 & 3,66 & 12,67 & 15,12 . & 13,38 & 21,02 \\
\hline & & & & & & $\cdots$ & $\ldots$ & $\ldots$ & $\ldots$ \\
\hline Média geral & & 4,706 & 4,348 & 4,185 & 4,200 & 1,9876 & 1,2612 & 0,9275 & 0,8317 \\
\hline
\end{tabular}

** Significativo a $1 \%$ de probabilidade.

Tabela 23. Continuação.

\begin{tabular}{|c|c|c|c|c|c|c|c|c|c|}
\hline \multirow{2}{*}{ C.V. } & \multirow{2}{*}{ G.L. } & \multicolumn{4}{|c|}{$\mathbf{P}$} & \multicolumn{4}{|c|}{$\mathbf{K}^{+}$} \\
\hline & & 0.25 & $25-50$ & $50-75$ & $75-100$ & $0-25$ & $25-50$ & $50-75$ & $75-100$ \\
\hline Bloco & 2 & 2,26 & 32,81 & 30,44 & 47,53 & 0,0004 & 0,0018 & 0,0001 & 0,0001 \\
\hline Gesso & 3 & 2,75 & 29,90 & 4,41 & 6,17 & $0,0009^{+}$ & 0,0002 & 0,0004 & 0,0001 \\
\hline Calcário & 3 & 3,74 & 21,27 & 0,24 & 1,84 & 0,0002 & 0,0002 & 0,0002 & 0,0001 \\
\hline $\begin{array}{l}\text { Gesso x } \\
\text { calcário }\end{array}$ & 9 & 9,94 & 32,25 & 1,78 & 6,00 & 0,0002 & 0,0002 & 0,0001 & 0,0001 \\
\hline Resíduo & 30 & 12,92 & 31,62 & $2 ; 08$ & 6,72 & 0,0004 & 0,0003 & 0,0001 & 0,0001 \\
\hline C.V. (\%) & & 32,59 & 75,76 & 34,42 & 62,17 & 29.05 & 32,61 & 29,84 & 28,36 \\
\hline Média geral & & 11,03 & 7,42 & 4,19 & 4,17 & 0,0673 & 0,0531 & 0,0371 & 0,0300 \\
\hline
\end{tabular}

+ Significativo a $10 \%$ de probabilidade. 
Tabela 23. Continuaçāo.

\begin{tabular}{|c|c|c|c|c|c|c|c|c|c|}
\hline \multirow{2}{*}{ C.v. } & \multirow{2}{*}{ G.L } & \multicolumn{4}{|c|}{$\mathrm{Ca}^{2+}$} & \multicolumn{4}{|c|}{$\mathbf{M g}^{2+}$} \\
\hline & & 0.25 & $25-50$ & $50-75$ & $75-100$ & $0-25$ & $25-50$ & $50-75$ & $75-100$ \\
\hline Bloco & 2 & 0,1048 & 0,1722 & 0,0051 & 0,0101 & 0,0283 & 0,0179 & 0,0032 & 0,0055 \\
\hline Gesso & 3 & $1,2716^{\circ \bullet}$ & $0,3906^{* *}$ & $0,3385^{* *}$ & $0,1264^{* *}$ & $0,0911^{* *}$ & 0,0103 & $0,0383^{* \bullet}$ & $0,0316^{\circ *}$ \\
\hline Calcário & 3 & $0,3888^{\circ}$ & 0,0134 & 0,0032 & 0,0035 & $0,0804^{* *}$ & 0,0023 & 0,0007 & 0,0017 \\
\hline $\begin{array}{l}\text { Gesso x } \\
\text { calcário }\end{array}$ & 9 & 0,1195 & 0,0474 & 0,0251 & 0,1100 & 0,0178 & 0,0077 & 0,0054 & 0,0031 \\
\hline Resíduo & 30 & 0,9700 & 0,0333 & 0,0160 & 0,0080 & 0,0109 & 0,0047 & 0,0031 & 0,0029 \\
\hline \multirow[t]{2}{*}{ C.V. (\%) } & & 19,93 & 24,03 & 30,59 & 30,27 & 25,05 & 28,84 & 30,62 & 36,16 \\
\hline & & $\cdots$ & 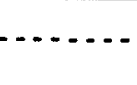 & $\cdots$ & - (meq/1 & $\left.\mathrm{cm}^{3}\right)$ & & $\cdots$ & $\cdots$ \\
\hline Média geral & & 1,5627 & 0,7594 & 0,4129 & 0,2960 & 0,4171 & 0,2388 & 0,1811 & 0,1498 \\
\hline
\end{tabular}

- Significativo a $5 \%$ de probabilidade.

* Significativo a $1 \%$ de probabilidade.

Tabela 23. Continuaçāo.

\begin{tabular}{|c|c|c|c|c|c|c|c|c|c|}
\hline \multirow{2}{*}{ C.V. } & \multirow{2}{*}{ G.L. } & \multicolumn{4}{|c|}{$\mathbf{H}^{+}+\mathbf{A l}^{3+}$} & \multicolumn{4}{|c|}{$\mathrm{Ar}^{3+}$} \\
\hline & & $0-25$ & $25 \cdot 50$ & $50-75$ & $75-100$ & $0-25$ & $25-50$ & $50-75$ & $75-100$ \\
\hline Bloco & 2 & 0,071 & 0,143 & 0,051 & 0,079 & $.0,0886$ & 0,2906 & 0,0708 & 0,0100 \\
\hline Gesso & 3 & 0,186 & 0,238 & 0,122 & 0,108 & 0,0305 & $0,0663^{+}$ & 0,0450 & 0,0316 \\
\hline Calcário & 3 & $1,886^{\circ}$ & 0,076 & 0,063 & 0,041 & $0,1690^{* *}$ & 0,0125 & 0,0118 & 0,0037 \\
\hline $\begin{array}{l}\text { Gesso x } \\
\text { calcário }\end{array}$ & 9 & 0,269 & 0,164 & 0,094 & 0,107 & 0,0108 & 0,0134 & 0,0071 & 0,0096 \\
\hline Resíduo & 30 & 0,236 & $.0,241$ & 0,147 & 0,110 & $.0,0158$ & 0,0257 & 0,0248 & 0,0192 \\
\hline C.V. (\%) & & 17,53 & 17,72 & 15,09 & 13,51 & 64,49 & 38,08 & 29,41 & 25,05 \\
\hline Média geral & & 2,771 & 2,769 & 2,542 & 2,458 & 0,1948 & 0,4210 & 0,5356 & 0,5536 \\
\hline
\end{tabular}

\footnotetext{
- Significativo a $1 \%$ de probabilidade.

+ Significativo a $10 \%$ de probabilidade.
} 
Tabela 23. Continuação.

\begin{tabular}{|c|c|c|c|c|c|c|c|c|c|}
\hline \multirow{2}{*}{ C.V. } & \multirow{2}{*}{ G.L. } & \multicolumn{4}{|c|}{$\mathbf{S}$} & \multicolumn{4}{|c|}{ CTC } \\
\hline & &.$^{0-25}$ & $25-50$ & $50-75$ & $75-100$ & $0-25$ & $25-50$ & $50-75$ & $75-100$ \\
\hline Bloco & 2 & 0,279 & 0,323 & 0,004 & 0,027 & 0,030 & 0,104 & 0,043 & 0,125 \\
\hline Gesso & 3 & $0,851^{\bullet \bullet}$ & $0,461^{\cdots \bullet}$ & $0,652^{\cdots \bullet}$ & $0,313^{\cdots \bullet}$ & $1,771^{*}$ & 0,532 & $1,449^{* \bullet}$ & $0,980^{\circ}$ \\
\hline Calcário & 3 & $0,764^{* *}$ & 0,015 & 0,001 & 0,010 & 0,635 & 0,291 & 0,188 & 0,221 \\
\hline $\begin{array}{l}\text { Gesso x } \\
\text { calcário }\end{array}$ & 9 & 0,213 & 0,095 & 0,047 & 0,022 & 0,345 & 0,398 & 0,340 & 0,289 \\
\hline Resíduo & 30 & 0,157 & 0,055 & 0,026 & 0,020 & 0,568 & 0,308 & 0,328 & 0,274 \\
\hline C.V. (\%) & . & 18,86 & 21,51 & 24,64 & 28,12 & 15,12 & 14,17 & 17,52 & 17,24 \\
\hline Média geral & & 2,098 & 1,087 & 0,659 & 0,500 & 4,984 & 3,919 & 3,271 & 3,039 \\
\hline
\end{tabular}

- Significativo a $5 \%$ de probabilidade.
- Significativo a $1 \%$ de probabilidade.

Tabela 23. Continuação.

\begin{tabular}{|c|c|c|c|c|c|c|c|c|c|}
\hline \multirow{2}{*}{ C.V. } & \multirow{2}{*}{ G.L. } & \multicolumn{4}{|c|}{$\mathbf{v}$} & \multicolumn{4}{|c|}{$\mathrm{SO}_{4}{ }^{2-}$} \\
\hline & & $0-25$ & $25 \cdot 50$ & $50-75$ & $75-100$ & $0-25$ & $25-50$ & $50-75$ & $75-100$ \\
\hline Bloco & 2 & 110,40 & 205,65 & 10,58 & 19,15 & 94,59 & 296,29 & 210,73 & 78,06 \\
\hline Gesso & 3 & $149,58^{+}$ & $272,72^{\bullet \bullet}$ & $384,92^{\bullet \bullet}$ & $235,64^{* *}$ & $6293,21^{* *}$ & $2904,67^{* \bullet}$ & $3961,92^{* *}$ & $2615,88^{* \bullet}$ \\
\hline Calcário & 3 & $472,75^{* \bullet}$ & 4,06 & 14,75 & 5,14 & 340,33 & 256,52 & 145,83 & 89,14 \\
\hline $\begin{array}{l}\text { Gesso x } \\
\text { calcário }\end{array}$ & 9 & 109,44 & 52,04 & 27,66 & 21,36 & 211,33 & 146,52 & 102,83 & 56,63 \\
\hline Resíduo & 30 & 55,77 & 40,76 & 27,09 & 24,50 & 374,67 & 93,34 & 95,54 & 48,98 \\
\hline \multirow[t]{2}{*}{ c.V. (\%) } & & 17,80 & 23,50 & 26,75 & 31,35 & 76,32 & 37,21 & 32,52 & 25,91 \\
\hline & & 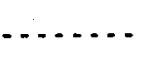 & $\cdots$ & $\ldots$. & $\ldots$ & $\ldots \ldots$ & $\ldots . .$. & $(p m) \cdots$ & $\ldots$ \\
\hline Média geral & & 41,96 & 21,17 & 19,46 & 15,79 & 25,36 & 25,97 & 30,05 & 27,01 \\
\hline
\end{tabular}

" Significativo a $1 \%$ de probabilidade.

+ Significativo a $10 \%$ de probabilidade. 
Tabela 24. Quadrados médios da análise de regressão polinomial dos resultados da análise de solo, 4 meses após a aplicaçāo dos insumos.

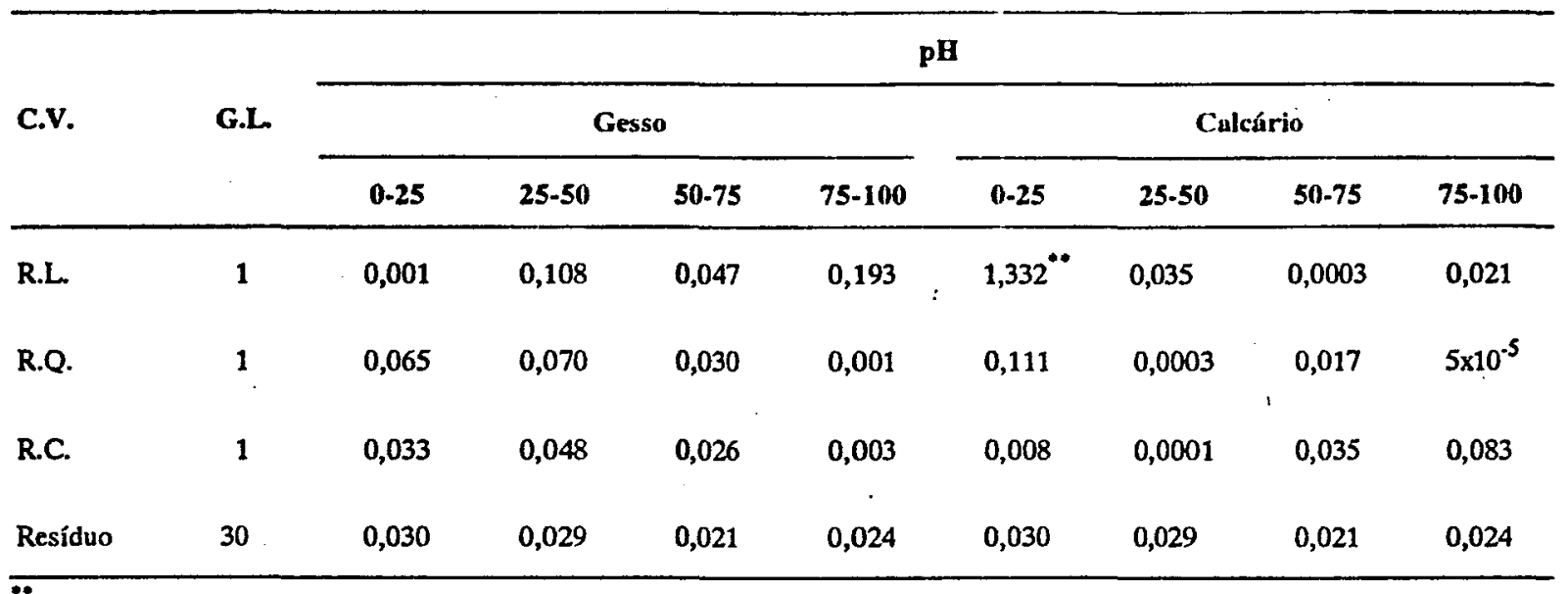

Significativo a $1 \%$ de probabilidade.

Tabela 24. Continuaçāo.

\begin{tabular}{|c|c|c|c|c|c|c|c|c|c|}
\hline \multirow{3}{*}{ C.v. } & \multirow{3}{*}{ G.L. } & \multicolumn{8}{|c|}{ M.O. } \\
\hline & & \multicolumn{4}{|c|}{ Gesso } & \multicolumn{4}{|c|}{ Calcário } \\
\hline & & $0-25$ & $25-50$ & $50-75$ & $75-100$ & $0-25$ & $25-50$ & $50-75$ & $75-100$ \\
\hline R.L & 1 & $7 \times 10^{-6}$ & 0,0001 & 0,0053 & 0,0001 & $\mathbf{0 , 1 0 2 1}$ & 0,0323 & 0,0009 & 0,0068 \\
\hline R.Q. & 1 & 0,0847 & 0,0001 & $1 \times 10^{-6}$ & 0,0481 & 0,1189 & 0,0378 & 0,0060 & 0,0006 \\
\hline R.C. & 1 & 0,0241 & 0,0529 & 0,0005 & 0,0008 & 0,0242 & 0,0220 & 0,0001 & 0,0192 \\
\hline Resíduo & 30 & 0,0634 & 0,0364 & 0,0154 & 0,0306 & 0,0634 & 0,0364 & 0,0154 & 0,0306 \\
\hline
\end{tabular}

Tabela 24. Continuação.

\begin{tabular}{|c|c|c|c|c|c|c|c|c|c|}
\hline \multirow{3}{*}{ c.V. } & \multirow{3}{*}{ G.L. } & \multicolumn{8}{|c|}{$\mathbf{P}$} \\
\hline & & \multicolumn{4}{|c|}{ Gesso } & \multicolumn{4}{|c|}{ Calcário } \\
\hline & & $0-25$ & $25-50$ & $50-75$ & $75-100$ & $0-25$ & $25-50$ & $50-75$ & $75-100$ \\
\hline R.L & 1 & 0,74 & 11,67 & 0,26 & 4,20 & 7,87 & 17,62 & 0,17 & 2,44 \\
\hline R.Q. & 1 & 5,97 & 56,12 & 8,58 & 12,83 & 1,47 & 12,16 & 0,34 & 2,73 \\
\hline R.C. & 1 & 1,53 & 21,91 & 4,38 & 1,47 & 1,89 & 34,04 & 0,22 & 0,33 \\
\hline Residuo & 30 & 12,92 & 31,62 & 2,08 & $.6,72$ & 12,92 & 31,62 & 2,08 & 6,72 \\
\hline
\end{tabular}


Tabela 24. Continuação.

\begin{tabular}{|c|c|c|c|c|c|c|c|c|c|}
\hline \multirow{3}{*}{ C.V. } & \multirow{3}{*}{ G.L. } & \multicolumn{8}{|c|}{$\mathbf{K}^{+}$} \\
\hline & & \multicolumn{4}{|c|}{ Gesso } & \multicolumn{4}{|c|}{ Calcário } \\
\hline & & $0-25$ & $25-50$ & $50-75$ & $75-100$ & $0-25$ & $25-50$ & $50-75$ & $75-100$ \\
\hline R.L. & 1 & $0,0025^{* \bullet}$ & 0,0001 & 0,0004 & 0,0001 & 0,0001 & 0,0002 & 0,0002 & 0,0001 \\
\hline R.Q. & 1 & 0,0001 & 0,0001 & 0,0006 & 0,0001 & 0,0001 & 0,0003 & 0,0003 & 0,0001 \\
\hline R.C. & 1 & 0,0002 & 0,0003 & 0,0001 & $1 \times 10^{-5}$ & 0,0004 & 0,0001 & 0,0001 & 0,0001 \\
\hline Resíduo & 30 & 0,0004 & 0,0003 & 0,0001 & 0,0001 & 0,0004 & 0,0003 & 0,0001 & 0,0001 \\
\hline
\end{tabular}

- Significativo a $1 \%$ de probabilidade.

Tabela 24. Continuação.

\begin{tabular}{|c|c|c|c|c|c|c|c|c|c|}
\hline \multirow{3}{*}{ C.V. } & \multirow{3}{*}{ G.L. } & \multicolumn{8}{|c|}{$\mathrm{Ca}^{2+}$} \\
\hline & & \multicolumn{4}{|c|}{ Gesso } & \multicolumn{4}{|c|}{ Calcário } \\
\hline & & $0-25$ & $25-50$ & $50-75$ & $75-100$ & 0.25 & $25-50$ & $50-75$ & $75-100$ \\
\hline R.L & 1 & $3,6820^{\circ \bullet}$ & $1,0848^{* \bullet}$ & $1,0133^{* \bullet}$ & $0,3652^{* *}$ & $1,0001^{* *}$ & 0,0016 & 0,0050 & 0,0094 \\
\hline R.Q. & 1 & 0,0547 & 0,0867 & 0,0006 & 0,0014 & 0,1420 & 0,0190 & 0,0006 & 0,0004 \\
\hline R.C. & 1 & 0,0780 & 0,0002 & 0,0014 & 0,0126 & 0,0243 & 0,0197 & 0,0042 & $1 \times 10^{5}$ \\
\hline Resíduo & 30 & 0,0970 & 0,0333 & 0,0160 & 0,080 & 0,0970 & 0,0333 & 0,0160 & 0,080 \\
\hline
\end{tabular}

- Significativo a $1 \%$ de probabilidade.

Tabela 24. Continuaçăo.

\begin{tabular}{|c|c|c|c|c|c|c|c|c|c|}
\hline \multirow{3}{*}{ C.V. } & \multirow{3}{*}{ G.L. } & \multicolumn{8}{|c|}{$\mathbf{M g}^{2+}$} \\
\hline & & \multicolumn{4}{|c|}{ Gesso } & \multicolumn{4}{|c|}{ Calcário } \\
\hline & & $0-25$ & 25.50 & $50-75$ & $75-100$ & $0-25$ & $25-50$ & $50-75$ & $75-100$ \\
\hline R.L & 1 & $0,1858^{\circ *}$ & 0,0007 & $0,0957^{* *}$ & $0,0900^{* *}$ & $0,2343^{* \bullet}$ & 0,0042 & 0,0004 & 0,0026 \\
\hline R.Q. & 1 & 0,0170 & 0,0214 & 0,0149 & 0,0048 & 0,0018 & 0,0003 & $1 \times 10^{-7}$ & 0,0010 \\
\hline R.C. & 1 & 0,0705 & 0,0088 & 0,0043 & 0,0001 & 0,0050 & 0,0023 & 0,0017 & 0,0014 \\
\hline Resíduo & 30 & 0,0109 & 0,0047 & 0,0031 & 0,0029 & 0,0109 & 0,0047 & 0,0031 & 0,0029 \\
\hline
\end{tabular}

Significativo a $1 \%$ de probabilidade. 
Tabela 24. Continuaçāo.

\begin{tabular}{|c|c|c|c|c|c|c|c|c|c|}
\hline \multirow{3}{*}{ C.V. } & \multirow{3}{*}{ G.L. } & \multicolumn{8}{|c|}{$\mathrm{H}^{+}+\mathrm{Al}^{3+}$} \\
\hline & & \multicolumn{4}{|c|}{ Gesso } & \multicolumn{4}{|c|}{ Calcário } \\
\hline & & $0-25$ & $25-50$ & $50-75$ & $75-100$ & $0-25$ & $25-50$ & $50-75$ & $75-100$ \\
\hline R.L. & 1 & 0,013 & 0,102 & 0,046 & 0,008 & $5,417^{* *}$ & 0,025 & 0,130 & 0,080 \\
\hline R.Q. & 1 & 0,230 & 0,377 & 0,122 & 0,069 & 0,036 & 0,197 & 0,018 & 0,003 \\
\hline R.C. & 1 & 0,315 & 0,235 & 0,199 & 0,248 & 0,204 & 0,005 & 0,040 & 0,038 \\
\hline Resíduo & 30 & 0,236 & 0,241 & 0,147 & 0,110 & 0,236 & 0,241 & 0,147 & 0,110 \\
\hline
\end{tabular}

Significativo a $1 \%$ de probabilidade.

Tabela 24. Continuação.

\begin{tabular}{|c|c|c|c|c|c|c|c|c|c|}
\hline \multirow{3}{*}{ c.v. } & \multirow{3}{*}{ G.L. } & \multicolumn{8}{|c|}{$\mathrm{Al}^{3+}$} \\
\hline & & - & \multicolumn{2}{|c|}{ Gesso } & \multirow[b]{2}{*}{$75-100$} & \multicolumn{4}{|c|}{ Calcário } \\
\hline & & $0-25$ & $25-50$ & $50-75$ & & $0-25$ & 25-50 & $50-75$ & $75-100$ \\
\hline R.L & 1 & $0,0744^{*}$ & $0,1275^{*}$ & $0,1245^{*}$ & $0,0895^{\circ}$ & $0,4839^{* \prime}$ & 0,0033 & 0,0060 & 0,0022 \\
\hline R.Q. & 1 & 0,0021 & 0,0547 & 0,0099 & 0,0032 & 0,0230 & 0,0244 & 0,0278 & 0,0088 \\
\hline R.C. & 1 & 0,0149 & 0,0168 & 0,0006 & 0,0020 & 0,0003 & 0,0097 & 0,0015 & 0,0002 \\
\hline Resíduo & 30 & 0,0158 & 0,0257 & 0,0248 & 0,0192 & 0,0158 & 0,0257 & 0,0248 & 0,0192 \\
\hline
\end{tabular}

* Significativo a $5 \%$ de probabilidade.

** Significativo a $1 \%$ de probabilidade:

Tabela 24. Continuaçāo.

\begin{tabular}{|c|c|c|c|c|c|c|c|c|c|}
\hline \multirow{3}{*}{ C.V. } & \multirow{3}{*}{ G.L. } & \multicolumn{8}{|c|}{$\mathbf{S}$} \\
\hline & & \multicolumn{4}{|c|}{ Gesso } & \multicolumn{4}{|c|}{ Calcário } \\
\hline & & 0.25 & $25-50$ & 50.75 & $75-100$ & $0-25$ & $25-50$ & $50-75$ & 75.100 \\
\hline R.L. & 1 & $2,187^{* \bullet}$ & $1,178^{\circ \bullet}$ & $1,895^{* \bullet}$ & $0,910^{* *}$ & $2,090^{\circ \prime \prime}$ & 0,010 & 0,003 & 0,030 \\
\hline R.Q. & 1 & 0,090 & 0,188 & 0,047 & 0,023 & 0,188 & 0,009 & 0,001 & 0,001 \\
\hline R.C. & 1 & 0,277 & 0,018 & 0,014 & 0,005 & 0,015 & 0,026 & $5 \times 10^{-5}$ & 0,001 \\
\hline Resíduo & 30 & 0,157 & 0,055 & 0,026 & 0,020 & 0,157 & 0,055 & 0,026 & 0,020 \\
\hline
\end{tabular}

Significativo a $1 \%$ de probabilidade. 
Tabela 24. Continuaçāo.

\begin{tabular}{|c|c|c|c|c|c|c|c|c|c|}
\hline \multirow{3}{*}{ c.V. } & \multirow{3}{*}{ G.L. } & \multicolumn{3}{|c|}{. } & \multicolumn{2}{|c|}{ CTC } & & & \\
\hline & & * & & & & \multicolumn{4}{|c|}{ Calcário } \\
\hline & & $0-25$ & $25-50$ & $50-75$ & $75-100$ & $0-2.5$ & $25-50$ & $50-75$ & $75-100$ \\
\hline R.L. & 1 & $4,836^{* \bullet}$ & 0,940 & $3,745^{* *}$ & $1,929^{\circ *}$ & $0,2.34$ & 0,022 & 0,008 & 0,046 \\
\hline R.Q. & 1 & 0,144 & 0,025 & 0,043 & $\mathbf{0 , 0 8 2}$ & 0,117 & 0,412 & 0,099 & 0,041 \\
\hline R.C. & 1 & 0,332 & 0,631 & 0,558 & 0,928 & 1,584 & 0,437 & 0,457 & 0,577 \\
\hline Resíduo & 30 & 0,568 & 0,308 & 0,328 & 0,274 & 0,568 & 0,308 & 0,328 & 0,274 \\
\hline
\end{tabular}

Tabela 24. Continuação.

\begin{tabular}{|c|c|c|c|c|c|c|c|c|c|}
\hline \multirow{3}{*}{ C.V. } & \multirow{3}{*}{ G.L. } & \multicolumn{8}{|c|}{$\mathbf{V}$} \\
\hline & & . & \multicolumn{2}{|c|}{ Gesso } & \multirow[b]{2}{*}{$75-100$} & \multicolumn{4}{|c|}{ Calcário } \\
\hline & & 0.25 & 25.50 & $50-75$ & & 0.25 & $25-50$ & $50-75$ & $75-100$ \\
\hline R.L. & 1 & $164,69^{+}$ & $530,44^{\circ \prime}$ & $1015,26^{\circ \bullet}$ & $621,72^{* \bullet}$ & $1314,40^{* *}$ & 11,67 & 9,45 & 8,29 \\
\hline R.Q. & 1 & 116,00 & 195,46 & 87,88 & 77,32 & 46,14 & 0,03 & 2,65 & 0,01 \\
\hline R.C. & 1 & 168,06 & 92,27 & 51,61 & 7,88 & 57.71 & 0,47 & 32,15 & 7,13 \\
\hline Resíduo & 30 & 55,77 & 40,76 & 27,09 & 24,50 & 55,77 & 40,76 & 27,09 & 24,50 \\
\hline
\end{tabular}

- Significativo a $1 \%$ de probabilidade.

+ Significativo a $10 \%$ de probabilidade.

Tabela 24. Continuaçāo.

\begin{tabular}{|c|c|c|c|c|c|c|c|c|c|}
\hline \multirow{3}{*}{ C.V. } & \multirow{3}{*}{ G.L. } & \multicolumn{8}{|c|}{$\mathrm{SO}_{4}^{2-}$} \\
\hline & & \multicolumn{4}{|c|}{ Gesso } & \multicolumn{4}{|c|}{ Calcário } \\
\hline & & $0-25$ & $25-50$ & $50-75$ & $75-100$ & $0-25$ & $25-50$ & $50-75$ & $75 \cdot 100$ \\
\hline R.L. & 1 & $17567,34^{* \bullet}$ & $8636,91^{\circ *}$ & $11837,05^{* \bullet}$ & $7698,86^{* *}$ & 1,43 & 234,15 & 0,96 & 106,81 \\
\hline R.Q. & 1 & 1280,00 & 75,81 & 48,70 & 119,84 & 1014,45 & 535,40 & 431,33 & 118,37 \\
\hline R.C. & 1 & 32,27 & 1,29 & 0,01 & 28,93 & 5,09 & 0,01 & 5,19 & 42,23 \\
\hline Resíduo & 30 & 374,34 & 93,34 & 95,54 & 48,98 & 374,67 & 93,34 & 95,54 & 48,98 \\
\hline
\end{tabular}

" Significativo a $1 \%$ de probabilidade. 
Tabela 25. Médias dos resultados da análise de solo, 4 meses após a aplicação dos insumos.

\begin{tabular}{|c|c|c|c|c|c|c|c|c|c|c|c|c|}
\hline & \multicolumn{4}{|c|}{$\mathbf{p H}$} & \multicolumn{4}{|c|}{ M.o. } & \multicolumn{4}{|c|}{$\mathbf{P}$} \\
\hline & $0-25$ & $25-50$ & $50-75$ & $75-100$ & 0.25 & $25-50$ & $50-75$ & $75-100$ & $0-25$ & $25-50$ & $50-75$ & $75-100$ \\
\hline & & & & & ..... & $\cdots$ & \%) -. & 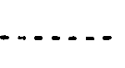 & $\ldots$. & $\cdot(\mu \mathrm{g} / \mathrm{cn}$ & $\left.\mathrm{m}^{3}\right)$ & $\ldots$ \\
\hline \multicolumn{13}{|l|}{ Gesso } \\
\hline$G_{1}$ & 4,683 & 4,267 & 4,133 & 4,125 & 1,9269 & 1,2399 & 0,9171 & 0,7921 & 10,67 & 7,17 & 4,75 & 4,50 \\
\hline$G_{2}$ & 4,692 & 4,300 & 4,150 & 4,158 & 2,0487 & 1,3116 & 0,9170 & 0,8578 & 11,59 & 7,34 & 3,42 & 3,42 \\
\hline $\mathbf{G}_{\mathbf{3}}$. & 4,783 & 4,442 & 4,250 & 4,225 & 2,0161 & 1,2243 & 0,9329 & $(1,8679$ & 11,26 & 9,51 & 4,00 & 3,75 \\
\hline $\mathbf{G}_{4}$ & 4,667 & 4,383 & 4,208 & 4,292 & 1,9586 & 1,2689 & 0,9430 & 0,8088 & 10,59 & 5,67 & 4,59 & 5,00 \\
\hline \multicolumn{13}{|c|}{ Calcário } \\
\hline$c_{1}$ & 4,417 & 4,308 & 4,192 & 4,175 & 2,0936 & 1,3273 & 0,9429 & 0,8488 & 10,59 & 6,26 & 4,34 & 4,34 \\
\hline $\mathrm{C}_{2}$ & 4,725 & 4,342 & 4,192 & 4,150 & 1,9569 & 1,2049 & 0,9146 & 0,8521 & 10,51 & 7,01 & 4,17 & 4,42 \\
\hline$c_{3}$ & 4,842 & 4,358 & 4,133 & 4,275 & 1,8978 & 1,2626 & 0,9171 & 0,7929 & 11,42 & 9,34 & 4,00 & 4,34 \\
\hline $\mathrm{C}_{4}$ & 4,842 & 4,383 & 4,225 & 4,200 & 2,0020 & 1,2499 & 0,9354 & 0,8329 & 11,59 & 7,09 & 4,25 & 3,59 \\
\hline
\end{tabular}

Tabela 25. Continuaçāo.

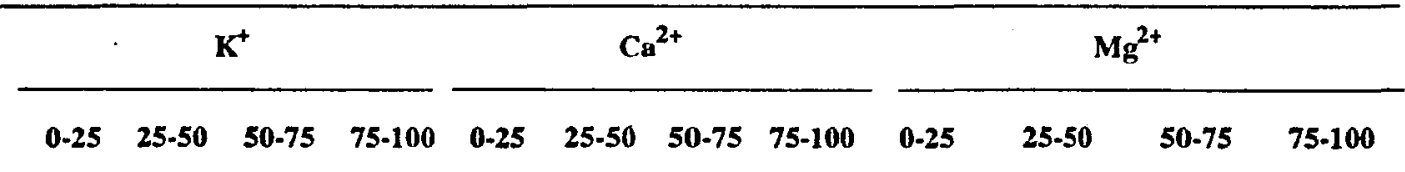

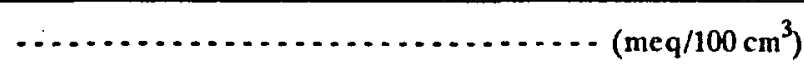

\section{Gesso}

$\begin{array}{lllllllllllll}\mathrm{G}_{1} & 0,0757 & 0,0542 & 0,0300 & 0,0275 & 1,2200 & 0,5325 & 0,2400 & 0,1775 & 0,4914 & 0,2182 & 0,1138 & 0,0878 \\ G_{2} & 0,0683 & 0,0502 & 0,0367 & 0,0292 & 1,3825 & 0,7133 & 0,3333 & 0,2800 & 0,4023 & 0,2297 & 0,1554 & 0,1321 \\ G_{3} & 0,0703 & 0,0576 & 0,0433 & 0,0325 & 1,6992 & 0,8375 & 0,4483 & 0,2992 & 0,4748 & 0,2822 & 0,2221 & 0,1712 \\ G_{4} & 0,0548 & 0,0503 & 0,0384 & 0,0308 & 1,9492 & 0,9542 & 0,6300 & 0,4275 & 0,3000 & 0,2249 & 0,2330 & 0,2072\end{array}$

\section{Calcário}

\begin{tabular}{|c|c|c|c|c|c|c|c|c|c|c|c|}
\hline$c_{1}$ & $0,0707 \quad 0,0518$ & 0,0383 & 0,0292 & 1,2950 & 0,7483 & 0,3983 & 0,3150 & 0,3078 & 0,2239 & 0,1863 & 0,1655 \\
\hline $\mathrm{C}_{2}$ & $0,0687 \quad 0,0511$ & 0,0417 & 0,0350 & 1,6342 & 0,8092 & 0,4175 & 0,3025 & 0,4016 & 0,2323 & 0,1747 & 0,1388 \\
\hline$C_{3}$ & $0,06120,0508$ & 0,0358 & $.0,0292$ & 1,6367 & 0,7383 & 0,4017 & 0,2900 & 0,4721 & 0,2557 & 0,1888 & 0,1512 \\
\hline C & $0,06870,0585$ & 0,0326 & 0,0267 & 1,6850 & 0,7417 & 0,4342 & 0,2767 & 0,4870 & 0,2431 & 0,1745 & 0,1428 \\
\hline
\end{tabular}


Tabela 25. Continuação.

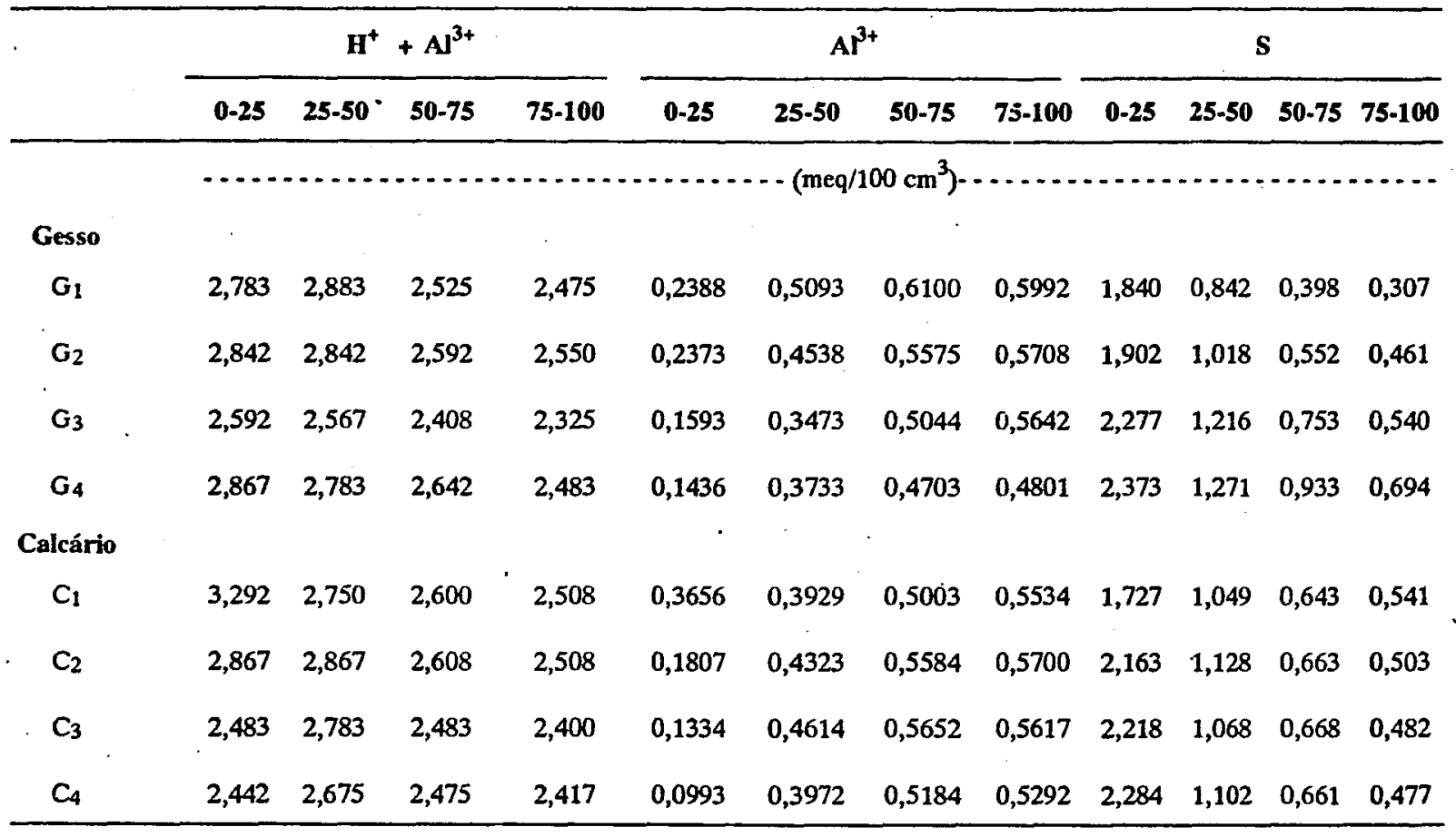

Tabela 25. Continuação.

\begin{tabular}{|c|c|c|c|c|c|c|c|c|c|c|}
\hline \multicolumn{4}{|c|}{ CTC } & \multicolumn{4}{|c|}{$\mathbf{V}$} & \multicolumn{3}{|c|}{$\mathrm{SO}_{4}{ }^{2-}$} \\
\hline $0-25$ & $25-50$ & $50-75$ & $75-100$ & $0-25$ & 25.50 & $50-75$ & $75-100$ & 0.25 & $25-50$ & $50.75 \quad 75-100$ \\
\hline
\end{tabular}

$\ldots .-\left(\mathrm{meq} / 100 \mathrm{~cm}^{3}\right)$

Gesso

\begin{tabular}{|c|c|c|c|c|c|c|c|c|c|c|c|c|}
\hline$G_{1}$ & 4,622 & 3,713 & 2,913 & 2,769 & 39,08 & 21,75 & 13,08 & 10,33 & 8,08 & 8,58 & 10,33 & 14,25 \\
\hline $\mathrm{G}_{2}$ & 4,914 & 4,008 & 3,275 & 3,123 & 39,17 & 24,67 & 16,42 & 14,17 & 13,58 & 20,23 & 22,75 & 18,38 \\
\hline $\mathrm{G}_{3}$ & 4,871 & 3,782 & 3,157 & 2,860 & 46,42 & 31,92 & 23,17 & 18,50 & 21,00 & 29,67 & 34,00 & 28,00 \\
\hline $\mathrm{G}_{4}$ & 5,527 & 4,172 & 3,741 & 3,404 & 43,17 & 30,33 & 25,17 & 20,17 & 58,78 & 45,39 & 53,13 & 47,40 \\
\hline
\end{tabular}

Calcário

\begin{tabular}{lllllllllllll}
$\mathrm{C}_{1}$ & 5,008 & 3,793 & 3,235 & 3,042 & 33,42 & 26,42 & 18,75 & 16,50 & 21,33 & 19,92 & 27,92 & 27,83 \\
$\mathrm{C}_{2}$ & 5,266 & 4,144 & 3,444 & 3,207 & 41,08 & 27,17 & 18,75 & 15,42 & 31,63 & 29,89 & 33,57 & 30,36 \\
$\mathrm{C}_{3}$ & 4,705 & 3,844 & 3,145 & 2,875 & 46,92 & 27,25 & 21,08 & 16,17 & 27,92 & 29,25 & 32,42 & 25,83 \\
$C_{4}$ & 4,955 & 3,895 & 3,261 & 3,032 & 46,42 & 27,83 & 19,25 & 15,08 & 20,57 & 24,01 & 26,32 & 24,01 \\
\hline
\end{tabular}


Os tratamentos com calcário produziram aumentos lineares e significativos do pH e dos teores de cálcio e de magnésio na profundidade de $0-25 \mathrm{~cm}$ (Figura 5), o que provocou, conseqüentemente, aumentos lineares de $\mathrm{S}$ e de $\mathrm{V}$ (Figura 6). Os resultados de $\mathrm{H}+\mathrm{Al}$ e de $\mathrm{Al}$ diminuiram de forma linear nesta mesma camada (Figura 6). Esses resultados já eram esperados e concordam com os encontrados por diversos autores em trabalhos com calcário (RAIJ, 1987; MORELLI et al., 1987; FERREIRA et al., 1987; ANDA, 1988; LOPES \& GUILHERME, 1990; RAIJ, 1992).

Os teores de potássio e de magnésio decresceram linear e significativamente na camada superficial do solo com o aumento da dose de gesso (Figura 7). Este efeito, também observado por REEVE \& SUMNER, (1972), RITCHEY et al. (1980), QUAGGIO et al. (1982), PAVAN et al. (1984), e não desejado, torna-se ainda maior em solos como o deste trabalho, onde os teores iniciais já eram muito baixos tanto de potássio quanto de magnésio. O magnésio lixiviado da camada superficial encontrava-se, já nesta ocasião, nas camadas mais profundas $(50-75$ e $75-100 \mathrm{~cm})$, conforme se observa nas Figura 7.

O teor de cálcio no solo praticamente dobrou em todas as profundidades entre os tratamentos sem gesso e o de 4 t/ha. Em conseqüência, aumentaram também $S$, CTC e V (Figura 8). Apesar do pequeno tempo decorrido entre a aplicação do gesso e esta primeira amostragem, a lixiviação de cálcio observada ao longo do perfil é semelhante à encontrada em vários trabalhos, como os citados por RAIJ (1988).

O cálcio foi acompanhado pelo íon sulfato em sua movimentação até $1 \mathrm{~m}$ de profundidade, cujos teores cresceram linearmente com as doses de gesso e ficaram 5 vezes maiores na dose máxima em relação ao teor da testemunha (Figura 9). Estes teores são considerados de médios a altos, segundo SIQUEIRA et al. (1987).

Com o aumento das doses de gesso diminuiram linearmente os teores de alumínio nas quatro profundidades (Figura 10). Esta redução nos teores de alumínio é conhecida desde os trabalhos de REEVE \& SUMNER (1972) e RITCHEY et alii (1980). 


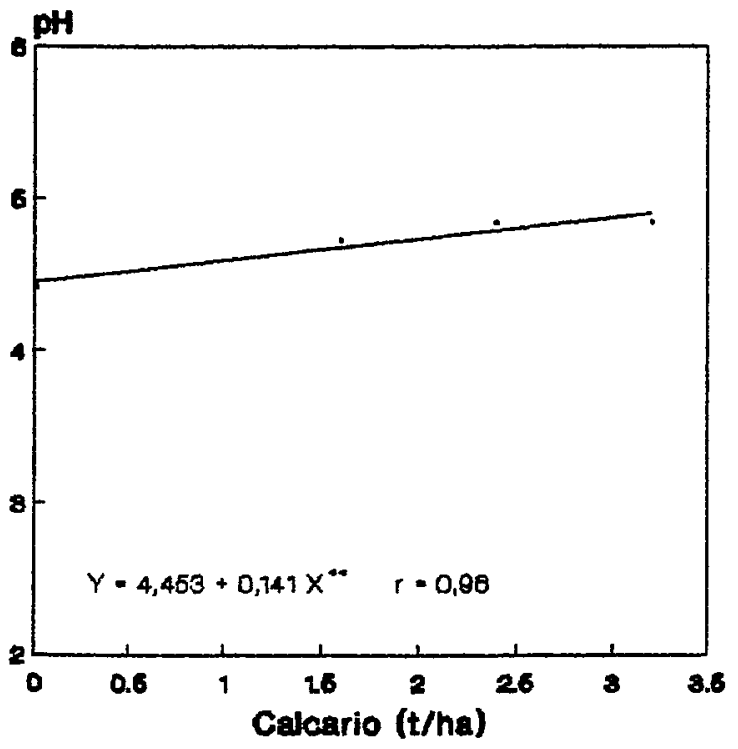

- $0-26$

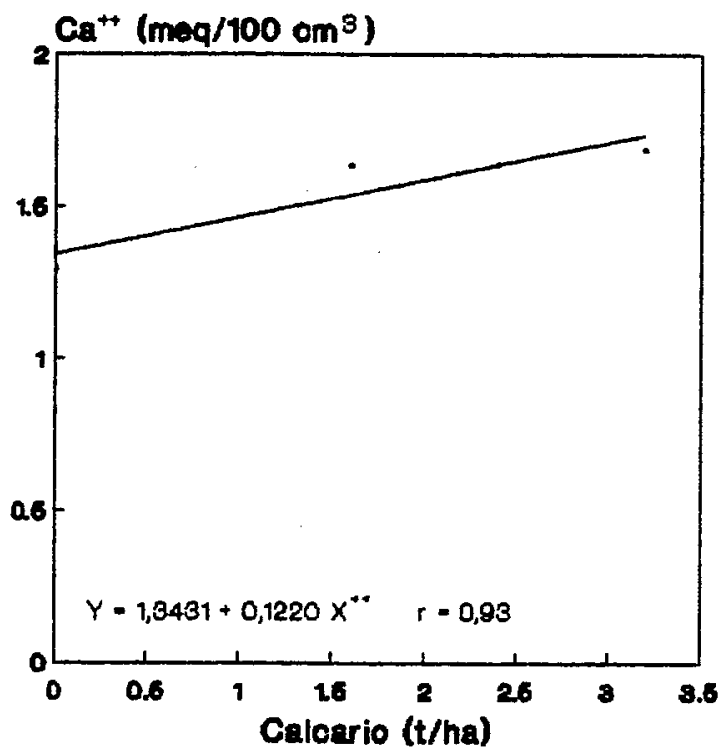

- $0-26$

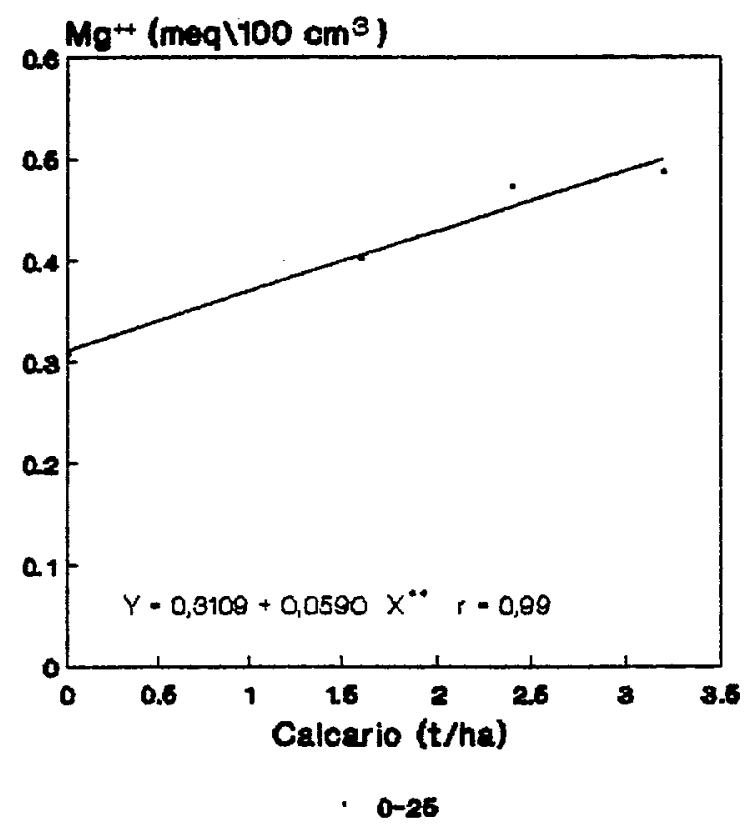

Figura 5. Efeitos das doses de calcário sobre $\mathrm{pH}, \mathrm{Ca}^{2+}, \mathrm{Mg}^{2+}$, na camada 0-25 cm, 4 meses após a aplicação dos insumos. 


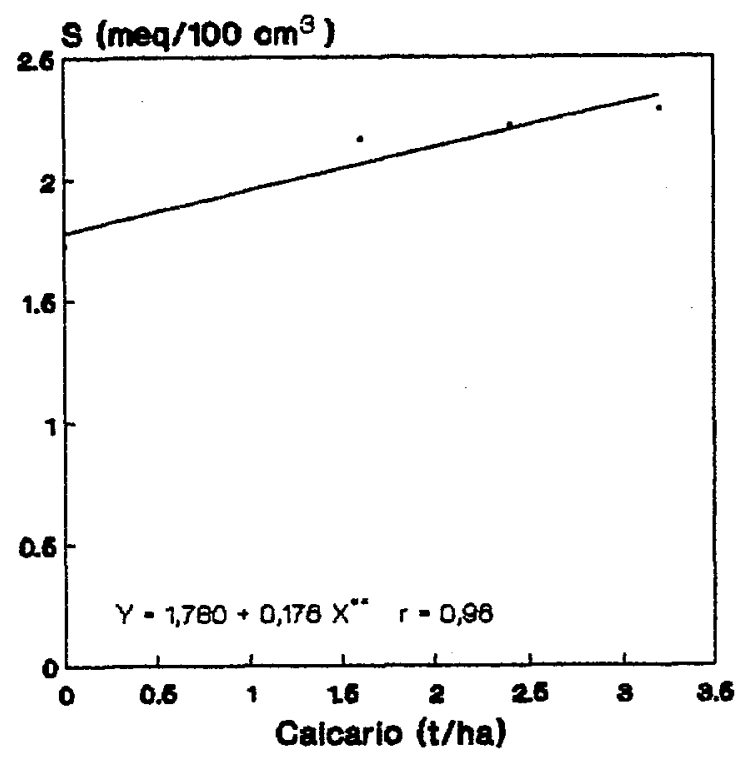

- 0-26

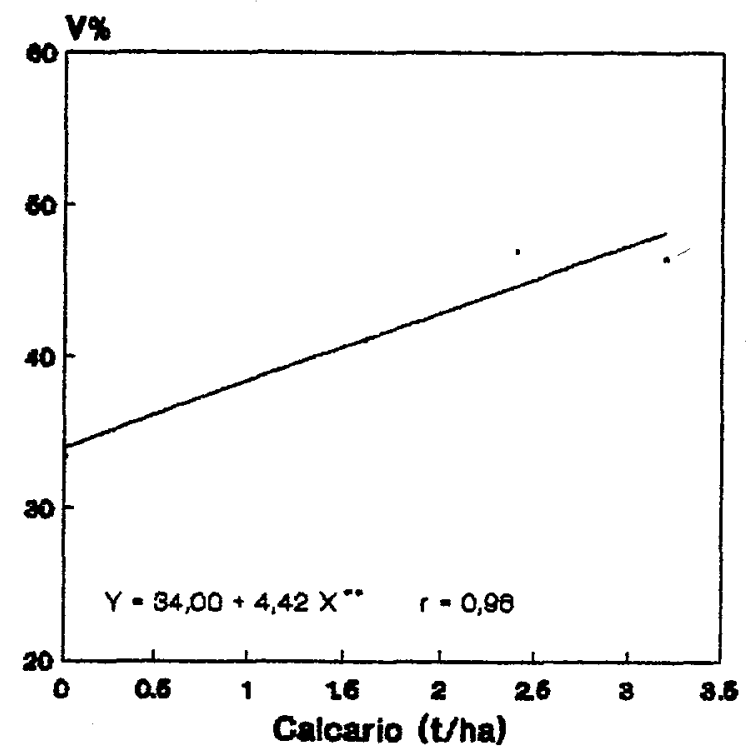

- $0-26$

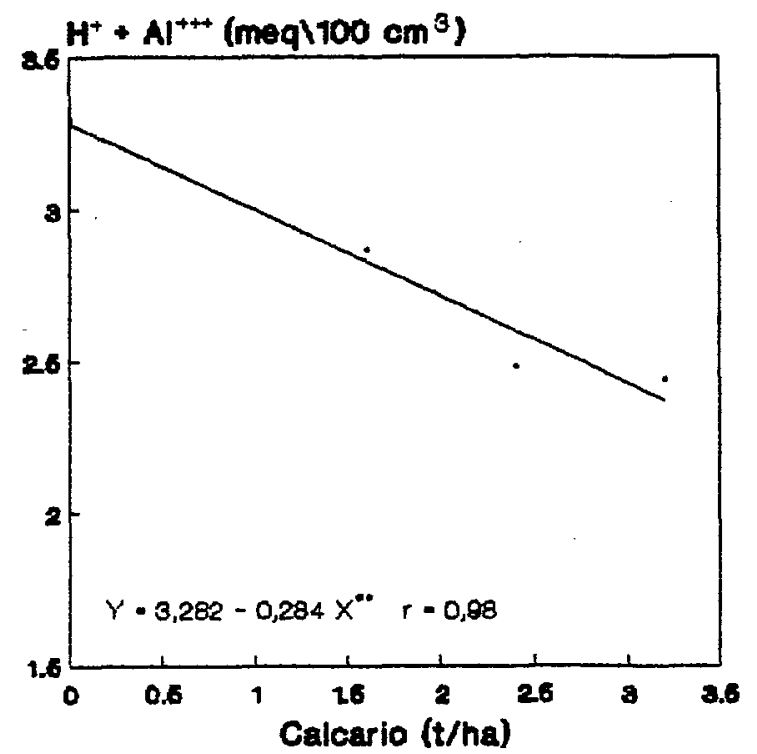

- $0-26$

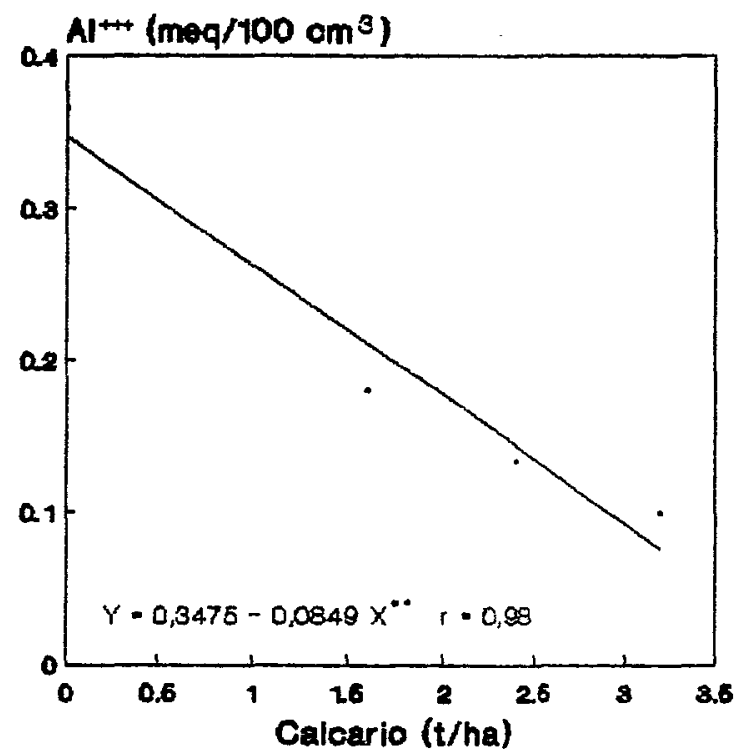

- $0-26$

Figura 6. Efeito das doses de calcário sobre $\mathrm{S}, \mathrm{V}, \mathrm{H}^{+}+\mathrm{Al}^{3+}$ e $\mathrm{Al}^{3+}$ na camada $0-25 \mathrm{~cm}, 4$ meses após a aplicação de insumos. 

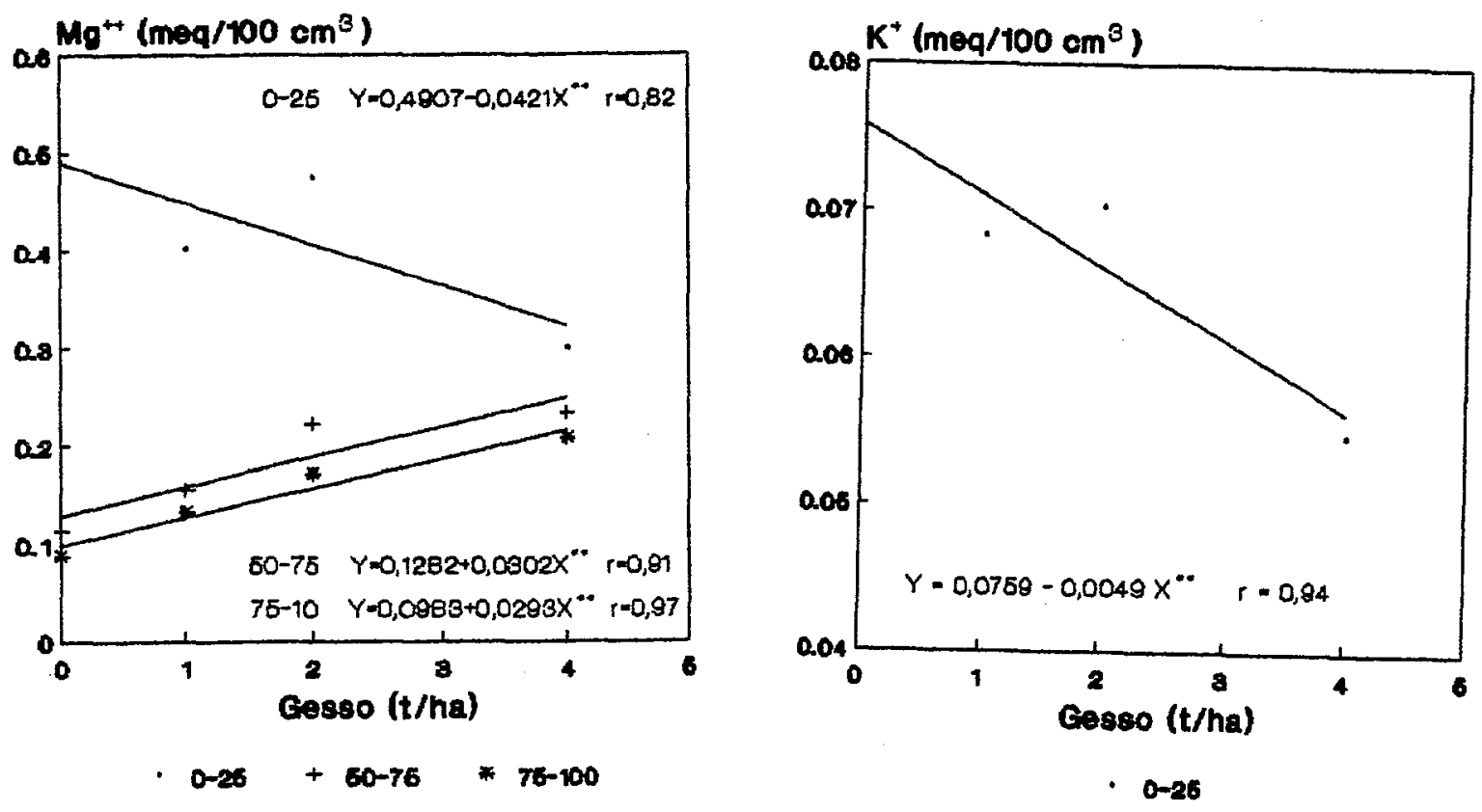

Figura 7. Efeito das doses de gesso sobre $\mathrm{K}^{+}$e $\mathrm{Mg}^{2+}, 4$ meses após a aplicação dos insumos..

\subsubsection{Dezoito meses após a aplicação de insumos}

Os resultados da análise de solo 18 meses após a aplicação do gesso e do calcário foram analisados e encontram-se nas Tabelas 26,27 e 28. Os teores de matéria orgânica não se alteraram com o uso desses insumos, tanto nesta época quanto aos 4 meses, como foi observado.

Os efeitos do aumento das doses de calcário observados aos 4 meses da aplicação persistiram até esta época e continuaram a se restringir à primeira camada (0-25 cm). BENEDINI (1988) e MARTINS (1991) observaram o efeito do uso de calcário nas camadas subsuperficiais do solo após 18 meses $(25-50 \mathrm{~cm})$ e 30 e 50 meses (30-60 cm), respectivamente, após a aplicação dos insumos. Esses autores, no entanto, usaram doses de até o triplo da dose recomendada. Os teores de cálcio e de magnésio e o pH aumentaram linearmente, como também S e V (Figuras 11 e 12), enquanto $\mathrm{H}$ $+\mathrm{Al}, \mathrm{Al}$ e m decresceram da mesma maneira (Figura 12). Resultados semelhantes foram obtidos por PENATTI et al. (1987) estudando cana-planta. Os coeficientes de correlação e os resultados médios obtidos encontram-se na Figura 13. 

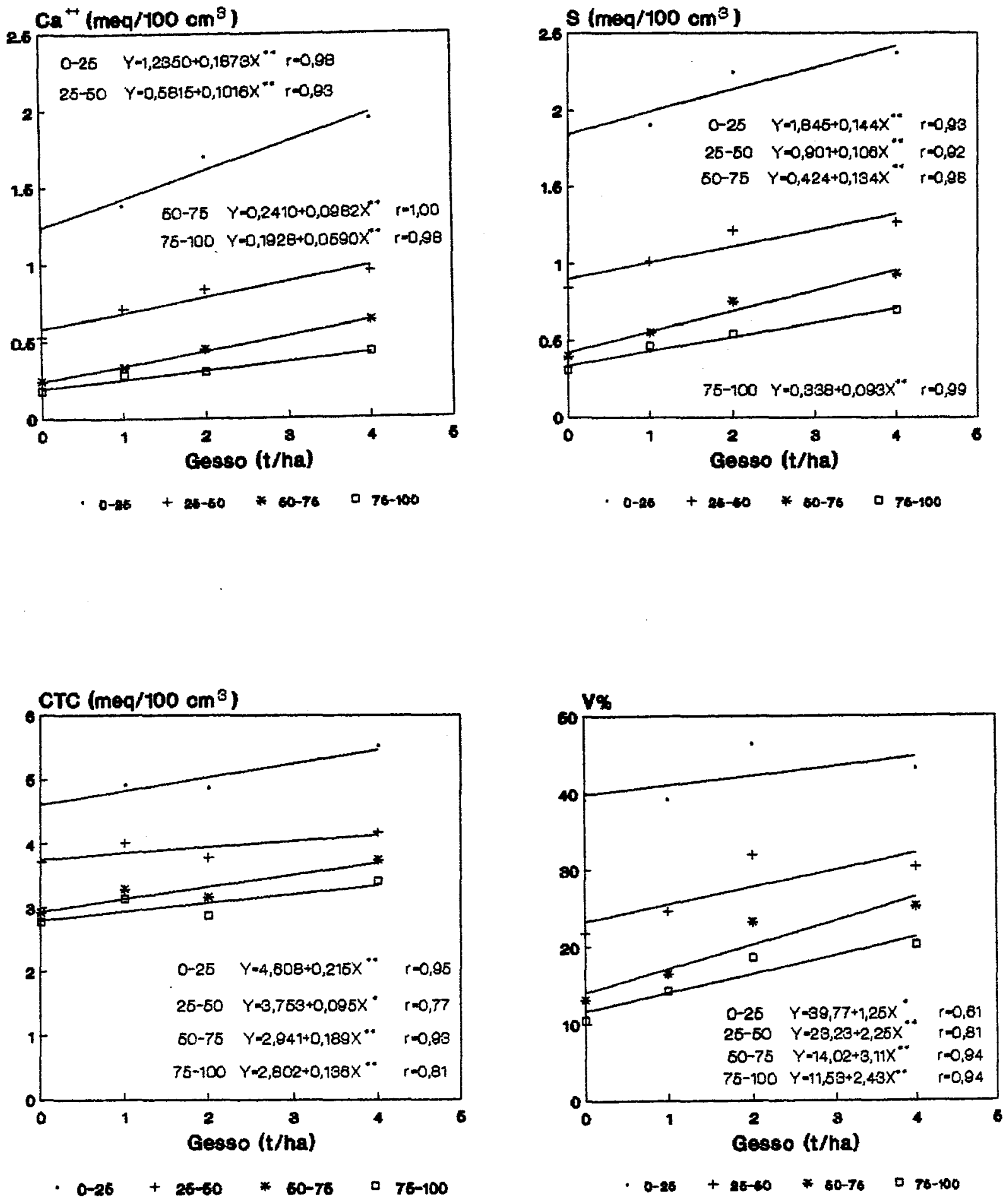

Figura 8. Efeito das doses de gesso sobre $\mathrm{Ca}^{2+}$, S, CTC e V nas 4 profundidades, 4 meses após a aplicaçáo dos insumos. 


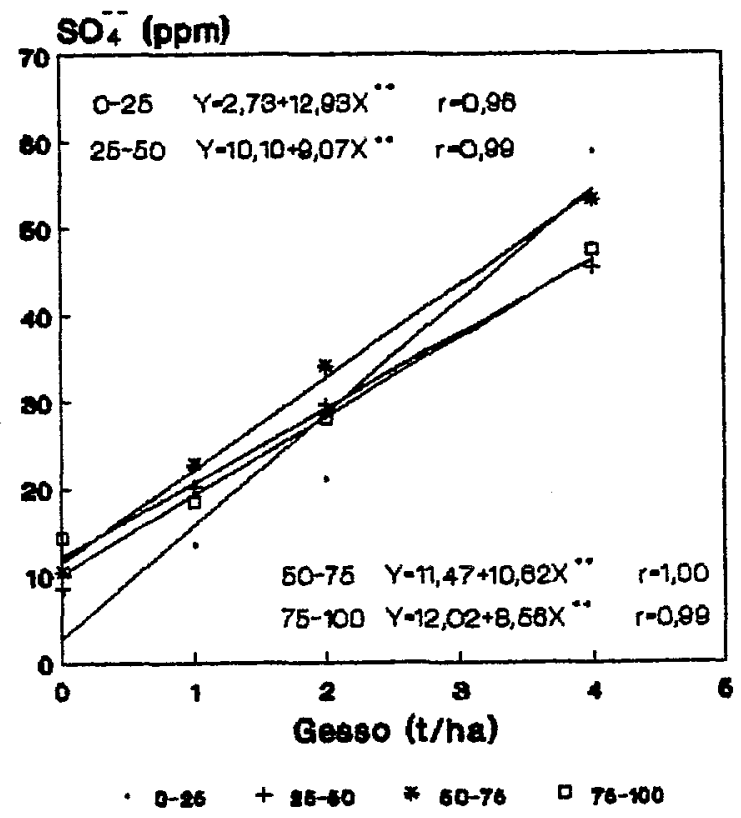

Figura 9. Efeito das doses de gesso sobre ${\mathrm{S}-\mathrm{SO}_{4}}^{2-}$ até $1 \mathrm{~m}$ de profundidade, 4 meses após a aplicação dos insumos.

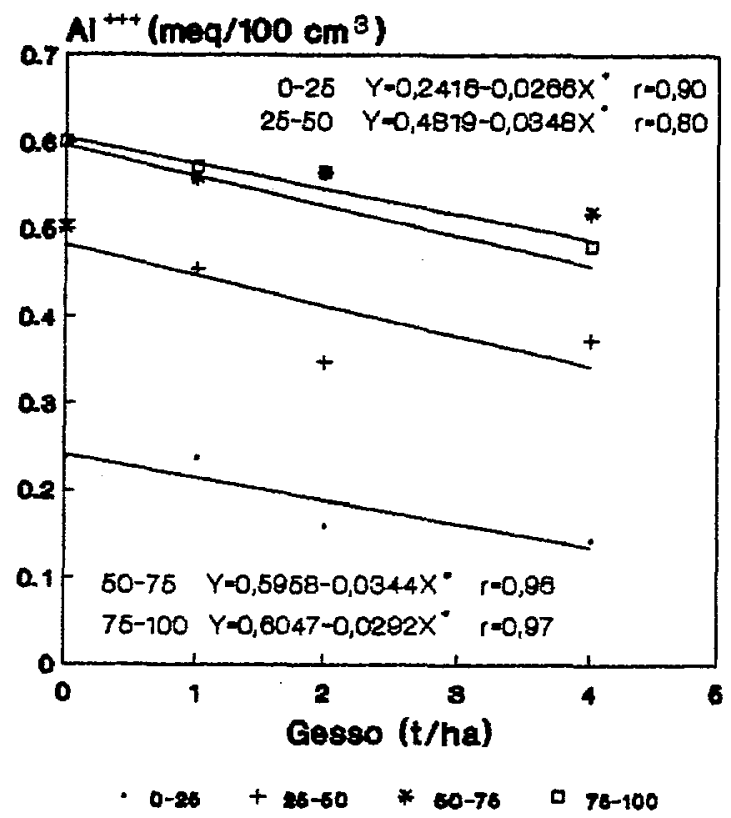

Figura 10. Efeitosdas doses de gesso sobre $\mathrm{Al}^{3+}$ nas 4 profundidades, 4 meses após a aplicação dos insumos. 
Tabela 26. Quadrados médios da análise de variância dos resultados da análise de solo, 18 meses após a aplicação dos insumos.

\begin{tabular}{|c|c|c|c|c|c|c|c|c|c|}
\hline \multirow{2}{*}{ C.V. } & \multirow{2}{*}{ G.L } & \multicolumn{4}{|c|}{ pH } & \multicolumn{4}{|c|}{ M.O. } \\
\hline & & $0-25$ & 25.50 & $50-75$ & $75-100$ & $0-25$ & $25-50$ & $50-75$ & $75-100$ \\
\hline Bloco & 2 & 0,241 & 0,275 & 0,079 & 0,038 & 0,0060 & 0,0106 & 0,0079 & 0,0021 \\
\hline Gesso & 3 & 0,090 & 0,024 & 0,021 & $0,014^{+}$ & 0,0902 & 0,0069 & 0,0041 & 0,0010 \\
\hline Calcário & 3 & $0,297^{* *}$ & 0,044 & 0,009 & 0,012 & 0,0486 & 0,0423 & 0,0055 & 0,0205 \\
\hline $\begin{array}{l}\text { Gesso x } \\
\text { calcário }\end{array}$ & 9 & $0,081^{\circ}$ & 0,047 & 0,015 & 0,007 & 0,0454 & 0,0142 & 0,0068 & 0,0078 \\
\hline Resíduo & 30 & 0,034 & 0,040 & 0,015 & 0,006 & 0,0493 & 0,0203 & 0,0060 & 0,0043 \\
\hline C.V. (\%) & & 3,95 & 4,67 & 2,91 & 1,86 & 11,71 & 12,42 & 8,38 & 8,18 \\
\hline
\end{tabular}

Média geral

4,665

4,292

4,231

4,200

1,8960

(\%)

- Significativo a $5 \%$ de probabilidade.

- Significativo a $1 \%$ de probabilidade.

+ Significativo a $10 \%$ de probabilidade.

Tabela 26. Continuação.

\begin{tabular}{|c|c|c|c|c|c|c|c|c|c|}
\hline \multirow{2}{*}{ C.v. } & \multirow{2}{*}{ G.L. } & \multicolumn{4}{|c|}{$\mathbf{P}$} & \multicolumn{4}{|c|}{$\mathbf{K}^{+}$} \\
\hline & & $0-25$ & 25.50 & $50-75$ & $75-100$ & $0-25$ & 25-50 & $50-75$ & $75 \cdot 100$ \\
\hline Bloco & 2 & 6,89 & 7,94 & 0,27 & 0,75 & $74 \times 10^{-6}$ & $25 \times 10^{-6}$ & $19 \times 10^{-6}$ & $119 \times 10^{-6}$ \\
\hline Gesso & 3 & 10,35 & $11,80^{+}$ & 0,41 & 0,39 & $88 \times 10^{-6}$ & $17 \times 10^{-6}$ & $35 \times 10^{-6}$ & $35 \times 10^{-6}$ \\
\hline Calcário & 3 & 2,91 & 2,35 & 1,19 & 0,22 & $90 \times 10^{-6}$ & $16 \times 10^{-6}$ & $63 \times 10^{-6}$ & $74 \times 10^{-6}$ \\
\hline $\begin{array}{l}\text { Gesso x } \\
\text { calcário }\end{array}$ & 9 & 4,86 & 4,39 & 1,02 & 0,32 & $33 \times 10^{-6}$ & $45 \times 10^{-6}$ & $45 \times 10^{-6}$ & $30 \times 10^{-6}$ \\
\hline Resíduo & 30 & 5,07 & 5,12 & 0,92 & 0,33 & $42 \times 10^{-6}$ & $34 \times 10^{-6}$ & $50 \times 10^{-6}$ & $43 \times 10^{-6}$ \\
\hline c.V. (\%) & & 29,13 & 46,97 & 30,39 & 22,89 & 17,18 & 19,94 & 30,54 & 36,26 \\
\hline Média geral & & 7,73 & 4,82 & 3,15 & 2,50 & 0,0378 & 0,0292 & 0,0231 & 0,0181 \\
\hline
\end{tabular}

+ Significativo a $10 \%$ de probabilidade. 
Tabela 26. Continuação.

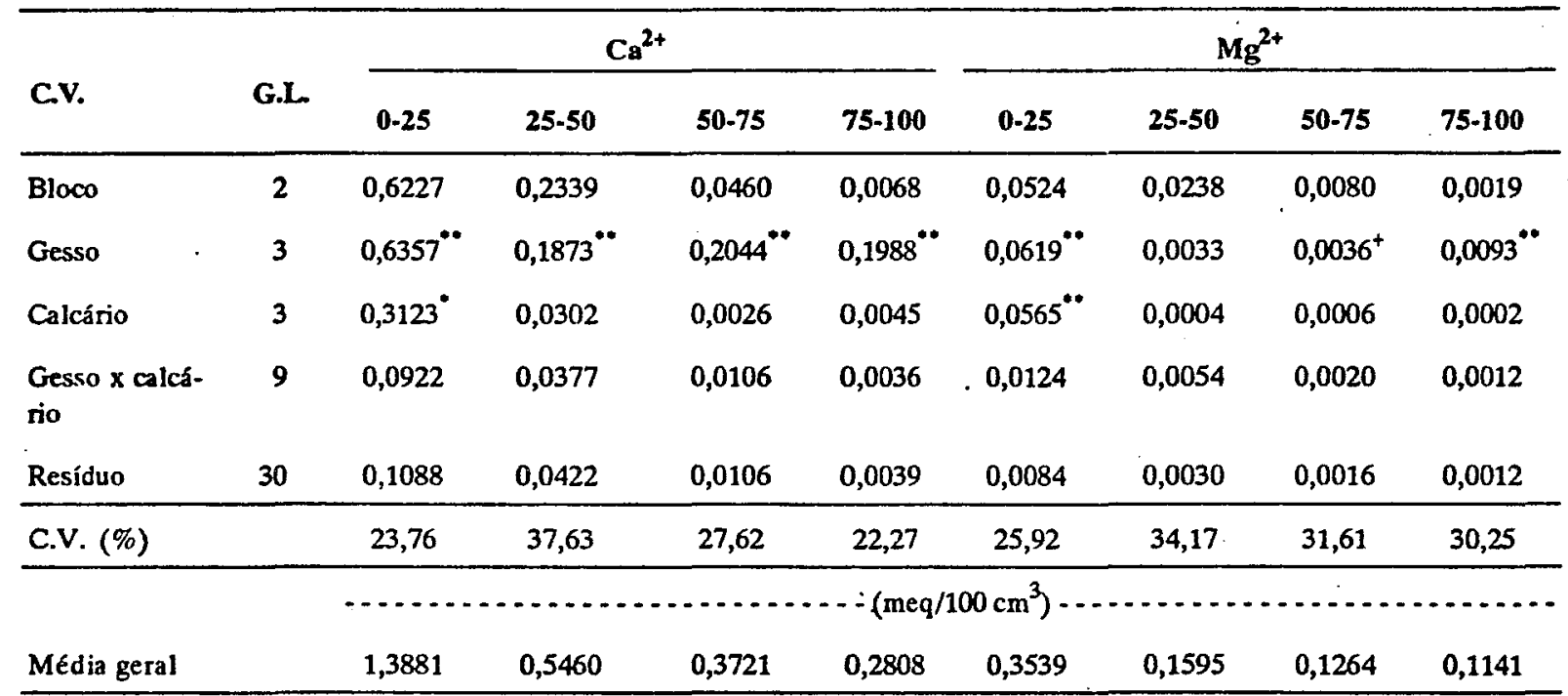

Significativo a $5 \%$ de probabilidade.

"* Significativo a $1 \%$ de probabilidade.

+ Significativo a $10 \%$ de probabilidade.

Tabela 26. Continuaçāo.

\begin{tabular}{|c|c|c|c|c|c|c|c|c|c|c|c|c|c|}
\hline \multirow{2}{*}{ c.v. } & \multirow{2}{*}{ G.L } & \multicolumn{4}{|c|}{$\mathrm{H}^{+}+\mathrm{Al}^{3+}$} & \multicolumn{4}{|c|}{$\mathrm{Al}^{3+}$} & \multicolumn{4}{|c|}{$\mathbf{S}$} \\
\hline & & 0.25 & $25-50$ & $50-75$ & $75-100$ & $0-25$ & $25-50$ & $50-75$ & $75 \cdot 100$ & $0-25$ & $25-50$ & $50-75$ & $75-100$ \\
\hline Blocos & 2 & 0,384 & 0,501 & 0,036 & 0,011 & 0,0855 & 0,1923 & 0,0703 & 0,0234 & 1,078 & 0,388 & 0,108 & 0,010 \\
\hline Gesso & 3 & 0,047 & 0,005 & 0,014 & 0,022 & 0,0226 & 0,0249 & 0,0206 & 0,0125 & $0,417^{+}$ & $0,175^{*}$ & $0,258^{\circ}$ & $0,325^{* *}$ \\
\hline Calcário & 3 & $1,341^{\circ *}$ & 0,266 & 0,046 & 0,020 & $0,1125^{* \ldots}$ & 0,0232 & 0,0020 & 0,0075 & $0,643^{\circ}$ & 0,038 & 0,005 & 0,009 \\
\hline Gessoxcalc. & 9 & 0,213 & 0,111 & 0,085 & 0,064 & 0,0226 & 0,0206 & 0,0142 & 0,0071 & 0,174 & 0,070 & 0,012 & 0,008 \\
\hline Resíduo. & 30 & 0,270 & 0,236 & 0,077 & 0,073 & 0,0158 & 0,0343 & 0,0161 & 0,0094 & 0,164 & 0,062 & 0,019 & 0,008 \\
\hline \multicolumn{2}{|l|}{ C.V. (\%) } & 17,76 & 17,36 & 10,71 & 10,89 & 58,56 & 40,91 & 25,28 & 13,22 & 22,17 & 32,03 & 25,43 & 20,88 \\
\hline & & & & & & & & & & & & & \\
\hline Média geral & & 2,927 & 2,798 & 2,590 & 2,485 & 0,2145 & 0,4530 & 0,5021 & 0,5315 & 1,828 & 0,777 & 0,544 & 0,441 \\
\hline
\end{tabular}

Significativo a $5 \%$ de probabilidade.

- Significativo a $1 \%$ de probabilidade.

+ Significativo a $10 \%$ de probabilidade. 
Tabela 26. Continuação.

\begin{tabular}{|c|c|c|c|c|c|c|c|c|c|}
\hline \multirow{2}{*}{ C.v. } & \multirow{2}{*}{ G.L. } & \multicolumn{4}{|c|}{ CTC } & \multicolumn{4}{|c|}{$\mathbf{v}$} \\
\hline & & $0-25$ & 25.50 & $50-75$ & $75-100$ & 0.25 & $25-50$ & $50-75$ & $75-100$ \\
\hline Blocos & 2 & 0,203 & 0,593 & 0,041 & 0,036 & 337,94 & 245,84 & 91,86 & 7,54 \\
\hline Gesso & 3 & 0,349 & 0,175 & $0,266^{\circ \bullet}$ & $0,188^{\circ}$ & 85,34 & 94,37 & $177,02^{\circ *}$ & $283,67^{* \bullet}$ \\
\hline Calcário & 3 & 0,138 & 0,212 & 0,056 & 0,007 & $391,18^{\circ *}$ & 37,67 & 4,82 & 10,99 \\
\hline Gesso $\times$ calcário & 9 & 0,175 & 0,060 & 0,059 & 0,058 & 61,38 & 49,70 & 15,54 & 9,92 \\
\hline Resíduo & 30 & 0,243 & 0,123 & 0,054 & 0,052 & 60,81 & 57,20 & 20,37 & 12,22 \\
\hline \multirow[t]{2}{*}{ C.V. (\%) } & & 10,39 & 9,85 & 7,46 & 7,83 & 20,47 & 34,98 & 26,32 & 23,49 \\
\hline & & $\ldots \ldots$ & $--(\mathrm{me}$ & $\left.\mathrm{cm}^{3}\right)-$ & $\ldots .$. & $\ldots \ldots$ & $\ldots .$. & $\%) \ldots \ldots$ & $\ldots+\ldots$ \\
\hline Média geral & & 4,751 & 3,565 & 3,123 & 2,917 & 38,10 & 21,62 & 17,15 & 14,88 \\
\hline
\end{tabular}

- Significativo a $5 \%$ de probabilidade.

- Significativo a $1 \%$ de probabilidade.

Tabela 26. Continuaçāo.

\begin{tabular}{|c|c|c|c|c|c|c|c|c|c|}
\hline \multirow{2}{*}{ C.V. } & \multirow{2}{*}{ G.L. } & \multicolumn{4}{|c|}{$\mathbf{m}$} & \multicolumn{4}{|c|}{$\mathrm{SO}_{4}^{2-}$} \\
\hline & & 0.25 & $25-50$ & $50-75$ & $75-100$ & $0-25$ & $25-50$ & $50-75$ & $75-100$ \\
\hline Blocos & 2 & 420,5230 & 1690,9148 & 776,4254 & 88,0778 & 3,94 & 151,56 & 48,30 & 14,77 \\
\hline Gesso & 3 & 133,4237 & 500,8892 & $1001,2205^{* *}$ & $1401,5827^{* *}$ & $1495,97^{\circ *}$ & $1181,08^{\circ *}$ & $1573,64 * *$ & $2506,74^{* *}$ \\
\hline Calcário & 3 & $563,3680^{* *}$ & 150,9218 & 43,2879 & 77,3380 & $\begin{array}{l}7,08 \\
:\end{array}$ & 24,69 & 51,03 & 76,91 \\
\hline Gesso $x$ calc. & 9 & 107,2480 & 220,4032 & 94,6363 & 68,8906 & 86,02 & 67,72 & 53,77 & 101,65 \\
\hline Resíduo & 30 & 67,6016 & 240,6708 & 154,0270 & 77,4758 & 51,74 & 89,90 & 106,16 & 134,37 \\
\hline \multirow[t]{2}{*}{ C.V. (\%) } & & 67,43 & 39,78 & 24,72 & 15,40 & 50,70 & 50,07 & 38,70 & 33,87 \\
\hline & & $\ldots$ & $\cdots(\%)$ & 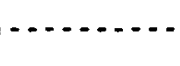 & 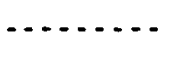 & $\ldots$. & $\cdots(p p$ & $\ldots$ & 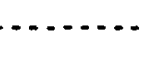 \\
\hline Média geral & & 12,19 & 39,0038 & 50,2087 & 57,1597 & 14,19 & 18,94 & 26,63 & 34,23 \\
\hline
\end{tabular}

\footnotetext{
* Significativo a $1 \%$ de probabilidade.
} 
Tabela 27. Quadrados médios da análise de regressão polinomial dos resultados da análise de solo, 18 meses após a aplicação dos insumos.

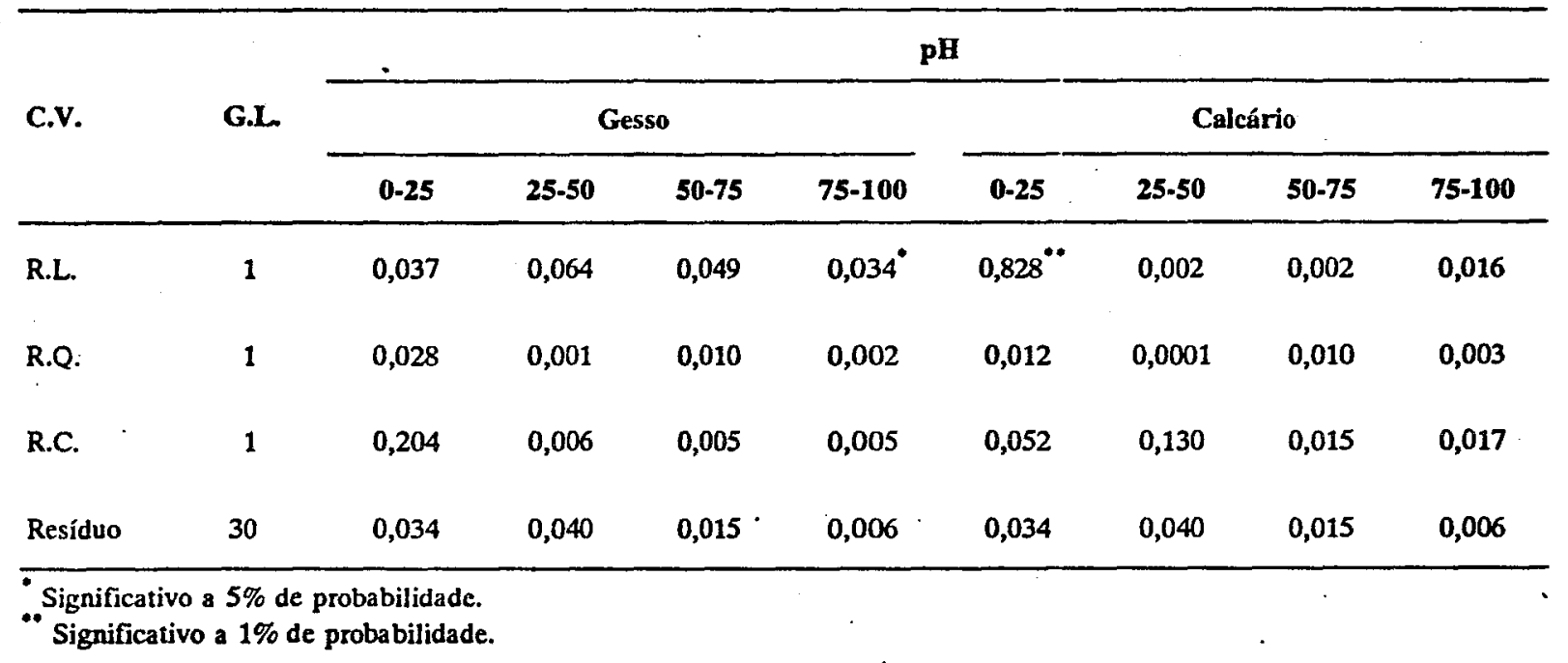

Tabela 27. Continuaçäo.

\begin{tabular}{|c|c|c|c|c|c|c|c|c|c|}
\hline \multirow{3}{*}{ C.V. } & \multirow{3}{*}{ G.L. } & \multicolumn{8}{|c|}{ M.O. } \\
\hline & & \multicolumn{4}{|c|}{ Gesso } & \multicolumn{4}{|c|}{ Calcário } \\
\hline & & $0-25$ & $25-50$ & $50-75$ & $75-100$ & 0.25 & 25-50 & $50-75$ & $75-100$ \\
\hline R.L. & 1 & 0,1440 & 0,0162 & 0,0075 & 0,0006 & 0,0952 & 0,0679 & 0,0054 & 0,0013 \\
\hline R.Q. & 1 & 0,1229 & 0,0043 & 0,0043 & 0,0005 & 0,0300 & 0,0367 & 0,0048 & 0,3430 \\
\hline R.C. - & 1 & 0,0037 & 0,0001 & 0,0005 & 0,0018 & 0,0204 & 0,0223 & 0,0063 & 0,0260 \\
\hline Resíduo & 30 & 0,0493 & 0,0203 & 0,0060 & 0,0043 & 0,0493 & 0,0203 & 0,0060 & 0,0043 \\
\hline
\end{tabular}

Tabela 27. Continuaçäo.

\begin{tabular}{|c|c|c|c|c|c|c|c|c|c|}
\hline \multirow{3}{*}{ C.V. } & \multirow{3}{*}{ G.L. } & \multicolumn{8}{|c|}{$\mathbf{P}$} \\
\hline & & \multirow{2}{*}{$\frac{\cdots}{0-25}$} & \multicolumn{2}{|c|}{ Gesso } & \multirow[b]{2}{*}{$75-100$} & \multicolumn{4}{|c|}{ Calcário } \\
\hline & & & $25-50$ & $50-75$ & & $0-25$ & 25.50 & $50-75$ & $75-100$ \\
\hline R.L. & 1 & $27,50^{*}$ & $29,60^{*}$ & 0,43 & 0,24 & 0,17 & 0,65 & 0,10 & 0,61 \\
\hline R.Q. & 1 & 3,38 & 0,70 & 0,02 & 0,45 & 3,47 & 6,19 & 1,00 & 0,01 \\
\hline R.C. & 1 & 0,17 & 5,09 & 0,78 & 0,47 & 5,09 & 0,22 & 2,46 & 0,05 \\
\hline & & & & & & & & & \\
\hline Resíduo & 30 & 5,07 & 5,12 & 0,92 & 0,33 & 5,07 & 5,12 & 0,92 & 0,33 \\
\hline
\end{tabular}

* Significativo a $5 \%$ de probabilidade. 
Tabela 27. Continuação.

\begin{tabular}{|c|c|c|c|c|c|c|c|c|c|}
\hline \multirow{3}{*}{ C.V. } & \multirow{3}{*}{ G.L. } & \multicolumn{8}{|c|}{$\mathbf{K}^{+}$} \\
\hline & & \multicolumn{4}{|c|}{ Gesso } & \multicolumn{4}{|c|}{ Calcário } \\
\hline & & $0-25$ & $25-50$ & $50-75$ & $75-100$ & $0-25$ & $25-50$ & $50-75$ & $75 \cdot 100$ \\
\hline R.L. & 1 & $175 \times 10^{-6+}$ & $23 \times 10^{-6}$ & $65 \times 10^{-6}$ & $32 \times 10^{-6}$ & $8 \times 10^{-6}$ & $45 \times 10^{-6}$ & $73 \times 10^{-6}$ & $1 \times 10^{-7}$ \\
\hline R.Q. & 1 & $31 \times 10^{-6}$ & $11 \times 10^{-6}$ & $29 \times 10^{-6}$ & $74 \times 10^{-6}$ & $129 \times 10^{-6}$ & $3 \times 10^{-6}$ & $24 \times 10^{-6}$ & $135 \times 10^{-6}$ \\
\hline R.C. & 1 & $57 \times 10^{-6}$ & $18 \times 10^{-6}$ & $13 \times 10^{-6}$ & $1 \times 10^{-6}$ & $132 \times 10^{-6}$ & $1 \times 10^{-6}$ & $93 \times 10^{-6}$ & $87 \times 10^{-6}$ \\
\hline Residuo & 30 & $42 \times 10^{-6}$ & $34 \times 10^{-6}$ & $50 \times 10^{-6}$ & $43 \times 10^{-6}$ & $42 \times 10^{-6}$ & $34 \times 10^{-6}$ & $50 \times 10^{-6}$ & $43 \times 10^{-6}$ \\
\hline
\end{tabular}

+ Significativo a $10 \%$ de probabilidade.

Tabela 27. Continuaçāo.

\begin{tabular}{|c|c|c|c|c|c|c|c|c|c|}
\hline \multirow{3}{*}{ C.V. } & \multirow{3}{*}{ G.L } & \multicolumn{8}{|c|}{$\mathrm{Ca}^{2+}$} \\
\hline & & \multirow{2}{*}{$\frac{0-25}{0}$} & \multicolumn{2}{|c|}{ Gesso } & \multirow[b]{2}{*}{$75-100$} & \multicolumn{4}{|c|}{ Calcário } \\
\hline & & & $25-50$ & $50-75$ & & $0-25$ & $25-50$ & $50-75$ & $75-100$ \\
\hline R.L. & 1 & $1,8104^{* *}$ & $0,5606^{* *}$ & $0,6057^{\circ \bullet}$ & $0,5899^{\circ \cdots}$ & $0,8654^{\circ}$ & 0,0033 & 0,0037 & 0,0033 \\
\hline R.Q. & 1 & 0,0008 & 0,0003 & 0,0067 & 0,0059 & 0,0040 & 0,0229 & 0,0006 & 0,0003 \\
\hline R.C. & 1 & 0,0959 & 0,0008 & 0,0009 & 0,0007 & 0,0674 & 0,0644 & 0,0035 & 0,0098 \\
\hline Residuo & 30 & 0,1088 & 0,0422 & 0,0106 & 0,0039 & 0,1088 & 0,0422 & 0,0106 & 0,0039 \\
\hline
\end{tabular}

Significativo a $1 \%$ de probabilidade.

Tabela 27. Continuação.

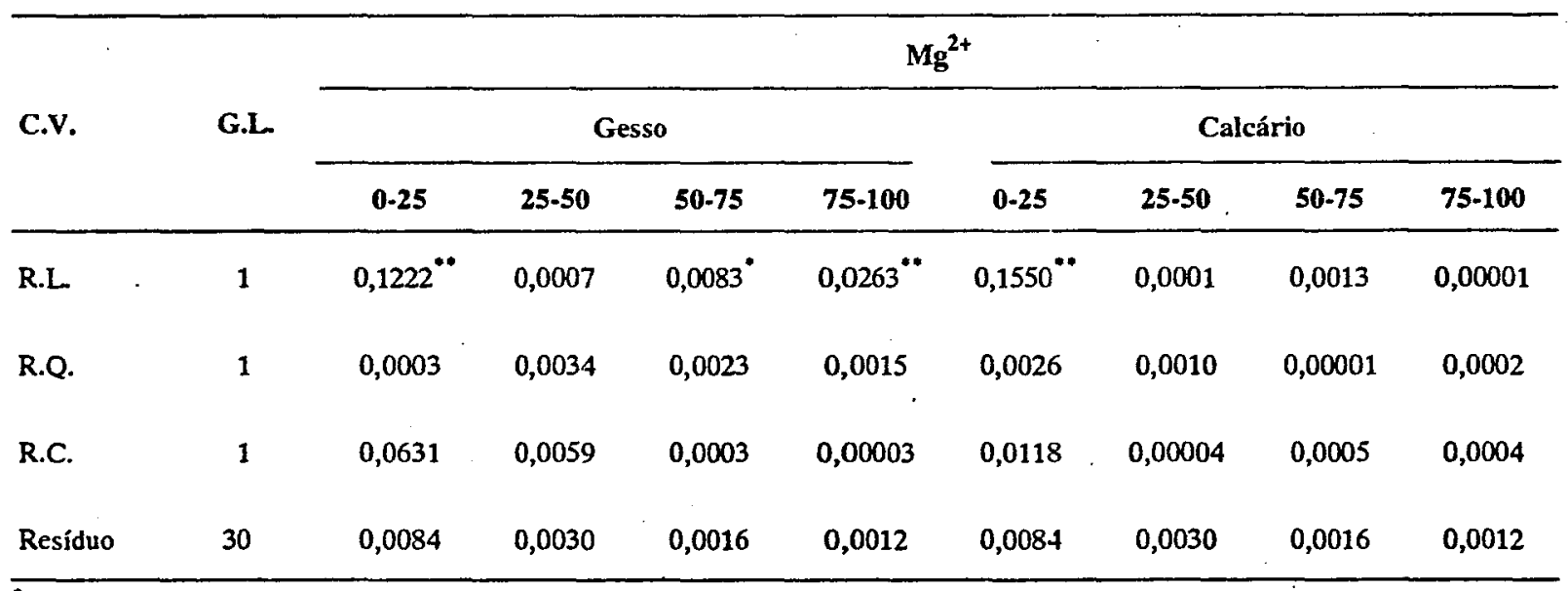

\footnotetext{
- Significativo a $5 \%$ de probabilidade.

Significativo a $1 \%$ de probabilidade.
} 
Tabela 27. Continuação.

\begin{tabular}{|c|c|c|c|c|c|c|c|c|c|}
\hline \multirow{3}{*}{ C.V. } & \multirow{3}{*}{ G.L. } & \multicolumn{8}{|c|}{$\mathbf{H}^{+}+\mathbf{A l}^{3+}$} \\
\hline & & \multicolumn{4}{|c|}{ Gesso } & \multicolumn{4}{|c|}{ Calcário } \\
\hline & & 0.25 & $25-50$ & $50-75$ & $75-100$ & $0-25$ & $25-50$ & $50-75$ & $75-100$ \\
\hline R.L. & 1 & 0,001 & 0,0001 & 0,0005 & 0,063 & $3,973^{\circ *}$ & 0,100 & 0,068 & 0,003 \\
\hline R.Q. & 1 & 0,064 & 0,0001 & 0,0400 & 0,003 & 0,006 & 0,168 & 0,070 & 0,045 \\
\hline R.C. & 1 & 0,077 & 0,0153 & 0,0001 & 0,001 & 0,045 & 0,620 & 0,001 & 0,012 \\
\hline Resíduo & 30 & 0,270 & 0,2359 & 0,0769 & 0,073 & 0,270 & 0,236 & 0,077 & 0,073 \\
\hline
\end{tabular}

** Significativo a $1 \%$ de probabilidade.

Tabela 27. Continuação.

\begin{tabular}{|c|c|c|c|c|c|c|c|c|c|}
\hline \multirow{3}{*}{ C.V. } & \multirow{3}{*}{ G.L. } & \multicolumn{8}{|c|}{$\mathrm{Al}^{3+}$} \\
\hline & & \multicolumn{4}{|c|}{ Gesso } & \multicolumn{4}{|c|}{ Calcário } \\
\hline & & $0-25$ & $25-50$ & $50-75$ & $75-100$ & 0.25 & 25.50 & 50.75 & $.75-100$ \\
\hline R.L. & 1 & 0,0034 & 0,0507 & 0,0523 & 0,0323 & $0,3159^{* *}$ & 0,0041 & 0,0039 & 0,0099 \\
\hline R.Q. & 1 & 0,0141 & 0,0011 & 0,0026 & 0,0024 & 0,0106 & 0,0030 & 0,0007 & 0,0087 \\
\hline R.C. & 1 & 0,0502 & 0,0230 & 0,0070 & 0,0028 & 0,0110 & 0,0625 & 0,0014 & 0,0039 \\
\hline Resíduo & 30 & 0,0158 & 0,0343 & 0,0161 & 0,0094 & 0,0158 & 0,0343 & 0,0161 & 0,0094 \\
\hline
\end{tabular}

Significativo a $1 \%$ de probabilidade.

Tabela 27. Continuação.

$\mathbf{S}$

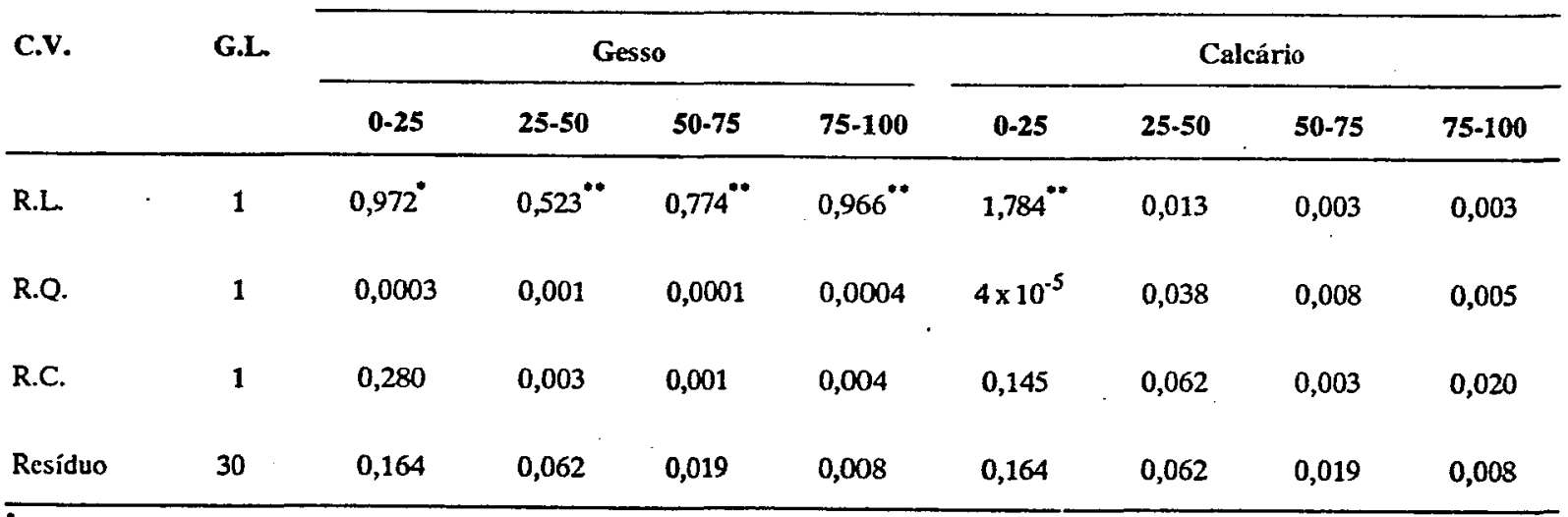

Significativo a $5 \%$ de probabilidade.

Significativo a $1 \%$ de probabilidade. 
Tabela 27. Continuação.

\begin{tabular}{|c|c|c|c|c|c|c|c|c|c|}
\hline \multirow{3}{*}{ c.v. } & \multirow{3}{*}{ G.L. } & \multicolumn{8}{|c|}{ CTC } \\
\hline & & \multicolumn{4}{|c|}{ Gesso } & \multicolumn{4}{|c|}{ Calcário } \\
\hline & & 0.25 & $25-50$ & 50.75 & $75-100$ & 0.25 & 25-50 & 50.75 & $75-100$ \\
\hline R.L & 1 & 0,929 & 0,521 & $0,756^{* *}$ & $0,553^{* *}$ & 0,379 & $2 \times 10^{-4}$ & 0,040 & $9 \times 10^{-5}$ \\
\hline R.Q. & 1 & 0,053 & $3 \times 10^{-5}$ & 0,040 & 0,001 & 0,007 & 0,359 & 0,127 & 0,019 \\
\hline R.C. & 1 & 0,066 & 0,005 & 0,001 & 0,011 & 0,028 & 0,277 & 0,001 & 0,001 \\
\hline Resíduo & 30 & 0,243 & 0,123 & 0,054 & 0,052 & 0,243 & 0,123 & 0,054 & 0,052 \\
\hline
\end{tabular}

"Significativo a $1 \%$ de probabilidade.

Tabela 27. Continuação.

\begin{tabular}{|c|c|c|c|c|c|c|c|c|c|}
\hline \multirow{3}{*}{ C.V. } & \multirow{3}{*}{ G.L. } & \multicolumn{8}{|c|}{$\mathbf{v}$} \\
\hline & & \multicolumn{4}{|c|}{ Gesso } & \multicolumn{4}{|c|}{ Calcário } \\
\hline & & $0-25$ & $25-50$ & $50-75$ & $75-100$ & $0-25$ & $25-50$ & $50-75$ & $75-100$ \\
\hline \multirow[t]{2}{*}{ RL } & 1 & 155,61 & 281,18 & $526,76^{\circ \bullet}$ & $846,65^{\circ \bullet}$ & $1134,87^{* *}$ & 6,98 & 10,18 & 4,40 \\
\hline & & & & & & $:$ & & & \\
\hline R.Q. & 1 & 10,77 & 1,42 & 3,91 & 0,05 & 0,39 & 2,96 & 1,20 & 6,20 \\
\hline R.C. & 1 & 89,65 & 0,51 & 0,38 & 4,30 & 38,27 & 103,07 & 3,08 & 22,38 \\
\hline Resíduo & 30 & 60,81 & 57,20 & 20,37 & 12,22 & 60,81 & 57,20 & 20,37 & 12,22 \\
\hline
\end{tabular}

* Significativo a $1 \%$ de probabilidade.

Tabela 27. Continuaçāo.

\begin{tabular}{|c|c|c|c|c|c|c|c|c|c|}
\hline \multirow{3}{*}{ C.V. } & \multirow{3}{*}{ G.L. } & \multicolumn{8}{|c|}{$\mathbf{m}$} \\
\hline & & \multicolumn{4}{|c|}{ Gresso } & \multicolumn{4}{|c|}{ Calcário } \\
\hline & & $0-25$ & $25-50$ & $50-75$ & $75-100$ & $0-25$ & $25-50$ & $50-75$ & $75-100$ \\
\hline R.L. & 1 & 81,4413 & $1466,7284^{\circ}$ & $2953,5875^{\circ \bullet}$ & $4137,5008^{\circ *}$ & $1564,2679^{* *}$ & 42,6129 & 28,9790 & 55,0368 \\
\hline R.Q. & 1 & 45,5333 & 3,7775 & 49,0023 & 63,7893 & 88,0375 & 22,4525 & 21,0925 & 47,4187 \\
\hline R.C. & 1 & 273,2965 & 32,1617 & 1,0720 & 3,4605 & 37,7989 & 387,7001 & 79,7925 & 129,5590 \\
\hline Resíduo & 30 & 67,6016 & 240,6708 & 154,0270 & 77,4758 & 67,6016 & 240,6708 & 154,0270 & $\mathrm{~T} 77,4758$ \\
\hline
\end{tabular}

\footnotetext{
- Significativo a $5 \%$ de probabilidade.

- Significativo a $1 \%$ de probabilidade.
} 
Tabela 27. Continuação.

\begin{tabular}{|c|c|c|c|c|c|c|c|c|c|}
\hline \multirow{3}{*}{ C.V. } & \multirow{3}{*}{ G.l. } & \multicolumn{8}{|c|}{$\mathrm{SO}_{4}{ }^{2-}$} \\
\hline & & \multicolumn{4}{|c|}{ Gesso } & \multicolumn{4}{|c|}{ Calcário } \\
\hline & & $0-25$ & $25-50$ & $50-75$ & $75-100$ & $0-25$ & $25-50$ & $50-75$ & $75-100$ \\
\hline R.L & 1 & $4214,83^{* *}$ & $3535,10^{* *}$ & $4320,02^{* *}$ & $7105,37^{* *}$ & 20,81 & 9,60 & 114,19 & 13,57 \\
\hline R.Q. & 1 & 253,91 & 7,53 & 387,29 & 268,19 & 0,37 & 10,46 & 6,43 & 9,15 \\
\hline R.C. & 1 & 19,15 & 0,59 & 13,60 & 146,67 & 0,05 & 54,01 & 32,46 & 208,01 \\
\hline Resíduo & 30 & 51,74 & 89,90 & 106,16 & 134,37 & 51,74 & 89,90 & 106,16 & 134,37 \\
\hline
\end{tabular}

\footnotetext{
Significativo a $1 \%$ de probabilidade.
}

Quanto ao gesso, observou-se mudanças em relação a outra época. Um pequeno mas consistente aumento do $\mathrm{pH}$ na profundidade de $75-100 \mathrm{~cm}$, mas consistente, pode ser observado na Figura 13.

$O$ gesso utilizado neste trabalho, por ser resíduo da fabricação de ácido fosfórico, possui aproximadamente $0,67 \%$ de $\mathrm{P}_{2} \mathrm{O}_{5}$ em sua composição (PAOLINELLI et al., 1986) e em função disso, nesta época, observou-se aumentos lineares nos teores de $\mathbf{P}$ do solo das duas primeiras profundidades amostradas, apesar de serem todos os teores (Figura 14) considerados muito baixos (RAIJ, 1987 e PENATTI, 1991).

A lixiviação maior dos nutrientes potássio e magnésio com o aumento da dose de gesso na camada superficial ainda ocorre após 18 meses após a aplicação (Figura 15) sendo que os teores de magnésio aumentam no subsolo $(50-75$ e $75-100 \mathrm{~cm})$, porém as médias dos teores de $\mathrm{K} \mathrm{e} \mathrm{Mg}$ são bastante inferiores às médias após 4 meses (Figura 15). FERREIRA et al. (1987) encontraram resultados semelhantes, trabalhando na região de Pirassununga-SP.

O aumento dos teores de cálcio e da soma de bases em todas as profundidades continua a ser linear, mas também com médias inferiores à primeira amostragem (Figura 16). A CTC e a V, embora tenham aumentado em todas as profundidades, têm médias mais consistentes apenas nas duas camadas mais profundas, onde os valores puderam ser bem explicados por uma regressão linear (Figura 16). 
Tabela 28. Médias dos resultados da análise de solo, 18 meses após a aplicação dos insumos.

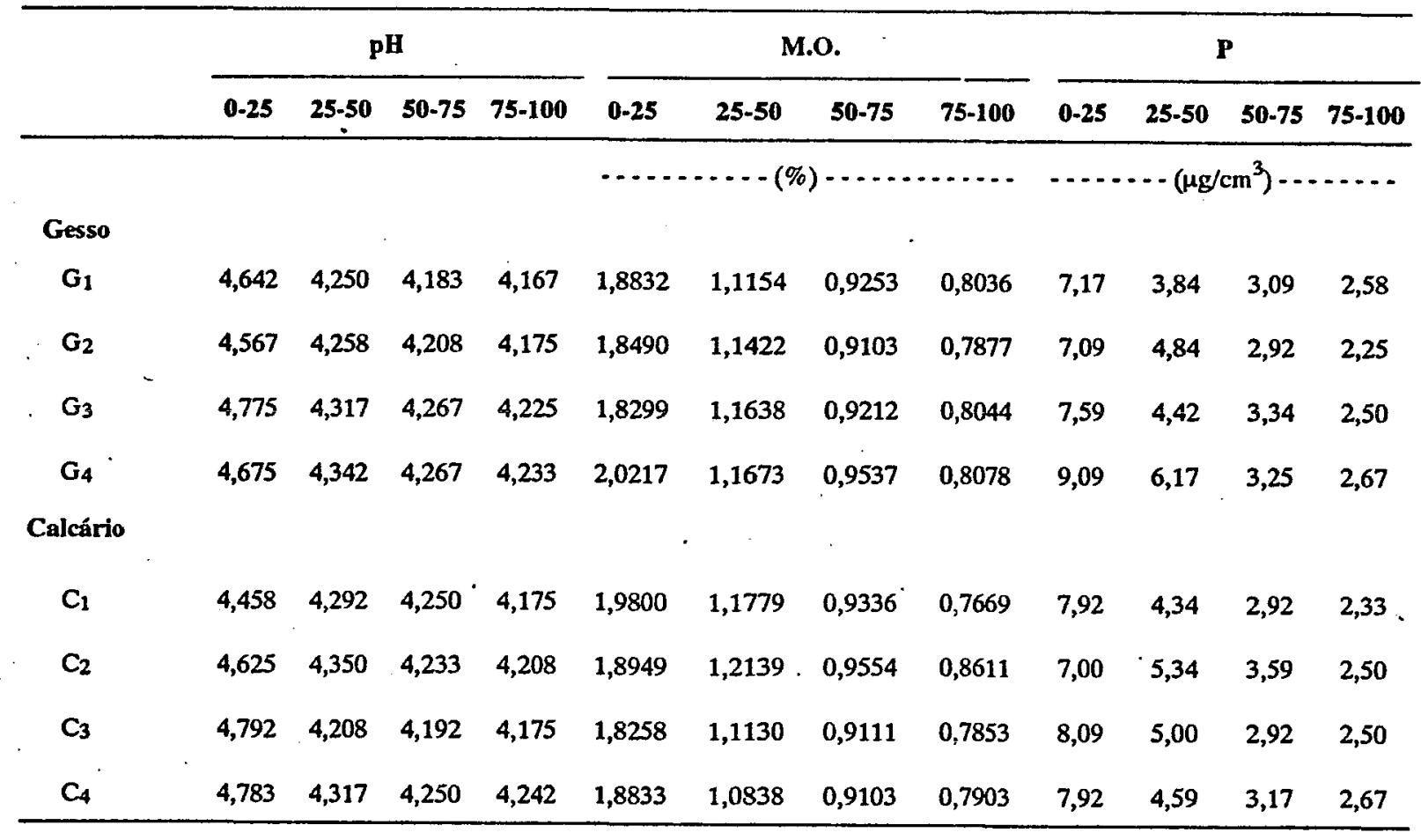

Tabela 28. Continuaçāo.

\begin{tabular}{|c|c|c|c|c|c|c|c|c|c|c|c|c|c|}
\hline & & \multicolumn{4}{|c|}{$\mathbf{K}^{+}$} & \multicolumn{4}{|c|}{$\mathrm{Ca}^{2+}$} & \multicolumn{4}{|c|}{$\mathbf{M g}^{2+}$} \\
\hline & & $0-25$ & $25-50$ & $50-75$ & $75-100$ & $0-25$ & $25-50$ & $50-75$ & $75-100$ & $0-25$ & $25-50$ & 50.75 & $75-100$ \\
\hline & & $\ldots$ & $\ldots$ & ....... & $\cdots$ & $\ldots$ & $--(m$ & $\left.100 \mathrm{~cm}^{3}\right)$ & - & $\ldots$ & $=-\cdot$ & $\cdots$ & $\ldots$ \\
\hline Gesso & $\cdot$ & & & & & & & & & & & & \\
\hline $\mathbf{G}_{1}$ & & 0,0416 & 0,0309 & 0,0233 & 0,0158 & 1,1792 & 0,4233 & 0,2500 & 0,1600 & 0,4317 & 0,1608 & 0,1046 & 0,0796 \\
\hline $\mathrm{G}_{2}$ & & 0,0366 & 0,0283 & 0,0250 & 0,0183 & 1,2242 & 0,4833 & 0,3142 & 0,2233 & 0,3257 & 0,1499 & 0,1204 & 0,1071 \\
\hline $\mathrm{G}_{3}$ & & 0,0377 & 0,0292 & 0,0233 & 0,0200 & 1,4775 & 0,5658 & 0,3708 & 0,2808 & 0,3900 & 0,1823 & 0,1403 & 0,1245 \\
\hline $\mathrm{G}_{4}$ & & 0,0353 & 0,0284 & 0,0208 & 0,0183 & 1,6717 & 0,7117 & 0,5533 & 0,4592 & 0,2683 & 0,1448 & 0,1404 & 0,1453 \\
\hline Calcário & & & & & & & $\therefore$ & & & & ' & & \\
\hline$c_{1}$ & & 0,0382 & 0,0308 & 0,0242 & 0,0192 & 1,1983 & 0,5342 & 0,3542 & $0,26.75$ & 0,2645 & 0,1582 & 0,1195 & 0,1145 \\
\hline$C_{2}$ & & 0,0375 & 0,0293 & 0,0258 & 0,0175 & 1,3108 & 0,6172 & 0,3850 & 0,2925 & 0,3360 & 0,1665 & 0,1213 & 0,1146 \\
\hline$C_{3}$ & & 0,0344 & 0,0283 & 0,0208 & 0,0150 & 1,5075 & 0,5000 & 0,3658 & 0,2617 & 0,4114 & 0,1602 & 0,1337 & 0,1087 \\
\hline$C_{4}$ & & 0,0411 & 0,0284 & 0,0217 & 0,0208 & 1,5358 & 0,5325 & 0,3833 & 0,31117 & 0,4038 & 0,1530 & 0,1312 & 0,1187 \\
\hline
\end{tabular}


Tabela 2Q: C'ontinuação.

\begin{tabular}{|c|c|c|c|c|c|c|c|c|c|c|c|c|}
\hline \multirow[t]{2}{*}{ ' } & \multicolumn{4}{|c|}{$\mathbf{H}^{+}+\mathrm{Al}^{3+}$} & \multicolumn{4}{|c|}{$\mathrm{Al}^{3+}$} & \multicolumn{4}{|c|}{$\mathbf{S}$} \\
\hline & $0-25$ & $25-50$ & 50.75 & $75-100$ & $0-25$ & $25-50$ & $50-75$ & 75.100 & 0.25 & $25-50$ & $50-75$ & $75-100$ \\
\hline \multicolumn{13}{|l|}{ Gesso } \\
\hline$G_{1}$ & 2,950 & 2,792 & 2,625 & 2,517 & 0,2253 & 0,4735 & 0,5425 & 0,5658 & 1,700 & 0,655 & 0,393 & 0,271 \\
\hline $\mathbf{G}_{2}$ & 2,967 & 2,825 & 2,575 & 2,517 & 0,2571 & 0,5059 & 0,5325 & 0,5517 & 1,641 & 0,715 & 0,484 & 0,382 \\
\hline $\mathbf{G}_{3}$ & 2,833 & 2,775 & 2,550 & 2,483 & 0,1540 & 0,4287 & 0,4733 & 0,5092 & 1,943 & 0,807 & 0,559 & 0,450 \\
\hline $\mathbf{G}_{4}$ & 2,958 & 2,800 & 2,608 & 2,425 & 0,2216 & 0,4038 & 0,4601 & 0,4992 & 2,028 & 0,933 & 0,738 & 0,661 \\
\hline \multicolumn{13}{|l|}{ Calcáris } \\
\hline$C_{1}$ & 3,350 & 2,750 & 2,617 & 2,475 & 0,3470 & 0,4395 & 0,5117 & 0,5442 & 1,544 & 0,773 & 0,519 & 0,433 \\
\hline$c_{2}$ & 3,025 & 2,742 & 2,642 & 2,508 & 0,2263 & 0,4203 & 0,5150 & 0,5408 & 1,733 & 0,858 & 0,568 & 0,449 \\
\hline$c_{3}$ & 2,742 & 3,017 & 2,600 & 2,525 & 0,1408 & 0,5177 & 0,4917 & 0,5467 & 2,010 & 0,733 & 0,544 & 0,408 \\
\hline$c_{4}$ & 2,592 & 2,683 & 2,500 & 2,433 & 0,1439 & 0,4344 & 0,4901 & 0,4942 & 2,023 & 0,747 & 0,543 & 0,474 \\
\hline
\end{tabular}

Tabela 2 ż: Continuaçāo.

\begin{tabular}{|c|c|c|c|c|c|c|c|c|c|c|c|c|}
\hline & \multicolumn{4}{|c|}{ CTC } & \multicolumn{4}{|c|}{$\mathbf{V}$} & \multicolumn{4}{|c|}{$\mathbf{m}$} \\
\hline & $0-25$ & $25-50$ & $50-75$ & $75-100$ & 0.25 & $25-50$ & $50-75$ & $75-100$ & $0-25$ & $25-50$ & $50-75$ & $75-100$ \\
\hline & $\ldots$ & - (meq & $100 \mathrm{~cm}$ & $\cdots$ & $\cdots$ & $\ldots$ & $\cdots$ & $\cdots$ & $-(\%)=$ & $\cdots$ & $\cdots$ & ......... \\
\hline \multicolumn{13}{|c|}{ Gessin } \\
\hline$G_{\text {ij }}$ & 4,645 & 3,435 & 3,005 & 2,776 & 36,22 & 18,62 & 12,86 & 9,78 & 13,4680 & 45,3926 & 60,5446 & 69,5991 \\
\hline $\mathbf{G}_{2}$ & 4,602 & 3,529 & 3,049 & 2,888 & 35,41 & 20,35 & 15,79 & 13,19 & 15,8659 & 42,8748 & 53,7631 & 60,7149 \\
\hline $\mathrm{G}_{3}$ & 4,774 & 3,572 & 3,101 & 2,924 & 40,58 & 22,37 & 17,97 & 15,21 & 7,9870 & 36,7711 & 47,4091 & 54,4112 \\
\hline$G_{\$}$ & 4,982 & 3,725 & 3,339 & 3,080 & 40,20 & 25,14 & $21,97^{\circ}$ & 21,36 & 11,4514 & 30,9766 & 39,1180 & 43,9134 \\
\hline \multicolumn{13}{|c|}{ Calcárił } \\
\hline$c_{1}$ & 4,881 & 3,513 & 3,125 & 2,898 & 30,80 & 16,27 & 16,27 & 14,58 & 21,7997 . & 38,6635 & 52,1708 & 58,3010 \\
\hline $\mathrm{C}_{2}$ & 4,753 & 3,590 & 3,201 & 2,949 & 36,37 & 17,56 & 17,56 & 15,15 & 12,4272 & 34,7110 & 48,0102 & 56,7424 \\
\hline $\mathrm{CB}$ & 4,750 & 3,736 & 3,134 & 2,922 & 41,99 & 17,10 & 17,10 & 13,76 & 7,0714 & 43,3763 & 51,3543 & 59,7637 \\
\hline $\mathrm{C}_{3}$ & 4,618 & 3,422 & 3,034 & 2,899 & 43,24 & 17,66 & 17,66 & 16,04 & 7,4740 & 39,2643 & 49,2996 & 53,8315 \\
\hline
\end{tabular}




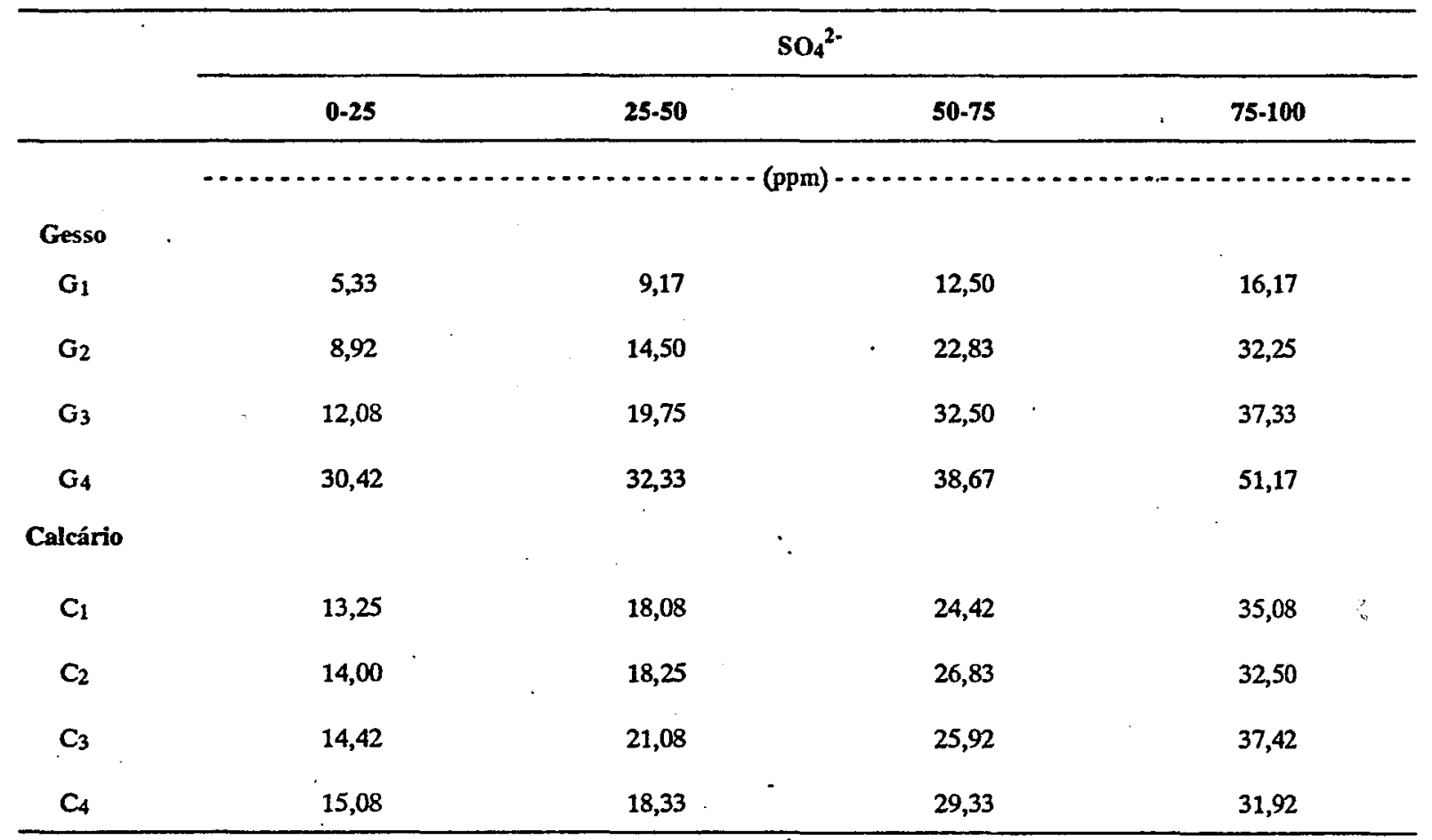

Quatro retas representam o aumento de sulfato em função das doses de gesso nas quatro profundidades (Figura 17). Os teores encontrados na camada superficial foram sempre superiores aos encontrados por MALAVOLTA (1989) como necessários para se obter as maiores produções de cana-de-açúcar. Após 18 meses da aplicação do gesso, observa-se que as três primeiras camadas tiveram seus teores médios menores que os encontrados na amostragem após 4 meses; no entanto, a camada de 75-100 $\mathrm{cm}$ apresentou um acúmulo maior de $\mathrm{SO}_{4}{ }^{2-}$.

O efeito do gesso sobre os teores de alumínio observados na primeira época não se repetiu nesta época, porém a saturação por alumínio, que é função dos teores de alumínio e da soma de bases, decresceu linearmente abaixo dos $25 \mathrm{~cm}$ (Figura 18).

Neste trabalho, como também no de MARTINS (1991), não houve interação significativa para nenhuma das variáveis estudadas entre o uso de gesso e calcário. 


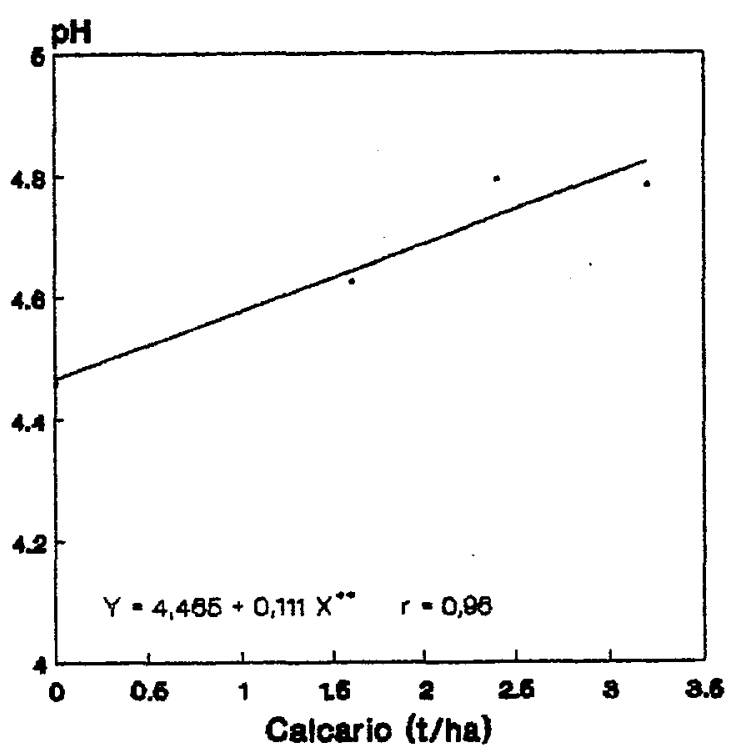

- 0-26

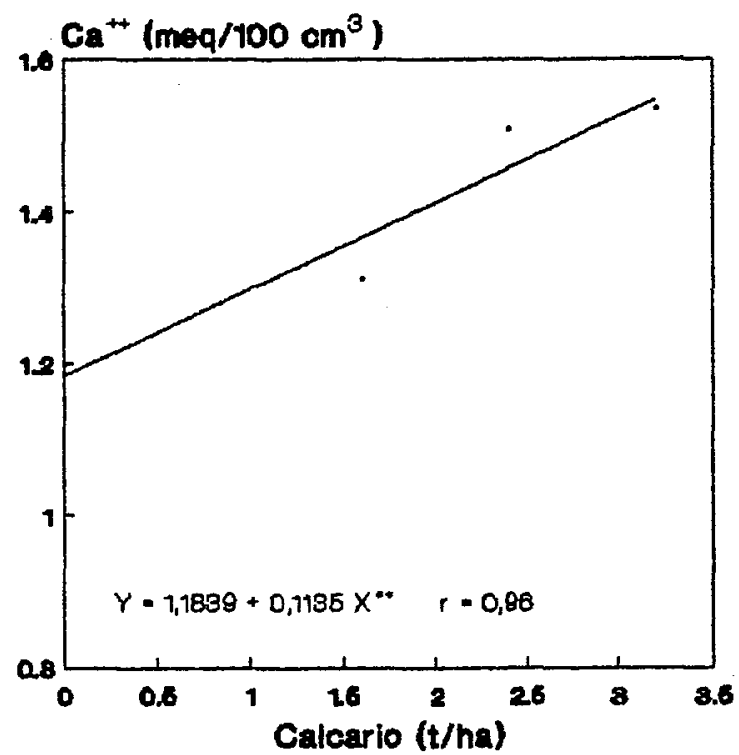

- $0-26$

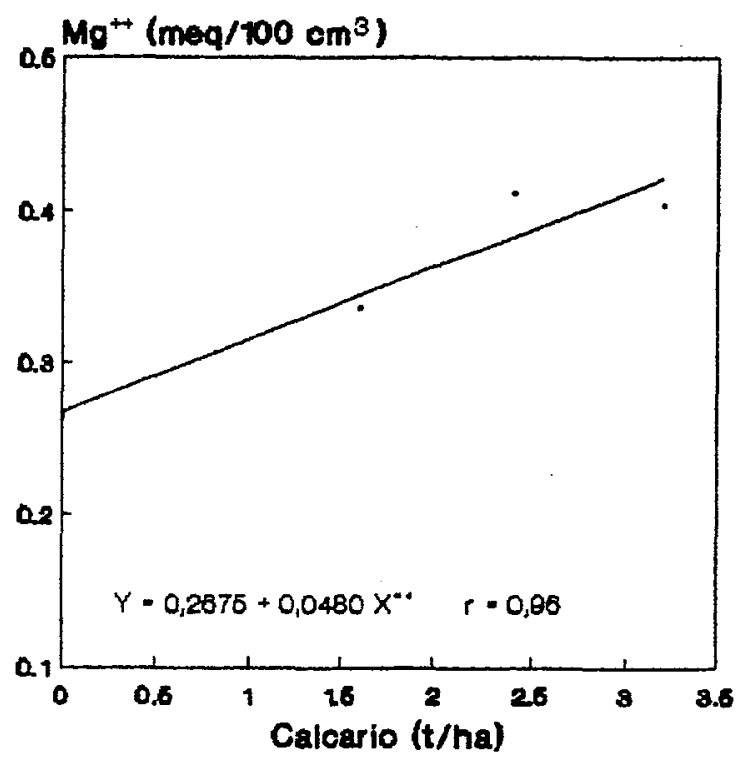

0-25

Figura 11. Efeitos das doses de $\mathrm{pH}, \mathrm{Ca}^{2+}, \mathrm{Mg}^{2+}$ e $\mathrm{S}$, na camada 0-25 cm, 18 meses após a aplicação dos insumos. 

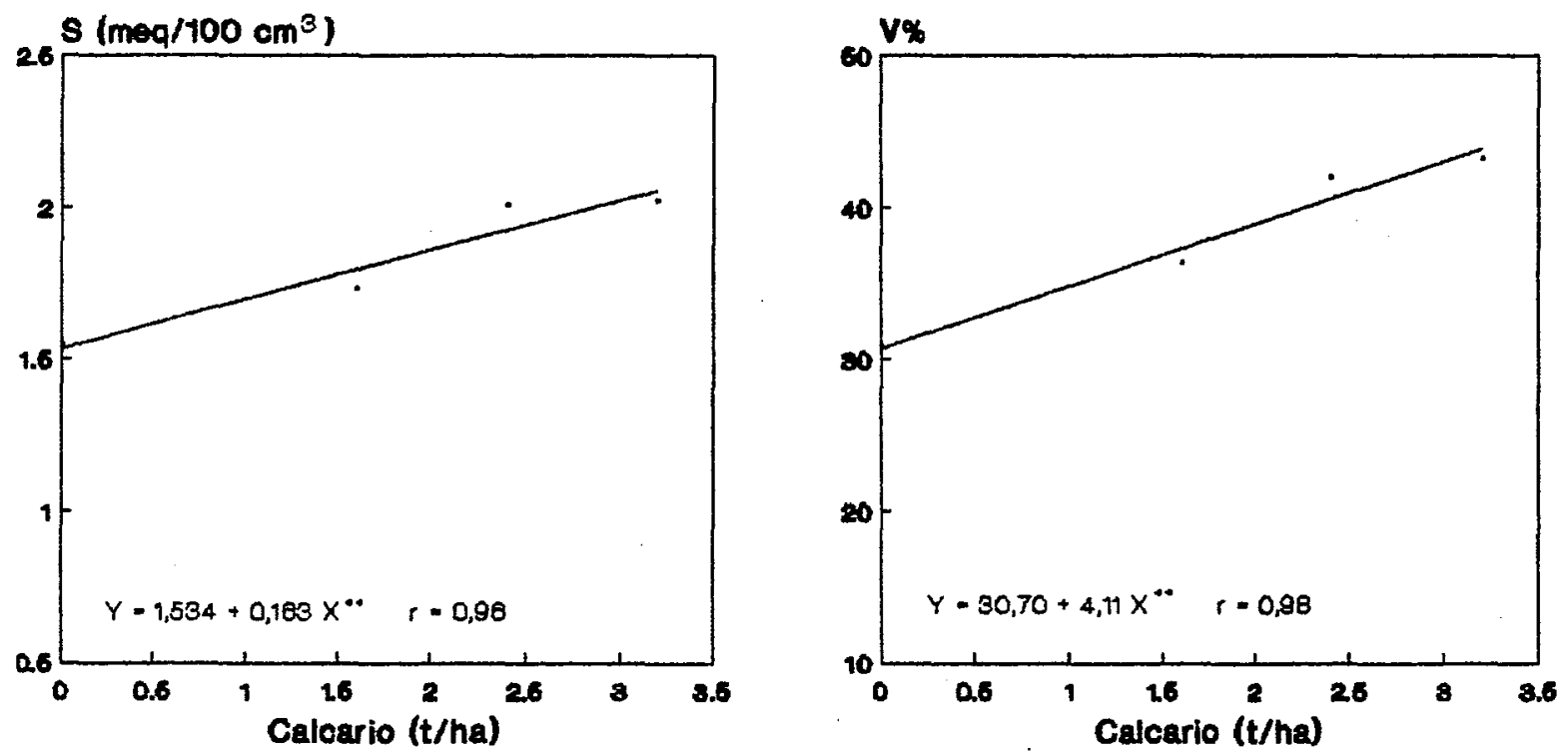

- 0-26

- 0-26

Figura 11. Continuação. 


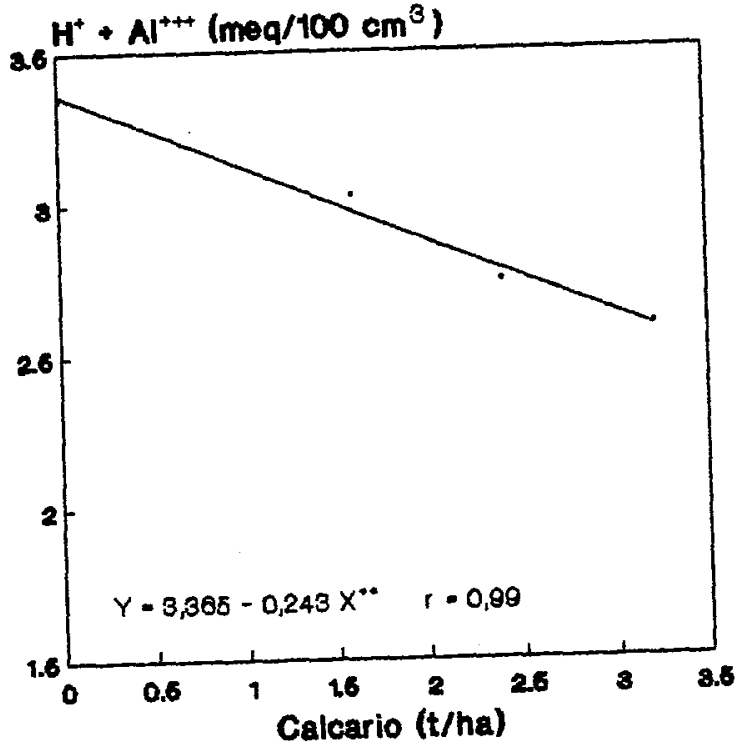

- $0-25$

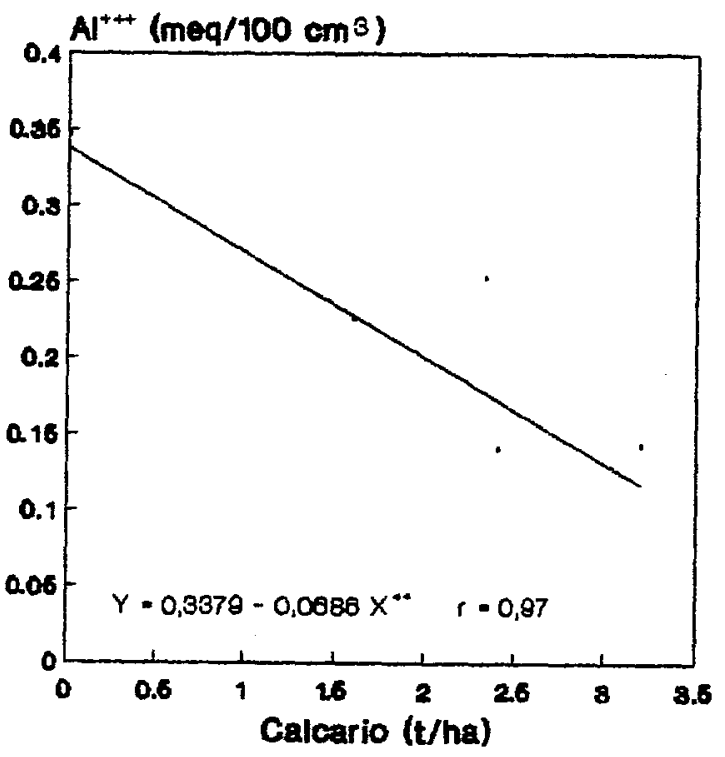

- $0-26$

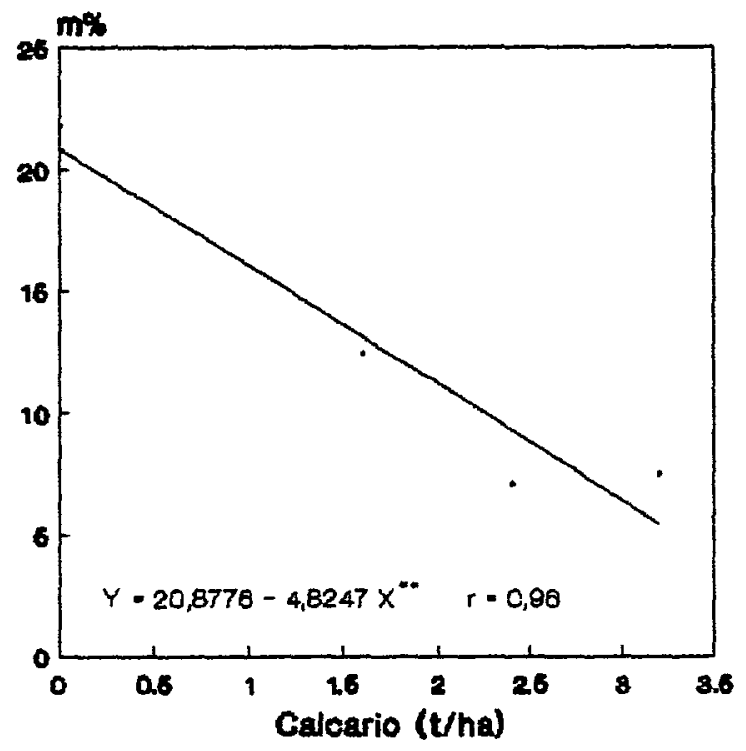

- $0-26$

Figura 12. Efeitos das doses de gesso sobre $\mathrm{H}^{+}+\mathrm{Al}^{3+}, \mathrm{Al}^{3+}$ e m na camada $0-25 \mathrm{~cm}$. 


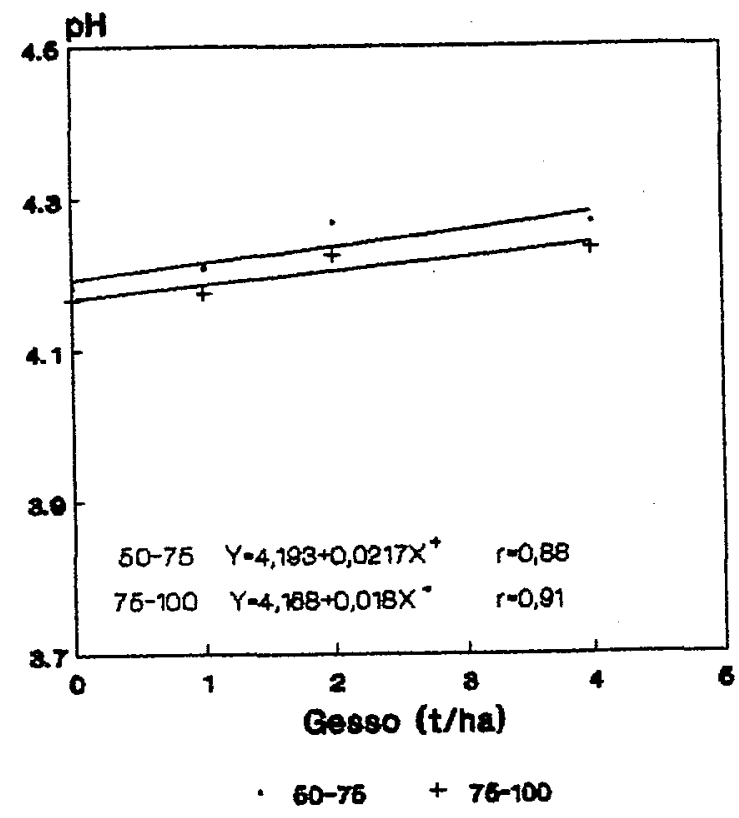

Figura 13. Efeito das doses de gesso sobre o pH nas camadas $50-75 \mathrm{~cm}$ e $75-100 \mathrm{~cm}, 18$ meses após a aplicação dos insumos.

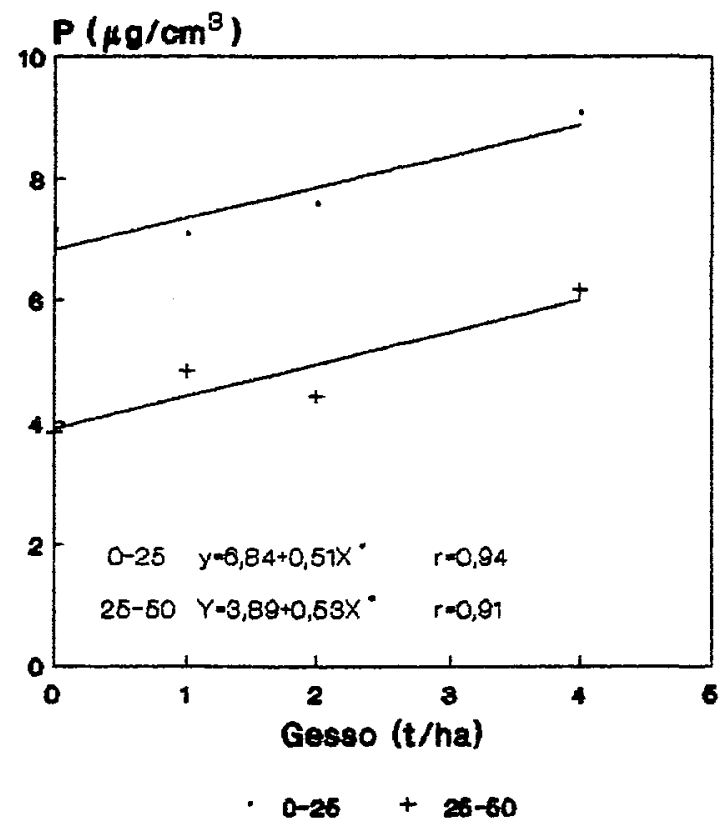

Figura 14. Efeito das doses de gesso sobre $P$ nas profundidades $0-25$ e $25-50 \mathrm{~cm}, 18$ meses após a aplicação dos insumos. 

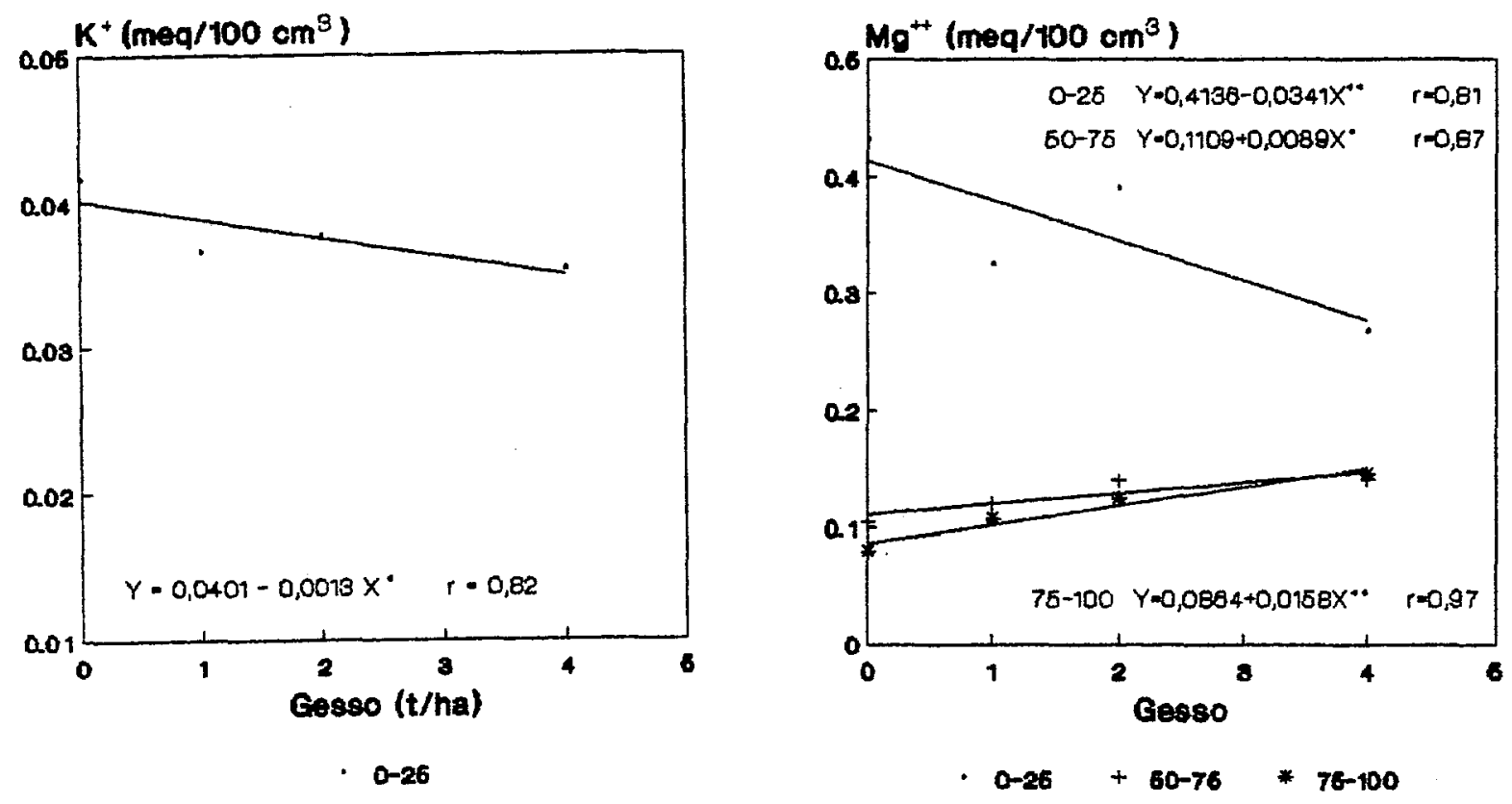

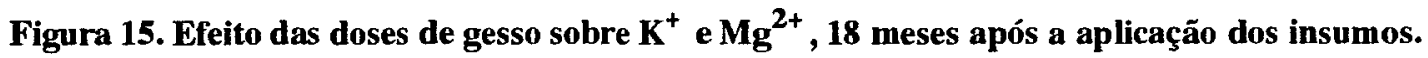



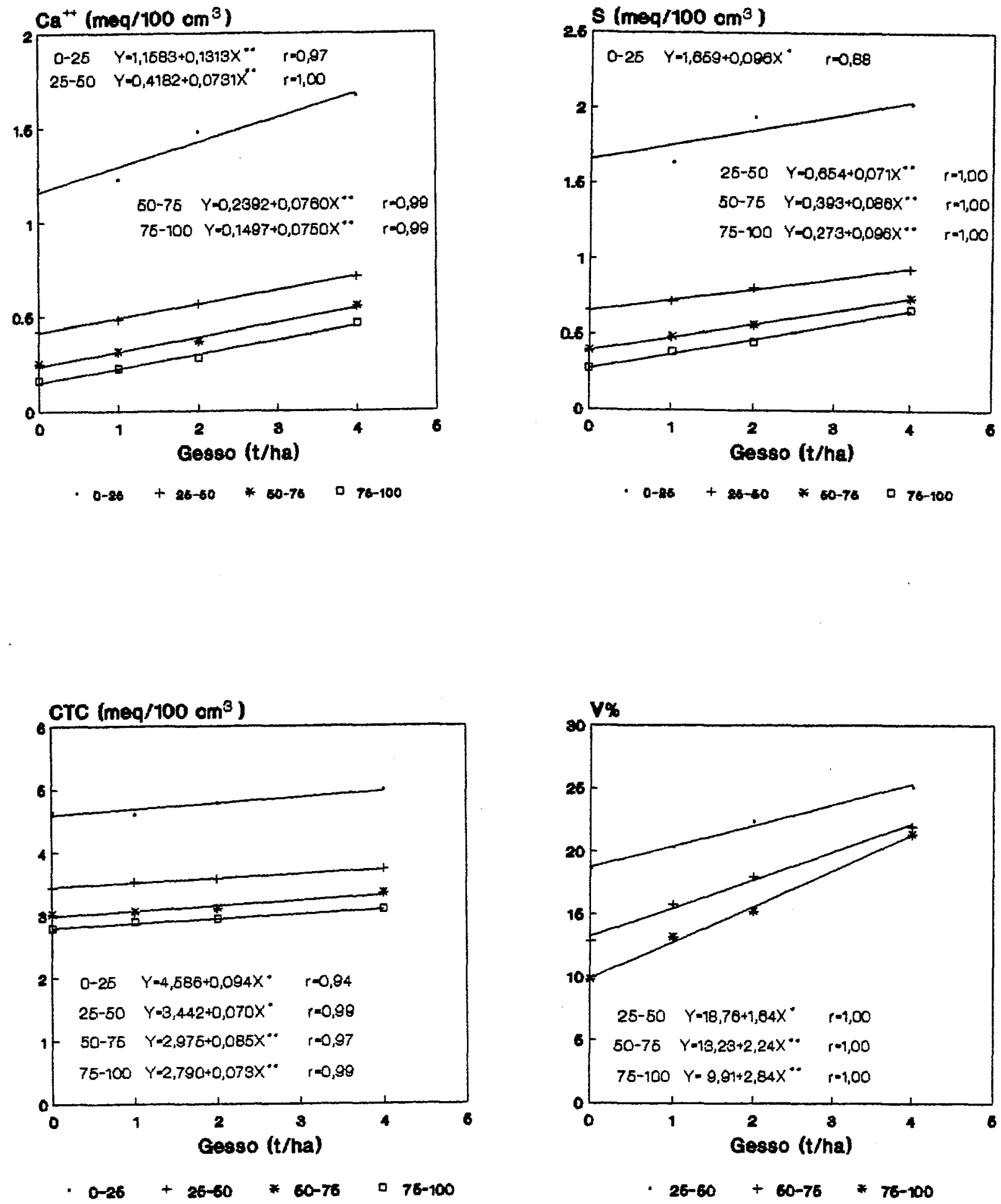

Figura 16. Efeito das doses de gesso sobre $\mathrm{Ca}^{2+}, \mathrm{S}, \mathrm{CTC}$ e V, 18 meses após a aplicação dos insumos. 


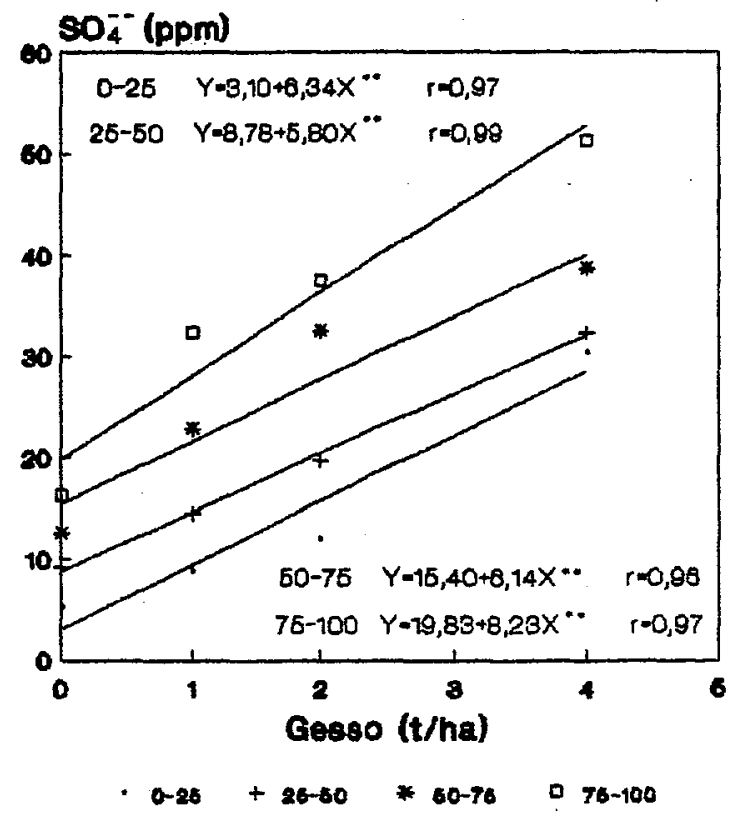

Figura 17. Efeito das doses de gesso sobre $\mathrm{S}_{-} \mathrm{SO}_{4}{ }^{2-}$ nas 4 profundidades, 18 meses após a aplicação dos insumos.
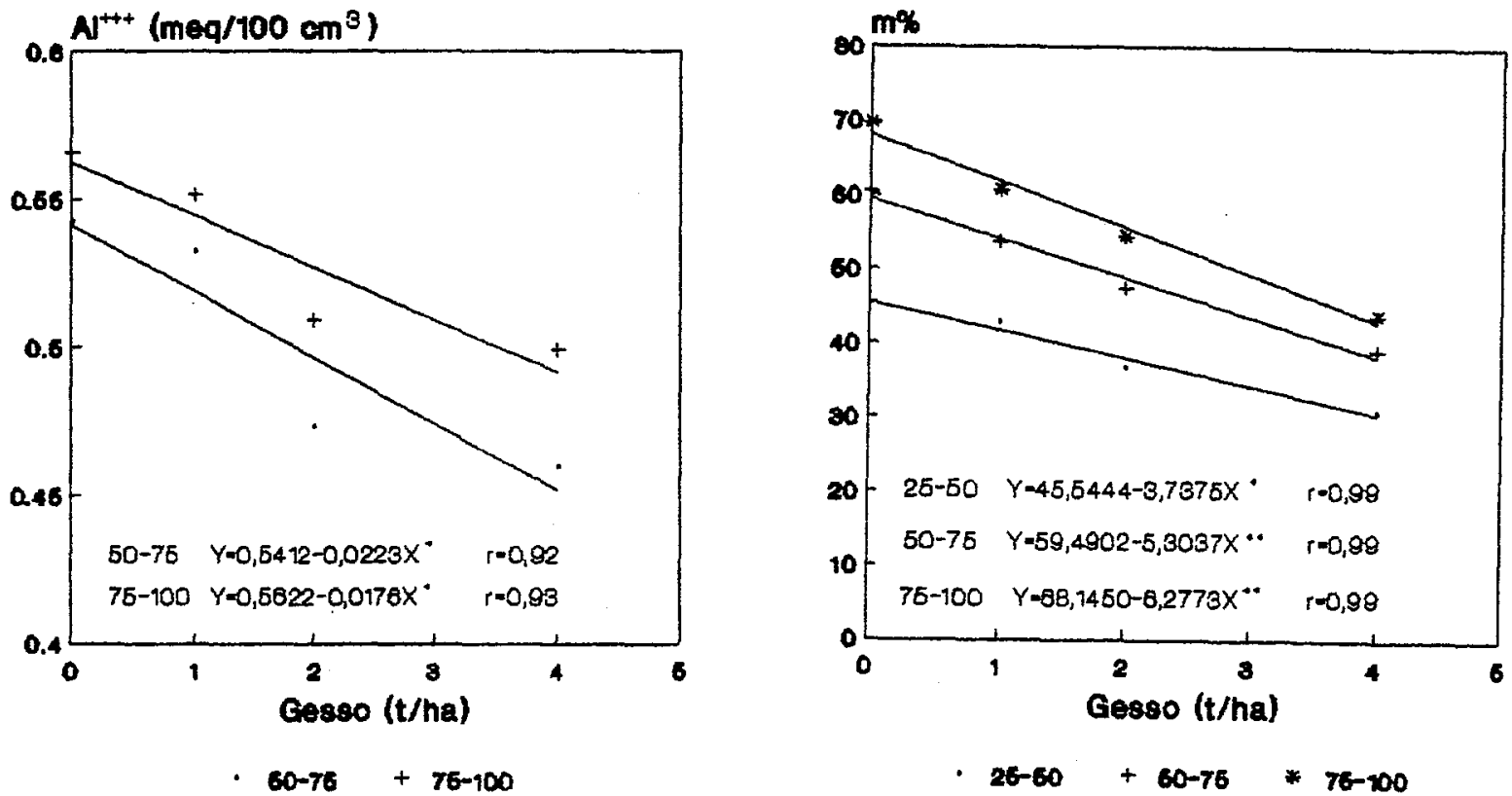

Figura 18. Efeito das doses de gesso sobre $\mathrm{Al}^{3+}$ e $\mathbf{m}, 18$ meses após a aplicação dos insumos. 


\section{CONCLUSÕES}

De acordo com os resultados obtidos e suas análises, concluiu-se que:

- O calcário aumentou a brotação do canavial, porém o maior número de perfilhos estabilizados foi decorrente da aplicação de gesso;

- As doses de insumos foram responsáveis pela maior concentração de cálcio e enxofre nas folhas +3 , no caso do gesso, e de magnésio, nos tratamentos com calcário;

- O sistema radicular desenvolveu-se mais com o aumento da dose de gesso, principalmente nas duas primeiras profundidades;

-A produção de cana-de-açúcar aumentou linearmente em função das doses de gesso;

- Os efeitos do gesso, nas duas épocas, foram: diminuição dos teores de potássio e magnésio na primeira camada, aumento dos teores de magnésio no subsolo (50-75 e 75-100 cm), aumento dos teores de cálcio e sulfato e soma de bases, capacidade de troca de cátions e saturação por bases até $1 \mathrm{~m}$ de profundidade. Os teores de alumínio decresceram até a quarta camada de maneira linear apenas aos 4 meses, mas a saturação por alumínio diminuiu em ambas as época;

- As doses aplicadas de calcário produziram aumento do $\mathrm{pH}$, dos teores de cálcio e de magnésio, $\mathrm{S}$ e $\mathrm{V}$, e diminuição dos teores de hidrogênio + alumínio, alumínio e saturação por alumínio apenas na primeira camada, nas duas épocas;

- Os teores de matéria orgânica não sofreram influência da aplicação de gesso e calcário. 


\section{REFERÊNCIAS BIBLIOGRÁFICAS}

ALCAR DE, J.C. Acalagem e a eficiência dos fertilizantes e produtos utilizados para a correção da acidez dos solos. Rio Claro, ASPR OCAL, s.d. 49p.

ALCARDE, J.C. A calagem e a eficiência dos fertilizantes. Informações Agronômicas, Piracicaba, (26):3-6, 1984.

ANJOS, J.T. \& ROWELL, D.L. Perdas de calcário em solos: efeito de doses de óxidos de cálcio, temperatura e períodos de secagem em colunas de solo. Revista Brasileira de Ciência do Solo, Campinas, 7:75-81, 1983.

ASSOCIAÇÃO NACIONAL PARA DIFUSÃO DE ADUBOS E CORRETIVOS AGRÍCOLAS. Acidez do solo e calagem. São Paulo, 1988. 16p. (Boletim Técnico, 1)

BENEDINI, M.S. Novo conceito no uso de calcário em cana-de-açúcar. Cadernos Copersucar. São Paulo, Centro de Tecnologia Copersucar, 1988. 19p. (Série Agronomia, 16)

BOR KER T, C.M.; PAVAN, M.A.; LANTMANN, A.F. Considerações sobre o uso de gesso na agricultura. Informações Agronômicas, Piracicaba; (40):1-3, dez. 1987.

CAMARGo, C.E.O. de; VEIGA, A.A. de; PESSINI, A.L.; MONTEIRO, D.A. Adubação do trigo. Experiências com N, P, K e S em diferentes tipos de solos do Estado de São Paulo. Bragantia, Campinas, 34(18):273-86, 1975.

CHALITA, R. Calibração da adubação potássica através da análise química do solo, para cultura de cana-de-açúcar. Piracicaba, 1991. 76p. (Mestrado - Escola Superior de Agricultura "Luiz de Queiroz"/USP) 
CHAVES, J.C.D.; PAVAN, M.A.; MIYASAWA, M. Redução de acidez subsuperficial em solo cultivado com o cafeeiro. I. Experimento em coluna de solo. In: REUNIÃO BRASILEIRA DE FERTILIDADE DO SOLO, 17., Londrina, 1986. Resumos. Campinas, SBCS, 1986. p.61.

COOPERATIVA DE PRODUTORES DE CANA, AÇÚCAR E ÁlCOOL DO ESTADO DE SÃO PAULO LTDA. - COPERSUCAR. Centro de Tecnologia Copersucar. Recomendação de adubação para a cultura da cana-de-açúcar. Cadernos Copersucar. São Paulo, 1988. 8p. (Série Agronomia, 17)

CRAVO, M. S.; SMYTH, T.J.; MELGAR, R.J. Resposta de culturas anuais ao calcário e à associação calcário-gesso em latossolo amarelo do Amazonas. In: CONGRESSO BRASILEIRO DE CIÊNCIA DO SOLO, 21., Campinas, 1987. Resumos. Campinas, SBCS, 1987. p.107.

DAL BÓ, M.A.; RIBEIRO, A.C.; COSTA, L.M. da; THIÉBAUT, J.T.L.; NOVAIS, R.F. E feito da adição de diferentes fontes de cálcio em colunas de solo cultivadas com cana-de-açúcar. I. Movimentação de bases no solo. In: REUNIÃO BRASILEIRA DE FERTILIDADE DO SOLO, 17., Londrina, 1986. Resumos. Campinas, SBCS, 1986. p.62.

DEMATTÊ, J.L.I. Solos arenosos de baixa fertilidade; estratégias de manejo. In: SEMINÁRIO AGROINDUSTRIAL "LUIZ DE QUEIROZ" - STAB, 5., Piracicaba, 1986.

DILLEWIJN, C. van. Botany of sugarcane. Wageningen, Veeman \& Zonen, 1952. 371p.

EMPRESA BRASILEIRA DE PESQUISA AGROPECUÁRIA. Serviço nacional de levantamento e conservação de solo. Manual de métodos de análise de solo. R io de Janeiro, 1979.

ESPIR ONELO, A. Cana-de-açúcar. In: R AIJ, B. van; SILVA, N.M.; BATAGLIA, O.C.; QUAGGIO, J.A.; HIROCE, R.; CANTARELLA, H.; BELLINAZZI Jr., R.; DECHEN, A.R.; TRANI, P.E. Recomendações de adubação e calagem para o Estado de São Paulo. Campinas, Instituto Agronômico, 1985. p.10.

FERREIRA, E.S.; CACERES, N.T.; KORNDORFER, G.H.; MARTINS, J.; MATHIESEN, L.A. Uso do multifosfato magnesiano na adubação ou plantio da cana-de-açúcar. Boletim Técnico Copersucar, São Paulo, (46):6-11, 1989.

FERREIRA, E.S.; KORNDÖRFER, G.H.; MARTINS, J.; MATHIESEN, L.A. Efeitos da aplicação de gesso + calcário sobre algumas características químicas em latossolo vermelho-amarelo. Boletim Técnico Copersucar, São Paulo, (30):13-5, 1987. 
GALLO, J.R.; HIR OCE; R .; ALVAREZ, R. Levantamento do estado nutricional de canavia is de São Paulo pela análise foliar. Bragantia, Campinas, 27:365-81, 1968.

GALLO, P.A. Efeito do gesso na cultura do amendoim (A rachis hypogaea L.) em área de reforma de cana-de-açúcar em oxissolos. Jaboticabal, 1987. (Graduação - Universidade Estadual Paulista Julio de Mesquita Filho)

GUILHERME, M.R. Fertilizante minercal + S: Ca $+\mathbf{M g}+\mathbf{S}$; características e eficiência. 2.ed. Sorocaba, Mineradora Pagliato, 1985. 52p. (Boletim Técnico, 3)

GUIMARÃES, P.T.G. O gesso agrícola na neutralização do alumínio nas camadas subsuperficiais do solo: aplicações às culturas anuais e perenes. In: SEMINÁR IO SOBRE O USO DO FOSFOGESSO NA AGRICULTURA, 1., Brasília, 1985. Anais. Brasília, EMBRAPA-DDT, 1986. p.145-67.

KOR NDÖR FER, G.H.; PRIMAVESI, O.; DEUBER, R. Crescimento e distribuição do sistema radicular da cana-de-açúcar em solo LVA. Boletim Técnico Copersucar, São Paulo, (47):32-6, 1989.

LOPES, A.S. \& ALVES, H.M.R. E feitos da aplicação de corretivos e fertilizantes na diminuição da toxidez de alumínio em profundidade, em amostras de solos sob vegetação de cerrado em Minas Gerais. In: CONGRESSO BRASILEIRO DE CIÊNCIA DO SOLO, 18., Salvador, 1981. Programa e Resumos. Campinas, SBCS, 1981. p.96.

LOPES, A.S. \& GUILHERME, L.R.G. Uso eficiente de fertilizantes; aspectos agronômicos. São Paulo, Associação Nacional para Difusão de Adubos e Corretivos Agrícolas, 1990. 60p. (Boletim Técnico, 4)

MALAVOLTA, E. Nutrição mineral da cana-de-açúcar. São Paulo, Ultraférfil, 1982. 80p. (Divulgação Técnica, 9)

MAlAvolta, E. A prática da calagem. 2.ed. Sorocaba, Mineradora Pagliato, 1985a. 46p. (Boletim Técnico, 2)

MALAVOLTA, E. A prática da calagem. In: SEMINÁRIO SOBRE COR RETIVOS AGR ÍCOLAS. Piracicaba, 1983. Trabalhos apresentados, coord. por E. Malavolta. Campinas, Fundação Cargill, 1985b. p.313-57.

MALAVOLTA, E. Efeitos de doses e fontes de enxofre em culturas de interesse econômico. V. Cana-de-açúcar. São Paulo, SN Centro de Pesquisa e Promoção de Sulfato de Amônio, 1989. 50 p. (SN, Boletim Técnico, 5) 
MALAVOLTA, E.; ROMERO, J.P.; LIEM, T.H.; VITTI, G.C. Gesso agrícola; seu uso na adubação e correção do solo. São Paulo, Ultrafértil, 1979. 32p. (Série Divulgação Técnica, 7)

MALAVOLTA, E,; VITTI, G.C.; OLIVEIR A, S.A. Avaliação do estado nutricional das plantas; princípios e aplicações. Piracicaba, POTAFOS, 1989. $201 \mathrm{p}$.

MARTINS, M. E feitos da calagem na cultura da cana-de-açúcar (Saccharum spp) em solo sob vegetação de cerrado. Piracicaba, 1991. 86p. (Mestrado - Escola Superior de Agricultura "Luiz de Queiroz"/USP)

MENGEL, K. \& KIRKBY, E.A. Principles of plant nutrition. Bern, International Potash Institute, 1987. 655p.

MORELLI, J.L.; NELLI, E.J.; DEMATTÊ, J.L.I.; DALBEN, A.E. E feito do gesso e do calcário nas propriedades químicas de solos arenosos álicos e na produção de cana-de-açúcar. In: CONGRESSO BRASILEIRO DE CIÊNCIA DO SOLO, 21., Campinas, 1987. Resumos. Campinas, SBCS, 1987. p.96.

NEPTUNE, A.M.L. O magnésio como nutriente para as culturas. In: SEMINÁRIO $\mathrm{P}, \mathrm{Ca}, \mathrm{Mg}, \mathrm{S}$ e MICRONUTRIENTES - SITUAÇÃO ATUAL E PERSPECTIVAS NA AGRICULTUR A, São Paulo, 1984. Anais, coord. por M.C. Silva. São Paulo, MANAH, 1986. p.74-7.

NOGUEIRA, A.R. de A. \& MOZETO, A.A. Caracterização físico-química dos efeitos de tratamentos com calcário e gesso em alguns solos de cerrado do Estado de São Paulo. In: REUNIÃo BR ASILEIR A DE FERTILIDADE DO SOLO, 17., Londrina, 1986. Resumos. Campinas, SBCS, 1986. p.15.

OR LANDO, FILHO, J. Nutrição e adubação da cana-de-açúcar no Brasil. Piracicaba, IAA/PLANALSUCAR, 1983. 369p.

PARANHOS, S.B. Cana-de-açúcar: cultivo e utilização. Campinas, Fundação Cargill, 1987. 431p.

PAVAN, M.A. O cálcio como nutriente para as culturas. In: SILVA, M. de C., coord. SEMINÁRIO SOBRE P, Ca, Mg, S E MICRONUTRIENTES - SITUAÇÃO ATUAL E PERSPECTIVAS NA AGRICULTURA, São Paulo, 1984. Anais., coord. por M.C. Silva. São Paulo, MANAH, 1986. p. 82-91.

PAVAN, M.A. \& VOLKWEISS, S.J. Efeitos do gesso nas relações solo-planta; princípios. In: SEMINÁRIO SOBRE O USO DO FOSFOGESSO NA AGR ICULTURA, 1., Brasília, 1985. Anais. Brasília, EMBRAPA-DDT, 1986. p.10718. 
PAVAN, M.A.; BINGHAM, F.T.; PRATT, P.F. Redistribution of exchangeable calcium, magnesium and aluminum following lime or gypsum applications to a Brazilian Oxisoil. Soil Science Society of America Journal, Madison, 48(1):33-8, 1984.

PAOLINELLI, M.T.; OLIVEIRA, P.M.; SANTOS, P.R.R.S.; LEANDRO, V.P.; MORAES, W.V. Aplicação direta do fosfogesso. In: SEMINÁRIO SOBRE O USO DE FOSFOGESSO NA AGR ICULTURA, Brasília, 1985. Anais. Brasília, EMBR APA-DDT, 1986. p.197-207.

PENATTI, C.P. Uso de ácido fosfórico ou superfosfato triplo como fonte de fósforo para a cultura da cana-de-açúcar. Piracicaba, 1991. 105p. (Mestrado - Escola Superior de Agricultura "Luiz de Queiroz"/USP)

PENATTI, C.P.; BONI, P.S.; CONDE, A.J.; SALATA, J.C. Efeito da aplicação de calcário no sulco de plantio de cana-de-açúcar. Piracicaba, Copersucar, 1987. 35p. (Boletim Técnico, 39)

QUAGGIO, J.A.; DECHEN, A.R.; RAIJ, B. van. Efeitos da aplicação de calcário e gesso sobre a produção de amendoim e lixiviação de bases no solo. Revista Brasileira de Ciência do Solo, Campinas, 6(3):189-94, 1982.

RAIJ, B. van. Avaliação da fertilidade do solo. Piracicaba, Associação Brasileira para Pesquisa da Potassa e do Fosfato, 1987. 142p.

R AIJ, B. van. Fertilidade do solo e adubação. Piracicaba, Associação Brasileira para Pesquisa da Potassa e do Fosfato, 1991. 343p.

R AIJ, B. van. Gesso agrícola na melhoria do ambiente radicular no subsolo. São Paulo, Associação Nacional para Difusão de Adubos e Corretivos Agrícolas, 1988. 88p.

R AIJ, B. van. Reações de gesso em solos ácidos. In: SEMINÁRIO SOBRE' O USO DE GESSO NA AGRICULTURA, 2., Uberaba, 1992. Anais. IBR AFOS, São Paulo, 1992. p.105-19.

RAIJ, B. van \& QUAGGIO, J.A. Métodos de análise de solo para fins de fertilidade. Campinas, Instituto Agronômico, 1983. 31p. (IAC. Boletim Técnico, 81)

R AIJ, B. van \& QUAGGIO, J.A. Uso eficiente de calcário e gesso na agricultura. In: SIMPÓSIO SOBRE FERTILIZANTES NA AGRICULTURA BRASILEIRA, Brasília, 1984. Anais. Brasília, EMBR APA-DEP, 1984. p.323-46.

REEVE, N.G. \& SUMNER, M.E. Amelioration of subsoil acidity in Natal oxisols by leaching of surface - applied amendments. Agrochemophysica, Pretoria, 4:1-6, 1972. 
RITCHEY, K.D.; SILVA, J.E.; SOUZA, D.M.G. Lixiviação de cálcio e crescimento de raízes em solos de cerrados. In: CONGRESSO BR ASILEIRO DE CIÊNCIA DO SOLO, 18., Salvador, 1981. Programas e resumos. Salvador, Sociedade Brasileira de Ciência do Solo, 1981. p.96.

RITCHEY, K.D.; SILVA, J.E.; SOUZA, D.M.G. Lixiviação do cálcio e magnésio em solos. In: REUNIĀO BRASILEIRA DE FERTILIDADE DO SOLO, 15., Campinas, 1982. Campinas, Sociedade Brasileira de Ciência do Solo, 1983a. p.109-25.

RITCHEY, K.D.; SILVA, J.E.; SOUZA, D.M.G. Relação entre o teor de cálcio no solo e desenvolvimento de raízes avaliado por um método biológico. Revista Brasileira de Ciência do Solo, Campinas, 7(3):269-75, $1983 \mathrm{~b}$.

RITCHEY, K.D.; SOUZA, D.M.G.; LOBATO, E. CORREA, O. Calcium leaching to increase rooting depth in a Brazilian Savannah Oxisol. Agronomy Journal, Madison, 72:40-4, 1980.

ROSOLEM, C.A. \& MACHADO, J.R. Efeitos da calagem e gessagem na produção de algodão e na lixiviação de bases em dois latossolos. Revista Brasileira de Ciência do Solo, Campinas, 8:103-9, 1984.

ROTH, C.H.; PAVAN, M.A.; CHAVES, J.C.D.; MEYER, B.; FREDE, H.G. Efe itos das aplicações de calcário e gesso sobre a estabilidade de agregados e infiltrabilidade de água em um Latossolo Roxo cultivado com cafeeiros. Revista Brasileira de Ciência do Solo, Campinas, 10(2): 163-6, 1986.

SALATA, J.C.; CONDE, A.J.; DEMATTÊ, J.L.I. Influence of the type of furrow opdner on the development of the root system and on sugar cane yield. In: CONGRESS OF THE INTERNATIONAL SOCIETY OF SUGAR CANE TECHNOLOGISTS, 19., Jacarta, 1986. Proceedings. Indonésia, ISSCT, 1986. v.1. p.203-12.

SIQUEIRA, O.J.F.; SHERER, E.E.; TASSINARI, G.; ANGHINONI, I.; PATELLA, J.F.; TEDESCO, M.J.; MILAN, P.A.; ER NANI, P.R. Recomendações de adubação e calagem para os Estados do Rio Grande do Sul e de Santa Catarina. Passo Fundo, EMBR APA/CNPT, 1987. 100p.

SOPR ANO, E.; ALVAREZ, V.V.H.; RIBEIRO, A.C.; DEFELIPO, B.V. Movimentação de íons em colunas de solo submetidas a aplicação de diferentes sais de cálcio. In: REUNIÃO BR ASILEIRA DE FERTILIDADE DO SOLO, 17., Londrina, 1986. Resumos. Londrina, 1986. p.18-9.

SOUZA, D.M.G. \& RITCHEY, K.D. Uso de fosfogesso no solo de cerrado. In: SEMINÁRIO SOBRE O USO DO FOSFOGESSO NA AGRICULTURA, 1., Brasília, 1985. Anais. Brasília, EMBR APA-DDT, 1986. p. 119-44. 
SOUZA, D.M.G.; REIN, T.A.; LOBATO, E; RITCHEY, K.D. Sugestões para diagnose e recomendação de gesso em solos de cerrado. In: SEMINÁRIO SOBRE USO DO GESSO NA AGRICULTURA, 2., Uberaba, 1992. p.139-58.

TEDESCO, M.J.; VOLKWEISS, S.J.; GOEPFERT, C.F. Qualidade (PRNT), preço e necessidade de calcário dos solos do Rio Grande do Sul. Trigo e Soja. Porto Alegre, (75):4-7, set./out. 1984.

VITTI, G.C. Acidez do solo, calagem e gessagem. In: CURSO DE ATUALIZAÇÃo EM FERTILIDADE DO SOLO, 1., Ilha Solteira, 1987. Anais. Campinas, Fundação Cargill, 1987. p.303-48.

VITTI, G.C. \& MALAVOLTA, E. Fosfogesso; uso agrícola. In: SEMINÁRIO SOBRE CORRETIVOS AGRÍCOLAS, Piracicaba, 1984. Campinas, Fundação Cargill, 1985. p.161-201.

VITTI, G.C. \& NOVAES, N.J. Adubaçāo com enxofre. In: SIMPÓSIO SOBRE CALAGEM E ADUBAÇÃo DE PASTAGENS, 1., Nova Odessa, 1985. Anais. Piracicaba, POTAFOS, 1986. p.191-231.

VITTI, C.G.; MAZZA, J.A.; PEREIRA, H.S.; DEMATTÊ, J.L.I. Resultados experimentais do uso de gesso na agricultura - cana-de-açúcar. In: SEMINÁRIO SOBRE O USO DO GESSO NA AGRICULTURA, 2., Uberaba, 1992. p.191224.

YAMADA, T. Capacidade de adsorção máxima de sulfato do solo como parâmetro adicional na recomendação do gesso. Piracicaba, 1988. 73p. (Doutorado-Escola Superior de Agricultura "Luiz de Queiroz"/USP) 